\title{
The General Equilibrium Incidence of the Earned Income Tax Credit
}

\author{
C. Luke Watson*
}

22 December 2020

\begin{abstract}
The Earned Income Tax Credit is a $\$ 67$ billion tax expenditure that subsidizes $20 \%$ of all workers. Yet all prior analysis uses partial equilibrium assumptions on gross wages. I derive the general equilibrium incidence of wage subsidies and quantify the importance of EITC spillovers in three ways. I calculate the GE incidence of the 1993 and 2009 EITC expansions using new elasticity estimates. I contrast the incidence of counterfactual EITC and Welfare expansions. I quantify the effect of equalizing the EITC for workers with and without children. In all cases, I find spillovers are economically meaningful.
\end{abstract}

JEL: H22, H23, H24, H31, I32, J22

*Watson: Department of Economics, Michigan State University, email: watso220@msu.edu. I am grateful for the advice and support from my advisors John D. Wilson, Leslie Papke, and Oren Ziv. I thank participants at the 2019 National Tax Association for constructive comments. All mistakes are my own. 


\section{Contents}

$\begin{array}{lll}1 & \text { Introduction } & \mathbf{3}\end{array}$

$\begin{array}{lll}2 & \text { Overview of the EITC and Related Literature } & 7\end{array}$

3 Model $\quad 11$

$\begin{array}{lll} & \text { Incidence } & 15\end{array}$

5 Estimating Labor Market Elasticities $\quad 19$

6 Empirical Policy Evaluation Methodology 29

7 Incidence of 1993 EITC Expansion $\quad 31$

8 Comparing EITC and Welfare Reforms $\quad 35$

9 Structural Model Parameterization $\quad 40$

10 Childless Worker Reform

11 Incidence of the 2009 EITC Expansion $\quad 44$

12 Conclusion $\quad 48$

$\begin{array}{lll}\text { A Theory Appendix } & \mathbf{5 4}\end{array}$

B Data Description and Summary Statistics $\quad 66$

$\begin{array}{lll}\text { C } & \text { Empirical Tax Instruments } & 74\end{array}$

D Additional Estimation Results $\quad 82$

$\begin{array}{lll}\text { E Additional Incidence Results } & 87\end{array}$

$\begin{array}{lll}\text { F Structural Model Implied Parameters } & 93\end{array}$ 


\section{Introduction}

The Earned Income Tax Credit (EITC) is one of the largest anti-poverty programs in the United States. Over $20 \%$ of all workers and $40 \%$ of single parent workers receive a share of the $\$ 67$ billion expenditure. At the end of the 'phase-in' portion, the EITC yields a 19\%-34\% subsidy on gross earnings for workers with children. Lawmakers and policy advocates often propose expansions of EITC benefits and eligibility.

Yet essentially all prior research has assumed away the possibility of gross wage distortions when analyzing policy effects on labor supply. Since the EITC amount is based on gross earnings, if the program feeds-back into market wages - e.g., decreasing wages for low-income workers - then the anti-poverty policy goals will be undermined. With each expansion that increases benefits or expands eligibility, using partial equilibrium assumptions seems less tenable. Given the scope of the EITC, its place in anti-poverty policy discussions, and the importance of labor market earnings on its overall efficacy, this oversight looms large.

I model and evaluate the EITC by deriving a general equilibrium incidence equation that relates changes in average tax rates to changes market wages and labor supply. ${ }^{1}$ My approach allows me to decompose wage changes into the direct and indirect effects on both the treated and untreated workers. I parameterize the incidence equation by estimating EITC specific labor supply and substitution elasticities and then perform four quantitative evaluations. I calculate the empirical incidence of the 1993 expansion for different demographic groups. I compare counterfactual marginal expansions of the pre-reform (1992) EITC and social safety-net 'Welfare' programs to compare how different tax incentives affect incidence and spillovers. Using the estimated elasticities to parameterize a structural labor supply model, I calculate the incidence of the out-ofsample 2009 EITC expansion, and I conduct a counterfactual EITC reform that equalizes the credit schedule for workers with and without children.

\footnotetext{
${ }^{1}$ I refer to pre/post-tax wages as gross/net wages. I reference EITC tax rates as subsidies are 'negative taxes.' I define a 'partial equilibrium effect' as the direct effect of a policy change holding all else equal; a 'general equilibrium effect' as the total policy effect allowing all endogenous variables to adjust.
} 
To conduct these exercises, I estimate labor supply elasticities for different demographic groups and a labor substitution elasticity that governs the curvature of labor demand. I use EITC policy variation tied to the 1993 Omnibus Budget Reconciliation Act (OBRA) on labor market data from the Current Population Survey. I assign workers to demographic-based labor market cells and estimate the cell-specific expected EITC policy reform exposure via a simulated instrument approach that uses a fixed distribution of worker characteristics from the 1990 Census. This approach uses all possible EITC policy information but purges endogenous behavioral responses from the policy changes. My estimation strategy allows me to avoid the assumption that women with and without children respond the same way to wage changes, as in typical difference-in-differences based analysis of the EITC. ${ }^{2}$ Because the incidence depends on the wage responsiveness of different labor markets, capturing granular differences in supply responsiveness is important for accurately measuring incidence effects. ${ }^{3}$

My primary theoretical contribution is to formalize the labor market forces that generate 'spillover effects' from targeted wage taxes between treated and untreated workers and across labor market segments. A policy that increases the absolute quantity of one worker group increases the marginal product of complementary workers and decreases that of substitutable workers. These changes in marginal product cause labor demand shifts that I interpret as spillover effects. I show that these spillover effects have 'first order' importance in market wages changes, and for treated workers positive marginal product spillovers attenuate the negative direct wage effect. The partial equilibrium incidence (or direct effect) is the upper bound for treated workers and the lower bound for untreated workers relative to the general equilibrium gross wage incidence. Because the behavior of all other economic agents is held fixed in PE, the marginal product changes are ignored so wage spillover effects are also ignored. Since the spillover effects are 'first order' and opposite relative to the direct effects, the general equilibrium incidence is theoretically ambiguous due to cascading feedback across labor markets.

\footnotetext{
${ }^{2}$ In Appendix C.3, I show how previous estimation approaches confront worker heterogeneity and/or the presence of spillovers for identification.

${ }^{3}$ In Appendix E, I show that using a constant labor supply elasticity of 0.75 for all groups implies implies larger (in magnitude) wage declines (up to $33 \%$ ) yet $10 \%$ larger net earnings effects relative to my estimated elasticities results.
} 
For example, suppose there are two sets of workers, $\{A, B\}$ that are complementary to each other in the production process, ${ }^{4}$ and we treat group $A$ to a work subsidy. The labor supply increase of the treated set of workers will increase the marginal product of the untreated set; this causes labor demand to increase for the untreated workers; the resulting quantity increase in untreated workers will then increase the marginal product of the treated workers; and so on... Figure 1 displays these forces graphically using a two factor model with a targeted labor subsidy.

My primary empirical contribution is to quantify the magnitude of EITC induced spillovers using four policy evaluations. On an individual level, spillovers are small both in magnitude and relative to the direct effects; however, because spillovers affect every worker, spillovers are economically important when aggregated. ${ }^{5}$ In the empirical incidence evaluations, I find spillovers increase aggregate net earnings by about $15 \%$ for the 1993 OBRA EITC expansion and by $12.5 \%$ for the 2009 ARRA expansion. When comparing the EITC vs Welfare, the superiority of an EITC expansion relative to a Welfare expansion in terms of net-earnings becomes $73 \%$ larger when accounting for spillovers. Equalizing the EITC for workers with and without children would cause a $350 \%$ increase in net earnings change of unmarried women without children but at the expense of $88 \%$ decrease for unmarried mothers. I also calculate wage changes, labor supply changes, and the fiscal externality of EITC reforms across education, marriage, and parental status that highlights the heterogeneous distributional effects of the EITC.

My results highlight important features of the EITC and labor market programs in general. First, inducing labor supply mechanically expands the economy's possibilities frontier, while programs that incentivize leaving the labor force will contract the frontier. Thus, policies that expand the labor force, such as the EITC, have additional pro-growth benefits, while policies that subsidize leisure have additional costs to the economy. Second, the positive spillovers onto higher-income workers seems like an unintended transfer; however, with progressive taxation, these workers have a positive tax rate and the

\footnotetext{
${ }^{4}$ For example, research assistants and professors in the production of research, where more RAs increase productivity of professors and more vice versa.

${ }^{5}$ I focus on aggregate effects but Appendix E displays individual effects.
} 
Figure 1 - Labor Subsidy Incidence in Two Factor Model: $\{A, B\}$

(a) Partial Equilibrium

[Wage: $w$ ]

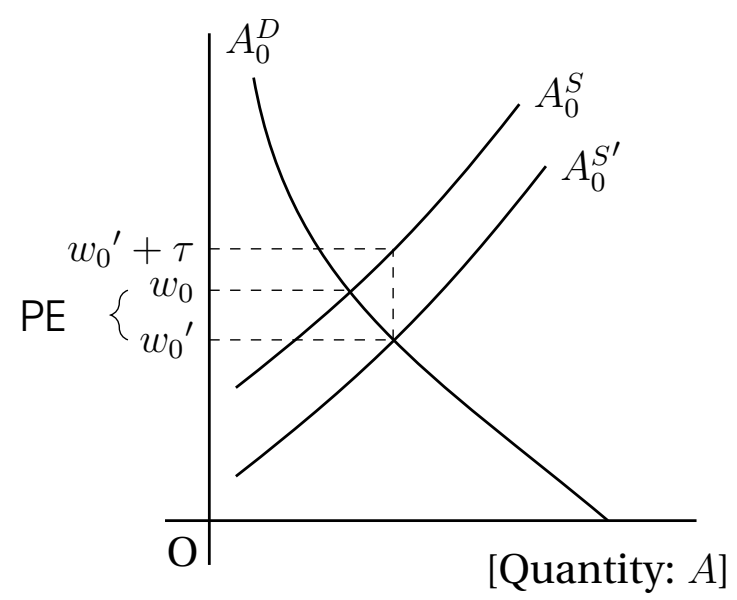

[Wage: $r$ ]

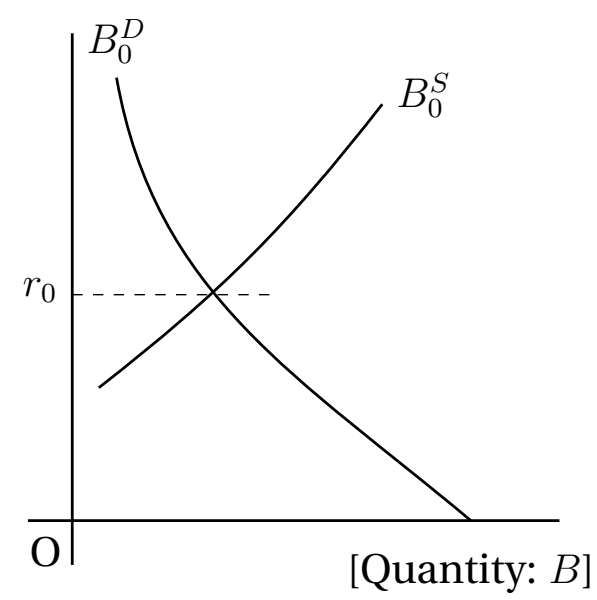

(b) General Equilibrium

[Wage: $w$ ]

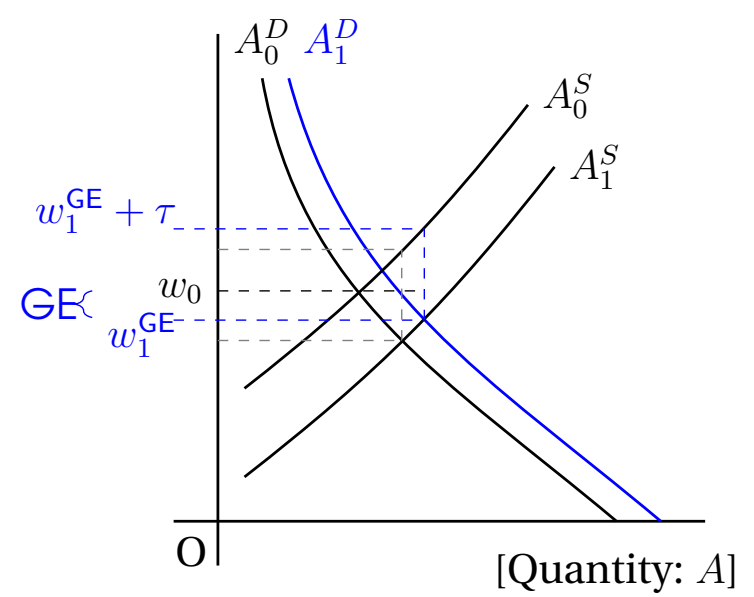

[Wage: $r$ ]

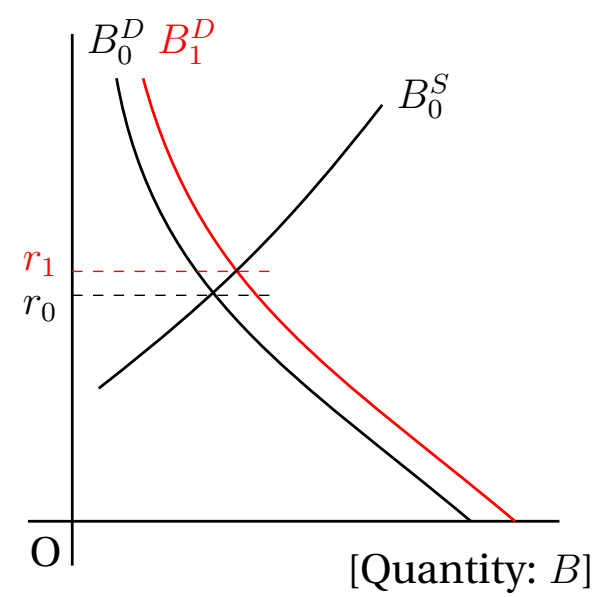

In (a), a supply subsidy shifts $A^{S}$ to the right. In (b), assuming worker complementarity, the resulting marginal product spillovers cause both labor demands to shift right, which attenuates the PE gross wage decline for $A$-market.

spillovers are taxed back. Thus, the EITC can help 'pay for itself' by indirectly increasing the tax-base, in addition to the direct effect of moving workers to employment (Bastian and Jones, 2018). Finally, untreated-substitute workers face downward pressure on wages while untreated-complementary workers, who are already have higher wages, get a wage bump. In the medium to long run, this may incentivize the untreated-substitute workers to either become eligible (have children) or to up-skill out of the low-wage market. 
An additional empirical contribution is that by isolating EITC specific policy variation, I allow for a more fine-tuned estimate of the treatment effects of the 1993 EITC expansion. Recently work by Kleven (2018) points out that Welfare reform during the 1990's potentially contaminates estimates of the EITC expansion effects. Partially, this is because prior analysis has used 'difference-in-differences' techniques where treatment is simply group membership interacted with year indicators. ${ }^{6}$ My estimates imply that labor supply for unmarried women with children increased $1.27 \%$ due to the 1993 EITC expansion, which is lower by a third to a tenth of the estimates summarized by Hotz and Scholz (2003). ${ }^{7}$ This supports the claim that prior EITC estimates were contaminated by macroeconomic conditions while also showing that the EITC did increase women's labor supply and thereby affected the market wages of the economy.

The overarching message of this paper is that the impact of general equilibrium spillovers of conditional wage subsidies - such as the EITC, social safety-net programs, or proposed Universal Basic Income - on labor market outcomes are of first order importance. Further, because the labor market is central to the distribution of goods and services in the economy, tax policy aimed at ameliorating the financial hardships of the working poor can nevertheless have unintended consequences across all sectors of the economy.

\section{Overview of the EITC and Related Literature}

This work is part of a long running effort to understand and quantify the economic and social effects of the Earned Income Tax Credit. The EITC is a $\$ 67$ billion federal tax expenditure program designed to encourage work by subsidizing earned income through a refundable tax credit using a non-linear benefit schedule. Figure 2 shows how the program has expanded since the early 1990's to the present.

\footnotetext{
${ }^{6}$ In a standard labor supply model, the DID estimator is equivalent the reduced-form regression where group and time are instrumenting net-wages.

${ }^{7}$ Table 4 in Hotz and Scholz (2003) summarize much of the earlier empirical literature and describe the effects in terms of elasticities.
} 
Figure 2 - EITC Schedule by Year and Number of Children
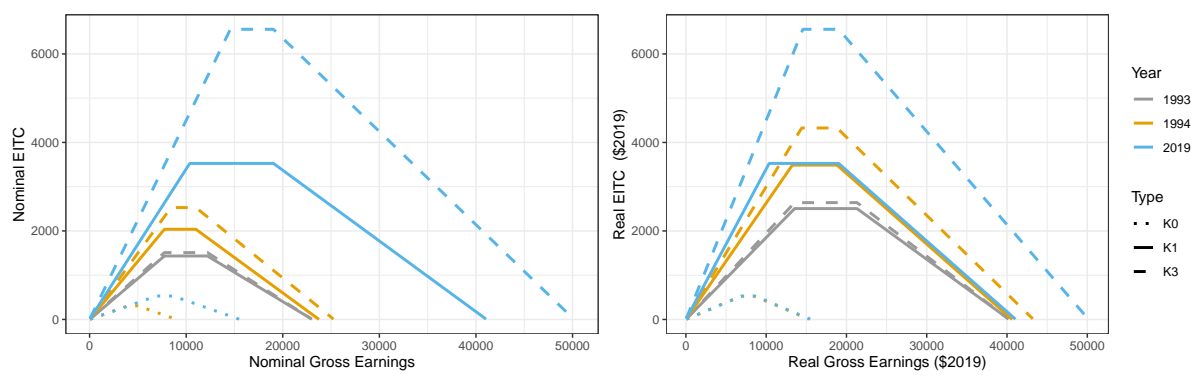

EITC schedules for single filing household for years 1993, 1994, and 2019 by zero, one, and three children. Joint filers have a higher maximum credit and extended plateau and phase out regions. Both nominal and real (\$2019) values plotted. Paraemeters from Tax Policy Center (2019).

The defining feature of the EITC is the phase-in region of the schedule, which increases the subsidy as earnings increase, and unambiguously promotes greater labor supply (Hotz and Scholz, 2003; Nichols and Rothstein, 2016). The phase-in differentiates the EITC from a Negative Income Tax and a traditional Welfare program, which start at a high level and tax away the benefit as earnings increase.

Roughly $40 \%$ of all single parent families and $25 \%$ of married parent families are eligible for the EITC, and $40 \%$ of all families where the primary earner has less than a high school degree are EITC eligible (Nichols and Rothstein, 2016). This massive intervention in the labor market should have economically meaningful effects on labor market sorting and equilibrium.

Previous studies have consistently found that the EITC benefit structure successfully encourages labor force participation and increases employment rates for eligible groups - primarily unmarried women workers with children and low levels of education. Two comprehensive survey articles - Hotz and Scholz (2003); Nichols and Rothstein (2016) or two specific applications of the labor supply effects - Eissa and Liebman (1996); Eissa and Hoynes (2004) - provide a general overview of prior EITC studies. ${ }^{8}$ Given the size of the EITC as a labor market intervention, we should expect wage and price distortions.

\footnotetext{
${ }^{8}$ More recent papers on labor market effects and net-income distributions include Fitzpatrick and Thompson (2010); Chetty et al. (2013); Jones (2017); Kasy (2017); Hoynes and Patel (2018); Bastian (forthcoming). In addition, there are many papers that assess the social impact of the EITC on various non-labormarket outcomes - health (Dahl and Lochner, 2012; Evans and Garthwaite, 2014; Hoynes et al., 2015); education (Maxfield, 2015; Bastian and Michelmore, 2018); and marriage \& fertility (Dickert-Conlin and Houser, 2002; Baughman and Dickert-Conlin, 2003).
} 
However, most papers in the EITC labor literature assume that the EITC has had no effect on gross wages (Dickert et al., 1995; Eissa and Liebman, 1996; Saez, 2002; Eissa and Hoynes, 2004; Chetty et al., 2013). As noted by Hotz and Scholz (2003), this assumption had never been tested in first decade of EITC research. ${ }^{9}$

Leigh (2010) and Rothstein (2010) study the gross wage incidence of the EITC in partial equilibrium. ${ }^{10}$ Leigh (2010), using state and federal variation, finds that a $10 \%$ increase in the maximum EITC amount leads to a 5\% decrease in the real wages of high school dropouts, and, using predicted labor supply within gender-age-education labor market cells, finds that $10 \%$ increase in cell labor supply leads to a $9 \%$ decrease in real wages within the labor market cell. As mentioned earlier, Rothstein (2010) simulates a hypothetical EITC expansion change and reports that for every dollar of intended transfer real wages decrease by $\$ 0.34$ (in partial equilibrium). These results imply that the EITC is not as effective a program as policy makers may believe and may be an unintended transfer to non-targeted groups, such as business owners and wealthier households. My contribution to these papers is to allow for labor market spillovers that affect both treated and untreated workers, to derive an analytical formula that allows me to estimate the empirical incidence of the EITC rather than its maximum credit or hypothetical expansion, and to create a framework to predict and evaluate out-of-sample expansions.

Agrawal and Hoyt (2018) study general equilibrium tax incidence in a multi-product consumer goods markets. They find that tax rate overshifting is possible when related goods are substitutes and find that spillovers are empirically important in alcohol markets. My paper considers taxes in multi-factor input markets, applies this to empirically to the EITC and Welfare programs, and also finds spillovers are empirically important.

\footnotetext{
${ }^{9}$ Some of these papers are explicit (Eissa and Liebman, 1996; Saez, 2002; Chetty et al., 2013) and others are implicit in by holding wages fixed when simulating labor market effects (Dickert et al., 1995; Eissa and Hoynes, 2004). In Chetty et al. (2013), their model's the production function implies workers are perfect substitutes (thus no spillovers) and their empirical results depend on the stable unit treatment assumption. One potential reason for the absence is a greater initial interest in the individual policy treatment effects of tax reforms rather than policy effect on labor markets.

${ }^{10}$ Azmat (2019) studies the incidence, also in partial equilibrium, of a conceptually similar Working Families Tax Credit program in the UK. She finds that, due to differences in salience unique to the UK program, gross wages fall by $7 \%$ for claimants and $1.7 \%$ for non-claimants. Also, Hoynes and Patel (2018) look at after-tax income distributional effects of the EITC and show that indirect effects increase net-income of workers near the poverty threshold.
} 
In terms of general equilibrium effects of the EITC, this work is part of a small group. Lee and Saez (2012) allow for endogenous wages and argue that an EITC combined with an optimal minimum wage policy can prevent some of the incidence effect; however, the authors do not actually attempt to calculate the GE incidence. To build on their work, I incorporate spillover effects between labor markets and firm entry decisions allowing for an arbitrary number of factors with heterogeneous supply responses and tax changes. Kasy (2017) develops a novel estimation procedure using maximum EITC amounts to calculate the change in gross wages and labor supply along age, education, gender, and income distribution cells and finds negative earnings effects that dominate the credit, as if labor demand were completely inelastic - similar to Leigh (2010); Rothstein (2010). Because I do not rely on a difference-in-difference strategy between those with and without children, I allow for labor supply heterogeneity along parental status. ${ }^{11}$ In addition, because I used empirical tax rates, I can compute both gross and net earnings effects. Finally, Froemel and Gottlieb (2019) develop a macroeconomic model to analyze consumption, savings, and wage determination, and find that both the gross earnings and wealth gap increase but the net earnings gap shrinks due to the EITC. To come to these conclusions, the authors use a two skill model, focus solely on married households, use an approximated EITC policy function, and ignore the distinction between workers with and without children. My work is able to account for most of these forces while maintaining a rich degree of individual heterogeneity in skills and wage responsiveness and exactly modeling the EITC.

Finally, my results are able to rationalize a startling null-finding by Kleven (2019). The author uses every state and federal EITC reform since the program's inception and only finds "clear employment increases" from the OBRA expansion, which he notes occurred along with confounding macroeconomic and policy forces. I contribute to his work by estimating labor supply elasticities using purely EITC policy variation and by calculating the incidence by a structural approach that holds these confounding variables constant. Additionally, by separately calculating the labor market effects of the OBRA and ARRA

\footnotetext{
${ }^{11}$ Additionally, the author omits common-policy-shock effects by using year indicator variables in his empirical specification. This may be one reason that his empirical estimates are similar to partial equilibrium analysis.
} 
expansion, I show that most EITC expansions likely do not generate economic forces large enough to be observed using difference-in-difference methods.

\section{Model}

In this section, I describe a general equilibrium labor market model to investigate the effect of targeted labor subsidies. The primary assumptions are that worker utility is quasi-linear in a composite consumption good, production technology has constant elasticity of substitution between factors and is constant returns to scale, and worker characteristics are observed by all market participants. To make analysis simpler, I abstract from other taxation issues by assuming the subsidy is financed by lump-sum taxes on workers, except I allow for an unemployment benefit.

For exposition, I present a model with only two labor skill levels. In Appendix A, I derive welfare measures for the model, show that the model easily generalizes to arbitrary labor types with type-specific tax changes, and discuss two extensions: allowing labor market 'switching' and two output sectors.

\subsection{Workers}

Let there be a mass $N$ of workers, where each is defined by a skill level, $e \in\{0,1\}$, a parental status, $c \in\{0,1\}$, and a continuous and stochastic disutility of labor, $\nu \sim F_{e, c}(\nu)$. Suppose that only skill determines worker productivity, so wages are positively related to skills but unrelated to parental status conditional on skill. Given perfect information and perfect labor competition, all workers with the same skill will earn the same wage.

Each worker has preferences over a homogeneous consumption good, $X$, and labor, $L$, representable by a quasi-linear utility function, $U(X, L ; \nu)=X-\nu \cdot L$. Workers maximize utility by choosing a feasible labor-consumption bundle given wages $(w)$ and the tax system. That is, each worker solves:

$$
\max _{X, L}\{X-\nu \cdot L\} \quad \text { s.t. } X \leq T_{c}\left(w_{e} \cdot L\right) \quad \& \quad L \in\{0,1\},
$$


where $T_{c}\left(w_{e}\right)$ is the net earnings after taxation, which depends on gross earnings and parental status. $^{12}$

After substituting the budget constraint, the utility maximization problem becomes a discrete choice problem:

$$
\max _{L=\{0,1\}}\{\underbrace{T_{c}(0)}_{L=0}, \underbrace{T_{c}\left(w_{e}\right)-\nu}_{L=1}\}
$$

The solution yields worker output demand and labor supply functions, $X_{i}^{D}$ and $L_{i}^{S}$. Let $\mathrm{\vee}_{e, c}=T_{c}\left(w_{e}\right)-T_{c}(0)$, then by definition $\operatorname{Pr}\left(\nu \leq \mathrm{\vee}_{e, c} \mid e, c\right)=F_{e, c}\left(\mathrm{\vee}_{e, c}\right)$. With specific density functions, $F_{e, c}(\mathrm{~V})$, the labor supply probability of each type of worker is known; e.g., with Type-1 Extreme Value draws, labor supply has a logit form: $F_{e, c}(\mathrm{v})=\mathrm{e}^{\mathrm{v}} /\left(1+\mathrm{e}^{\mathrm{v}}\right)$.

Thus, the aggregate labor supply functions are:

$$
L_{e, c}^{S}=F_{e, c}\left(\mathrm{v}_{e, c}\right) \cdot N_{e, c} \quad \& \quad L_{e}^{S}=\sum_{c \in \mathcal{C}} L_{e, c}^{S} \quad \& \quad L^{S}=\sum_{e \in \mathcal{E}} L_{e}^{S}
$$

The labor supply elasticity for demographic group $(e, c)$ is:

$$
\frac{\partial L_{e, c}^{S}}{\partial w} \frac{w_{e}}{L_{e, c}}=\left[\frac{\partial T_{e, c}}{\partial w} f_{e, c}\left(\mathbf{v}_{e, c}\right)\right] \cdot \frac{w_{e}}{L_{e, c}}:=\varepsilon_{e, c}^{L} .
$$

Using the logit example, $\varepsilon_{e, c}^{L}=\frac{\partial T_{e, c}}{\partial w} w_{e}\left(1-F_{e, c}\left(\mathrm{~V}_{e, c}\right)\right)$. As there are no income effects for labor supply, the Marshallian and Hicksian elasticities are equivalent.

\subsection{Production}

Let there be mass $J$ of potential producers indexed by $j \in \mathcal{J}$, each endowed with one unit of capital $(K)$, that can hire labor to produce a homogeneous consumption good. Firms draw a capital supply cost (or entry cost), $\xi_{j}$, from a continuous distribution, $G(\xi)$. Technology is represented by a nested constant elasticity of substitution (CES) production function:

$$
\begin{aligned}
q_{j}^{S} & =Q\left(\left\{L_{e ; j}\right\}_{e}, K_{j}\right)=A_{j}\left[\left(\sum_{e \in \mathcal{E}} \vartheta_{e}\left(L_{e ; j}^{D}\right)^{\frac{1+\rho}{\rho}}\right)^{\frac{\rho}{1+\rho}}\right]^{\alpha} K_{j}^{(1-\alpha)} \\
& =A_{j} \cdot \mathbf{L}_{j}^{\alpha} K_{j}^{(1-\alpha)}
\end{aligned}
$$

\footnotetext{
${ }^{12}$ In this section I ignore non-labor income as there are no income effects; however, in the empirical sections I incorporate non-labor income when calculating effective tax rates.
} 
where $A_{j}$ is a Hick-neutral productivity term, $L_{e ; j}^{D}$ is the firm- $j$ type- $e$ labor demand, and $\mathbf{L}_{j}$ denotes the aggregate labor index for the firm. The elasticity of substitution between labor skill-groups is parameterized by:

$$
\rho=\mathrm{d} \ln \left[L_{e^{\prime \prime}} / L_{e^{\prime}}\right] / \mathrm{d} \ln \left[w_{e^{\prime \prime}} / w_{e^{\prime}}\right]<0, \text { for } e^{\prime}, e^{\prime \prime} \in \mathcal{E} \text {. }
$$

This technology features constant returns to scale (CRS) and assumes fixed substitution elasticities between factors. ${ }^{13}$ Firms maximize profits: $\pi_{j}=p \cdot Q\left(\left\{L_{e ; j}\right\}_{e \in \mathcal{E}}, K_{j}\right)-$ $\sum_{e \in \mathcal{E}} w_{e} L_{e ; j}-r K_{j}$. Aggregate output is defined as $q^{S}=\int_{j} q_{j}^{S} \mathrm{~d} j$. Price taking, zero profits, and identical production functions imply all firms choose the same factor input bundle, so by CRS the aggregate production function is also nested CES. I normalize the output price to one, $p=1$, so wages and capital rents are in terms of the final good.

Under these assumptions, the firm capital supply is synonymous with firm entry and is endogenously determined by firm capital supply costs, $\xi_{j}$, and the price of capital, $r$. Firm $j$ will enter if $\xi_{j} \leq r$. In equilibrium, this determines the aggregate capital supply function, $K^{S}(r)$, and the aggregate capital supply elasticity, $\varepsilon_{K}^{S}=r \cdot \frac{g(r)}{G(r)}$.

\subsection{Tax and Transfer System}

For simplicity, suppose that initially the government raises revenue using lump-sum taxation at the level $n$, provides an unemployment benefit at level $b$, and balances its budget. Then, the government reforms the tax system to provide a labor subsidy for low skill workers with children, $\tau_{(0,1)}$ (that is paid for by lump-sum tax changes). This implies the following skill specific aggregate labor supply functions (recalling equation 3):

$$
\begin{aligned}
& L_{0}^{S}=L_{0,0}^{S}\left(w_{0}\right)+L_{0,1}^{S}\left(w_{0}+\tau_{(0,1)}\right) \\
& L_{1}^{S}=L_{1,0}^{S}\left(w_{1}\right)+L_{1,1}^{S}\left(w_{1}\right)
\end{aligned}
$$

\footnotetext{
${ }^{13}$ Note, when there are more than two skill groups, $\rho$ is the partial elasticity of substitution. The primary modeling benefit to this technology is that it allows for tractable analytic solutions with an arbitrary number of labor types, as I use in the generalized model for the empirical applications.
} 
Equation 8 provides intuition for the incidence formula I will demonstrate in the next section. The subsidy directly creates a work-incentive for the subsidized group. However, the equilibrium effect on gross wages distorts labor supply for unsubsidized workers.

\subsection{Equilibrium}

An equilibrium in the economy is a wage and rent schedule such that the factor market clears and firms make zero profits (thus clearing the output market). The economy is in equilibrium when no worker wishes to adjust her labor supply and no firm wishes to adjust its input bundle.

Due to the CRS assumption, the scale of factor demands cannot be determined. Fortunately, the model can be solved in terms of demand ratios. In equilibrium, the labor demand bundle must satisfy:

$$
\frac{L_{0}^{D}}{L_{1}^{D}}=\left(\frac{w_{0} / \vartheta_{0}}{w_{1} / \vartheta_{1}}\right)^{\rho}
$$

While the labor-aggregate and capital demand bundle must satisfy:

$$
\frac{\mathbf{L}^{D}}{K^{D}}=\left(\frac{\bar{w} / \alpha}{r /(1-\alpha)}\right)^{-1}
$$

where $\bar{w}=\left(\vartheta_{0}\left(\frac{w_{0}}{\vartheta_{0}}\right)^{1+\rho}+\vartheta_{1}\left(\frac{w_{1}}{\vartheta_{1}}\right)^{1+\rho}\right)^{\frac{1}{1+\rho}}$ is a labor cost index. The unit cost function has the following form: $c\left(w_{0}, w_{1}, r\right)=(1 / A)\left(\frac{\bar{w}}{\alpha}\right)^{\alpha}\left(\frac{r}{1-\alpha}\right)^{1-\alpha}$.

I find the the model's equilibrium conditions by equating the factor demand and supply functions and enforcing zero profits using the unit cost function, with output price normalized to one. Thus, the general equilibrium of the economy is any $\left\{w_{0}, w_{1}, r\right\}$ that solves the following equations:

$$
\begin{array}{cl}
\text { Labor Clearing } & \frac{L_{e_{0}}^{S}}{L_{e_{1}}^{S}}=\left(\frac{w_{0} / \vartheta_{0}}{w_{1} / \vartheta_{1}}\right)^{\rho} \\
\text { Factor Clearing } & \frac{L_{e_{0}}^{S}+L_{e_{1}}^{S}}{K^{S}}=\left(\frac{\bar{w} / \alpha}{r / 1-\alpha}\right)^{-1} \\
\text { Zero Profits } & 1=c\left(w_{0}, w_{1}, r\right) .
\end{array}
$$




\section{Incidence}

In this section, I present the partial and general equilibrium incidence of targeted labor subsidies for the two skill model which provides all necessary economic intuition. At the end, I present the incidence result for the full model that allows for arbitrary labor types which I use in the empirical applications. The partial equilibrium section essentially replicates Rothstein (2010) using the above model notation.

\subsection{Partial Equilibrium}

The tax reform introduces a labor subsidy for low skill workers with children, $\tau_{0,1}$. Because there is no subsidy for other types of workers, I refer to $\tau_{0,1} \operatorname{simply}$ as $\tau$. I find the partial equilibrium incidence by totally differentiating the labor clearing condition (equation 12) while holding $\left\{L_{1}, K, w_{1}, r\right\}$ constant. In the limit when the market size of subsidized group goes to zero, this result is equivalent to the general equilibrium result, discussed next. This yields (when $\hat{\tau}>0$ ):

$$
\hat{w}_{0}^{\mathrm{PE}}=\left(\frac{\varepsilon_{0,1}^{L}}{\varepsilon_{0}^{L}-\rho}\right) \cdot \theta_{0,1} \cdot \hat{\tau}:=\gamma_{0} \cdot \hat{\tau}<0
$$

where $\hat{x}_{e}=x_{e} / w_{e}$ is the percent of wage change for the $e$-group, $\theta_{e, c}=L_{e, c} / L_{e}$ is the within skill share of subsidized workers, and $\varepsilon_{e}^{L}$ and $\varepsilon_{e, c}^{L}$ are the group and sub-group supply elasticities, respectively, where $\varepsilon_{e}^{L}=\theta_{e, 1} \varepsilon_{e, 1}^{L}+\left(1-\theta_{e, 1}\right) \varepsilon_{e, 0}^{L}$. Recall equation 8 and note that the numerator uses the elasticity of the subsidized group while the denominator uses the aggregate supply elasticity for the low skill market.

Interestingly, the model implies that the partial equilibrium labor demand elasticity for labor is constant, equivalent for all labor types, and equal to the labor elasticity of substitution. To see why this is the case, consider the following: ${ }^{14}$

$$
L_{0}^{D}\left(w_{0}\right)=L_{1}^{S}\left(w_{1}\left(w_{0}\right)\right) \cdot\left(\frac{w_{0} / \vartheta_{0}}{w_{1}\left(w_{0}\right) / \vartheta_{1}}\right)^{\rho} \Longrightarrow \eta_{0}^{D}=\rho+\frac{\partial w_{1}}{\partial w_{0}}\left(\varepsilon_{1}^{L}-\rho\right) .
$$

\footnotetext{
${ }^{14}$ In the two factor CRS case, Lee and Saez (2012) show that in equilibrium, the supply responses of the second factor can be used to pin down the first factor's demand and second factor's price as only a function of the first factor's price, despite the unknown scale of production.
} 
When $\frac{\partial w_{1}}{\partial w_{0}}=0$ by partial equilibrium assumption, the demand elasticity equals the substitution elasticity between factors. ${ }^{15}$ Holding $w_{1}$ and $r$ fixed is equivalent to holding those factors' marginal product constant, but this is invalid when $L_{0}$ increases (except when the low skill group is infinitesimal).

\subsubsection{Implication and Interpretation for Policy}

When there are multiple labor types with heterogeneous subsidy changes, aggregating the PE results yields an 'employment weighted average partial equilibrium effect.' This is not of theoretical or practical interest unless it is ex-ante known that spillover effects will be negligible. The PE assumptions require that for any specific labor group no other group adjusts its supply, which creates a set of mutually exclusive assumptions.

Rothstein (2010) implies that decreases in gross wages are a transfer to firms at the expense of workers: "this implies that employers of low-skill labor capture a portion of the intended EITC transfer” and “...targeted work subsidies produce unintended transfers to employers..." ${ }^{16}$ While Rothstein's partial equilibrium analysis is technically correct, the interpretation of his result does not necessarily follow for two reasons.

First, with zero profits, there are no explicit profits for firms. With CRS technology, if one factor price goes down, then another must increase, so the owners of the other factors benefit if low skill wages fall. ${ }^{17}$ Second, if entrepreneurs own some of the other factors (such as capital), then entrepreneurs may 'capture' the wage subsidy because their own factor payments increase. However, the production function in Rothstein (2010) only includes labor factors, so there is no possible factor to be owned by entrepreneurs. ${ }^{18}$

However, the 'all else equal' for the PE incidence requires the prices and quantities of all other factors be held fixed, which means that owners of other factors cannot actually realize any factor price increases. Thus, a partial equilibrium story is incapable of yielding

\footnotetext{
${ }^{15}$ Another way to see this is that: $\eta_{e}^{D}=\frac{\mathrm{d} \ln \left[L_{e}^{D}\right]}{\mathrm{d} \ln \left[w_{e}\right]}=\frac{\mathrm{d} \ln \left[L_{e}^{D} / L_{e^{\prime}}^{D}\right]}{\mathrm{d} \ln \left[w_{e} / w_{e^{\prime}}\right]}=\rho$ if $\mathrm{d} \ln \left[L_{e^{\prime}}^{D}\right]=\mathrm{d} \ln \left[w_{e^{\prime}}\right]=0$.

${ }^{16}$ Kasy (2017) makes a similar claim based on his results.

${ }^{17}$ Alternatively, holding other wages and rents constant, the output price must decrease which benefits consumers - especially low income - rather than firm owners.

${ }^{18}$ In an earlier working paper, Rothstein's production function did include capital but this was omitted in the published version.
} 
Rothstein's conclusion about transfers to firms at the expense of workers. In order to render the conclusion about firm owners benefiting from changes in gross wages, one must use a general equilibrium analysis.

\subsection{General Equilibrium}

To calculate the incidence, I totally differentiate equations 12,13 , and 14 with respect to $\left\{w_{0}, w_{1}, r, \tau\right\}$. Since the two type model system has three equations and three unknowns ( $\left.\mathbf{d} w_{0}, \mathbf{d} w_{1}, \mathbf{d} r\right)$, I can solve the for a change in low skill wages using iterative substitution. Use the zero profits condition to solve $\mathrm{d} r=f\left(\mathrm{~d} w_{0}, \mathrm{~d} w_{1}\right)$, use the labor clearing condition to solve $\mathrm{d} w_{1}=g\left(\mathbf{d} w_{0}, \mathbf{d} \tau\right)$, and then substitute into the factor clearing condition for $\mathrm{d} w_{0}=h(\mathbf{d} \tau)$. This yields:

$$
\begin{aligned}
\hat{w}_{0}^{\mathrm{GE}} & =\left(\frac{-\varepsilon_{0,1}^{L} \theta_{0,1}}{\left(\varepsilon_{0}^{L}-\rho\right)}+\frac{s_{L 0}\left(\frac{\varepsilon_{0,1}^{L} \theta_{0,1}}{\left(\varepsilon_{0}^{L}-\rho\right)}\right)\left(\frac{\varepsilon^{K}+1}{s_{K}}+\frac{1+\rho}{s_{L}}\right)}{\left(\varepsilon_{0}^{L}-\rho\right)\left(1+\left(\frac{\varepsilon^{K}+1}{s_{K}}+\frac{1+\rho}{s_{L 0}+s_{L 1}}\right)\left(\frac{s_{L 0}}{\left(\varepsilon_{0}^{L}-\rho\right)}+\frac{s_{L 1}}{\left(\varepsilon_{1}^{L}-\rho\right)}\right)\right)}\right) \hat{\tau} \\
& :=\left(\gamma_{0}+\Gamma_{0}\right) \cdot \hat{\tau}
\end{aligned}
$$

where $\gamma_{0}$ is the PE gross wage effect and $\Gamma_{0}$ is the GE spillover term, and $s_{h}$ are factor cost shares. Thus, the GE incidence is the direct (PE) effect plus a weighted sum of cross-factor effects. ${ }^{19}$ Since $\Gamma_{0} \geq 0$, a subsidy increase for low skill labor implies that the spillover effects attenuate the PE wage effects, so workers retain more of the subsidy than is implied by the PE analysis.

Solving for the other price effects (when $\hat{\tau}>0$ ): $\hat{w}_{1}^{\mathrm{GE}}=\left(\frac{\varepsilon_{0}^{L}-\rho}{\varepsilon_{1}^{L}-\rho}\right) \Gamma_{0} \hat{\tau} \geq 0$ and $\hat{r}^{\mathrm{GE}}=$ $-\left(\frac{s_{L 0}}{s_{K}} \hat{w}_{0}^{\mathrm{GE}}+\frac{s_{L 1}}{s_{K}} \hat{w}_{1}^{\mathrm{GE}}\right) \cdot{ }^{20}$ With only a low skill labor subsidy, the PE analysis provides an upper bound for the low skill labor market wage effect, but PE is completely uninformative about the magnitude of the other input price effects since these depend on GE spillover terms.

\footnotetext{
${ }^{19}$ Equation 17 resembles the result in Agrawal and Hoyt (2018) in that the general equilibrium incidence is a linear function of the PE incidence and GE spillover effects.

${ }^{20} \mathrm{~A}$ sufficient condition for $\hat{r}^{\mathrm{GE}}>0$ is that $\left(s_{L} / s_{K}\right) \varepsilon^{K}+\left(1 / s_{K}\right)>-\rho$. If $s_{K}=0.33$ and $\varepsilon^{K}=1$, then $\hat{r}^{\mathrm{GE}}>0$ when $\rho>-5$, which other authors and I find empirically (Katz and Murphy, 1992; Goldin and Katz, 2009; Borjas et al., 2012).
} 
As alluded to before, $\hat{w}_{0}^{\mathrm{PE}}=\hat{w}_{0}^{\mathrm{GE}}$ only if $s_{L 0}=0$, which is a small-market assumption that makes little sense in a two type model. ${ }^{21}$ Figure 3 provides a visual comparison of PE and GE incidence for a $1 \%$ effective subsidy increase for $L_{0}$ as implied by different endogenous cost shares.

Figure 3 - Incidence Comparison Across Labor Substitutions

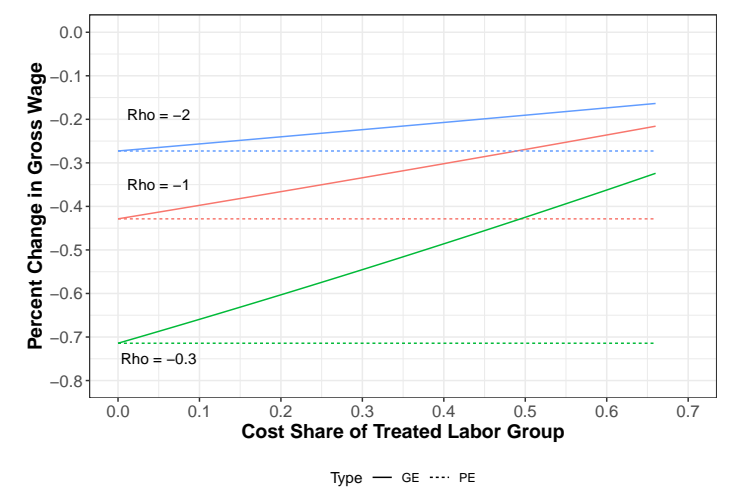

Plots percent change in gross wages for low skill workers from a $1 \%$ subsidy increase at different substitution elasticities and cost shares. Other parameters: $\varepsilon_{0}^{L}=0.75, \varepsilon_{1}^{L}=0.6, \varepsilon^{K}=1$. Details in Appendix A.

Figure 3 also shows the importance of the substitution elasticity, $\rho$. When inelastic, as in Rothstein (2010), the PE incidence implies large wage effects; however, when more elastic, as in my estimates presented in Section 5, the wage effects are smaller. This pattern is because a larger elasticity implies a firm can more easily adjust its factor demand bundle to take advantage of cost savings.

\subsubsection{General Equilibrium Incidence with Many Labor Markets}

Adding additional types of labor in this context is relatively simple given the symmetry of the model. ${ }^{22}$ Let skills be indexed by $e \in\{0,1,2, \ldots, E\}=\mathcal{E}$. I allow arbitrary skill-specific subsidies $\left(\hat{\tau}_{e}\right)$, and then solve the equations in the same manner as before using iterative substitution after totally differentiating. Full details are in Appendix A.

\footnotetext{
${ }^{21}$ As noted earlier, around $20 \%$ of tax units receive the EITC and $40 \%$ of all workers with children (Nichols and Rothstein, 2016).

${ }^{22}$ In the empirical applications, $|\mathcal{E}|=72$ based on age, education, and marital status of women.
} 
The general equilibrium incidence for type $e^{\prime}$ labor is:

$$
\begin{aligned}
\hat{w}_{e^{\prime}}^{G E} & =\frac{-\varepsilon_{e^{\prime}, 1}^{L} \theta_{e^{\prime}, 1} \hat{\tau}_{e^{\prime}}}{\varepsilon_{e^{\prime}}^{L}-\rho}+\frac{\Lambda\left(\sum_{e} \frac{s_{e} \varepsilon_{e, 1}^{L} \theta_{e, 1} \hat{\tau}_{e}}{\varepsilon_{e}^{L}-\rho}\right)}{\left(\varepsilon_{e^{\prime}}^{L}-\rho\right)\left(1+\Lambda\left(\sum_{e} \frac{s_{e}}{\varepsilon_{e}^{L}-\rho}\right)\right)} \\
& =\left(\gamma_{e^{\prime}}+\Gamma_{e^{\prime}}\right) \hat{\tau}_{e^{\prime}}+\Psi_{e^{\prime}}\left(\left\{\tau_{e}\right\}_{e \in \mathcal{E} \backslash e^{\prime}}\right) \\
\text { where } \Lambda & =\left(\frac{\varepsilon^{K}+1}{s_{K}}+\frac{1+\rho}{s_{L}}\right) .
\end{aligned}
$$

Generally, one cannot sign equation 18 without knowing the magnitude of each $\left\{\tau_{e^{\prime}}\right\}_{e}$. For example, if the tax change for one group is small but all other changes are large and positive, then the GE spillovers may dominate, so the wage change would be positive.

Equation 18 shows three first order terms with respect to a tax reform: the direct effect, the own-supply induced marginal product spillovers, and the received marginal product spillovers from other tax changes. Only if both spillover terms are small will $w^{\mathrm{GE}} \approx w^{\mathrm{PE}}$; e.g., if the cost share weighted average tax change is zero: $\mathrm{E}\left[s_{e} \tau_{e} \theta_{e, 1}\right]=0 .{ }^{23}$

\section{Estimating Labor Market Elasticities}

In this section, I describe how I estimate labor supply and substitution elasticities: $\left(\left\{\varepsilon_{e^{\prime}}\right\}, \rho\right)$, which are used in the empirical applications in sections 7- 11. In summary, I combine two data sets to calculate the labor market variables: the 1986-2000 Current Population Surveys (Flood et al., 2018) and the 1990 US Census 5\% sample, (Ruggles et al., 2018). ${ }^{24}$ Next, I use NBER's TAXSIM (Feenberg and Coutts, 1993) to create EITC induced average tax rate changes as the empirical analogue of $\hat{\tau}$. Finally, I use a two-step efficient GMM to estimate the supply and substitution elasticities. Additional details and results are in Appendices B-D.

\footnotetext{
${ }^{23}$ Agrawal and Hoyt (2018) make this point by supposing that the market share of taxed goods is small relative to a composite consumption good.

${ }^{24}$ I use two subsamples from the CPS: the Outgoing Rotation Groups (ORG) and the Annual Social and Economic (ASEC) samples.
} 


\subsection{Data}

I use the 1986 to 2000 CPS Outgoing Rotation Group (ORG) samples for labor market information by state and year. The sample asks detailed employment, earnings, and household structure information from roughly 100k households per month. I pool the monthly samples for annual level labor market variables. ${ }^{25}$

I assign workers to their labor skill levels based on observable demographic characteristics. Labor skill levels are defined by four education categories, nine age groups, and marriage status - this implies 72 skill levels. ${ }^{26}$ I assign workers to a labor markets based on the worker's skill level, state, and year. Additionally, I assign workers to demographic groups by dividing the labor market between workers with and without children. This yields $72 \times 51 \times 15$ labor market cells $-e \in \mathcal{E}$ - and $2 \times 72 \times 51 \times 15$ demographic cells $(e, c)=d \in\{\mathcal{E} \times\{0,1\}\} .{ }^{27}$

For labor market quantities, I use total hours worked divided by total potential workers at the labor market level. ${ }^{28}$ For labor market prices, I calculate a worker's real effective wage as earnings per week divided usual weekly hours deflated using the the BLS CPI All Items Research Series (Bureau of Labor Statistics, 2019). ${ }^{29}$ Appendix B includes additional details and summary statistics.

I use the 1990 US Census 5\% sample to calculate demographic-specific simulated instruments for the EITC policy changes. ${ }^{30}$ Specifically, I calculate EITC tax parameters for every tax year using NBER's Internet TAXSIM for the fixed 1990 worker population. The primary EITC tax parameter is the average tax rate associated with the EITC (EITC

\footnotetext{
${ }^{25}$ I drop individuals who were not interviewed or in group quarters, variable values that were allocated, married workers without a cohabitating spouse, full time students out of the labor force, and households with greater than 10 members because of the difficulty in assigning children for complex family structures (less than 0.5 percent of the sample).

${ }^{26}$ That is, 72 skill levels for each gender though I focus only on women workers for my empirical analysis.

${ }^{27}$ This follows the baseline market definition in Rothstein (2010), except I add geographic delineation by state. The benefit to this definition is that I 'observe' the skill level of unemployed workers.

${ }^{28}$ This measure captures both extensive and intensive margin responses that are relevant for labor market equilibrium. In Appendix D, I present results using the total number of workers that captures only the extensive margin response.

${ }^{29}$ This variable is the log geometric mean wage, which interpretable as an hours weighted productivity index (Borjas et al., 2012).

${ }^{30}$ Simulating tax parameters to generate instruments is also used in numerous prior studies such as: Dickert-Conlin and Houser (2002); Gruber and Saez (2002); Rothstein (2008); Leigh (2010); Bastian and Michelmore (2018).
} 
ATR). Let an individual worker's EITC ATR be the difference between the actual credit and the credit if not working ${ }^{31}$ divided by total earned income:

$$
\tau^{\text {EITC ATR }}=\frac{\text { EITC }(\text { Actual })-\text { EITC }(\text { No Work })}{\text { True Earnings }} .
$$

I calculate the above for each tax unit in the 1990 Census for each year in the 1990's, and then take the within demographic-skill and state-year average for empirical market rate.

I further describe the instrument construction and formalize the exogeneity requirements in Appendix C, but the virtue of this procedure is that by using the fixed population, all variation in the tax parameters is due to policy reforms over time and space and initial exposure levels of the EITC to these reforms. ${ }^{32}$ That is, the variation in the simulated tax parameters is not due to any endogenous behavioral response to the policy reforms - see Figure 5 below.

\subsection{Summary Statistics}

Table 1 displays the difference in labor market variable means before and after tax year 1993 conditional on marriage and parental status to highlight the identification using EITC policy tax changes. The first two variables are averages of the EITC Average Tax Rates, where the first is the instrument calculated from the 1990 Census and the second use values from the ASEC samples (described later), which incorporate endogenous behavioral responses. Before the reform, the true and simulated tax rates are similar, but post-OBRA the true tax rates are lower (implying a larger credit). This is due to endogenous labor supply increases in the true rates but not the simulated rates, as the instrument calculation holds fixed labor supply decisions. ${ }^{33}$

Additionally, Table 1 shows that labor supply increased for unmarried women with children and married women but decreased slightly for unmarried women without

\footnotetext{
${ }^{31}$ The not-working value is zero for unmarried tax units, but could be positive for married units depending on spousal income.

${ }^{32}$ In this way, the tax instruments are similar to 'shift-share' instruments. See the following on recent analysis concerning the general identifying assumptions of these instruments: Adao, Kolesár and Morales (2018); Borusyak, Hull and Jaravel (2018); Goldsmith-Pinkham, Sorkin and Swift (2018).

${ }^{33}$ While this could be due to earnings decreases (from lower wages or less supply) that cause workers to qualify for more credits, Table 1 shows wage and labor supply increased for unmarried mothers.
} 
children. Despite these supply increases, there are meaningful wage increases for every group in this period. The summary statistics show that the labor demand must dominate the supply increases to result in positive wage growth. ${ }^{34}$ For this reason, I use EITCspecific policy variation that is unrelated to demand shocks to untangle these competing forces.

I plot the data from Table 1 in Figures 4 and 5. In Figure 4 I plot log total hours per worker and mean log gross wages by demographic groups during the 1990's. These are the primary outcome and and endogenous explanatory variable in the empirical specification, respectively.

Figure 4 - Labor and Wages Across Demographic Groups

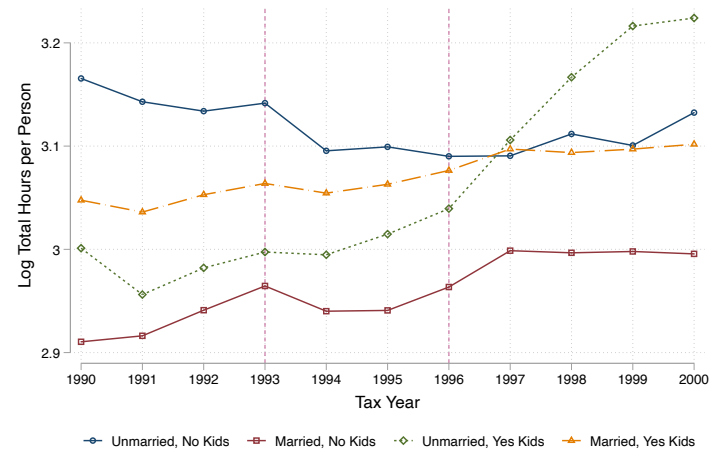

(a) Log Hours per Worker

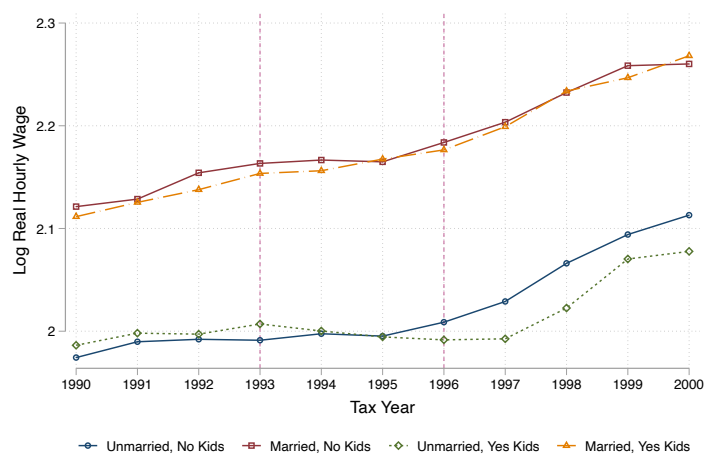

(b) Log Wage

(a) plots log total hours per workers and (b) plots mean log wage over; all data are women in tax units from CPS ORG samples 1989-1999.

In Figure 5, I plot the simulated EITC ATRs and EITC take-up shares against the empirical measures from the ASEC. The primary policy change for unmarried mothers occurred over tax years 1993 to 1996, while the only policy change for unmarried women without children was in tax year 1993. For unmarried mothers, the true ATR is less than the simulated ATR that holds labor supply fixed, which is consistent with workers entering the labor force at lower earnings. The simulated share predicts that fewer unmarried mothers would claim the EITC starting in tax year 1996 due to an added income test.

\footnotetext{
${ }^{34}$ The 1990s were a time of technological change and favorable macroeconomic conditions which can exaggerate EITC effects on labor supply and confound the wage effects (Nichols and Rothstein, 2016; Kleven, 2019).
} 
Table 1 - Summary Statistics for Estimation Sample

\begin{tabular}{|c|c|c|c|c|c|c|}
\hline \multirow[t]{2}{*}{ Tax Years } & \multicolumn{2}{|c|}{$1989-1993$} & \multicolumn{2}{|c|}{ 1995-1999 } & \multicolumn{2}{|c|}{ Difference } \\
\hline & Mean & SD & Mean & SD & $\mathrm{b}$ & $\mathrm{t}$ \\
\hline & \multicolumn{6}{|c|}{ Unmarried Women w/ Children } \\
\hline EITC ATR - 1990 Census & -0.08 & 0.04 & -0.14 & 0.08 & $-0.06^{* * *}$ & -40.86 \\
\hline EITC ATR - ASEC & -0.08 & 0.06 & -0.16 & 0.11 & $-0.08^{* * *}$ & -34.20 \\
\hline Log Hours Per Person - MORG & 3.08 & 0.54 & 3.19 & 0.44 & $0.11^{* * *}$ & 8.55 \\
\hline Log Real Wage - MORG & 2.15 & 0.31 & 2.47 & 0.33 & $0.32^{* * *}$ & 39.09 \\
\hline \multirow[t]{2}{*}{ Observations } & \multicolumn{2}{|c|}{2560} & \multicolumn{2}{|c|}{3854} & \multicolumn{2}{|c|}{6414} \\
\hline & \multicolumn{6}{|c|}{ Unmarried Women w/o Children } \\
\hline EITC ATR - 1990 Census & 0.00 & 0.00 & -0.01 & 0.01 & $-0.01^{* * *}$ & -69.49 \\
\hline EITC ATR - ASEC & 0.00 & 0.00 & -0.01 & 0.01 & $-0.01^{* * *}$ & -32.69 \\
\hline Log Hours Per Person - MORG & 3.32 & 0.37 & 3.28 & 0.35 & $-0.05^{* * *}$ & -5.01 \\
\hline Log Real Wage - MORG & 2.15 & 0.31 & 2.47 & 0.33 & $0.32^{* * *}$ & 39.47 \\
\hline \multirow[t]{2}{*}{ Observations } & \multicolumn{2}{|c|}{2589} & \multicolumn{2}{|c|}{3864} & \multicolumn{2}{|c|}{6453} \\
\hline & \multicolumn{6}{|c|}{ Married Women w/ Children } \\
\hline EITC ATR - 1990 Census & 0.00 & 0.00 & 0.00 & 0.01 & $0.00^{* * *}$ & 14.72 \\
\hline EITC ATR - ASEC & 0.00 & 0.01 & 0.00 & 0.02 & 0.00 & 1.92 \\
\hline Log Hours Per Person - MORG & 3.03 & 0.40 & 3.10 & 0.34 & $0.07^{* * *}$ & 8.34 \\
\hline Log Real Wage - MORG & 2.23 & 0.30 & 2.58 & 0.32 & $0.35^{* * *}$ & 54.45 \\
\hline \multirow[t]{2}{*}{ Observations } & \multicolumn{2}{|c|}{3809} & \multicolumn{2}{|c|}{5349} & \multicolumn{2}{|c|}{9158} \\
\hline & \multicolumn{6}{|c|}{ Married Women w/o Children } \\
\hline EITC ATR - 1990 Census & 0.00 & 0.00 & 0.00 & 0.00 & $-0.00^{* * *}$ & -7.65 \\
\hline EITC ATR - ASEC & 0.00 & 0.00 & 0.00 & 0.00 & $-0.00^{* * *}$ & -4.53 \\
\hline Log Hours Per Person - MORG & 3.27 & 0.39 & 3.29 & 0.34 & $0.02^{* *}$ & 2.68 \\
\hline Log Real Wage - MORG & 2.23 & 0.30 & 2.58 & 0.32 & $0.35^{* * *}$ & 54.49 \\
\hline Observations & \multicolumn{2}{|c|}{3844} & \multicolumn{2}{|c|}{5336} & \multicolumn{2}{|c|}{9180} \\
\hline
\end{tabular}

All data from CPS Samples 1990 to 2000 and 1990 US Census EITC ATRs calculated using TAXSIM 
Many empirical EITC studies assume that the EITC policy changes for workers without children is not enough to affect behavior. The figures show this is a reasonable assumption because I can predict the the EITC ATR and share using only the 1990 distribution of labor supply and inflation.

Figure 5 - Simulated vs True EITC Parameters

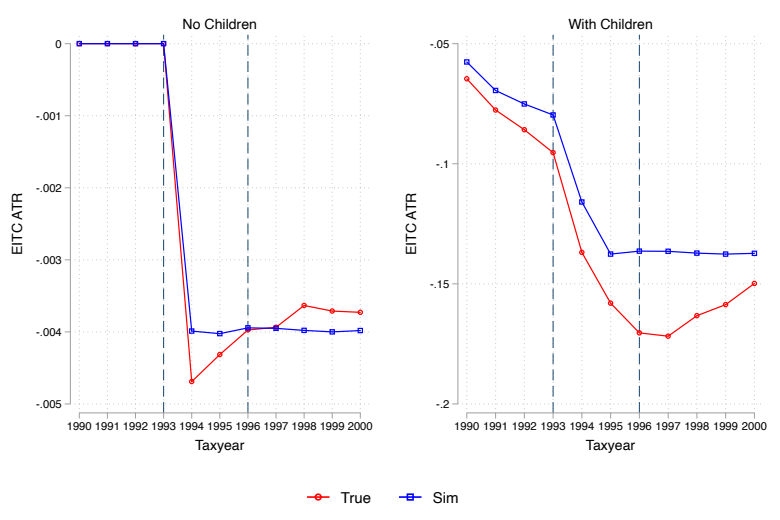

(a) EITC ATR
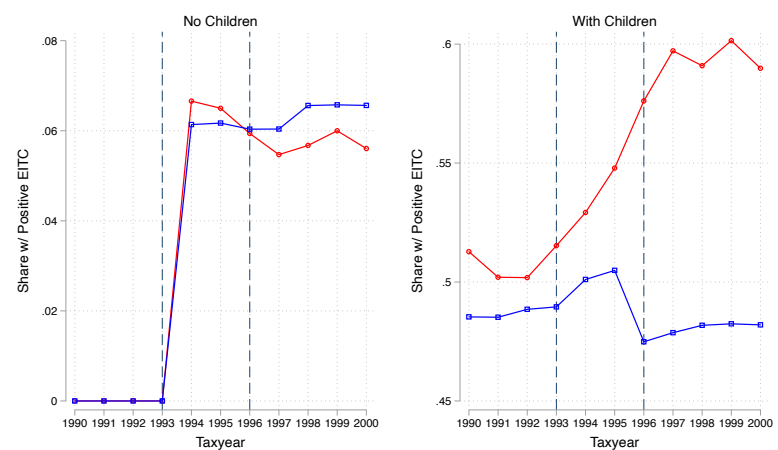

$\rightarrow$ True $\rightarrow$ Sim

(b) Share w/ EITC

Calculated using ASEC vs 1990 Census samples using NBER TAXSIM.

\subsection{Identification}

Succinctly, the incidence model - and Figure 1 - elucidates that the EITC creates both supply and demand variation in wages that can be used to identify labor supply and labor substitution elasticities:

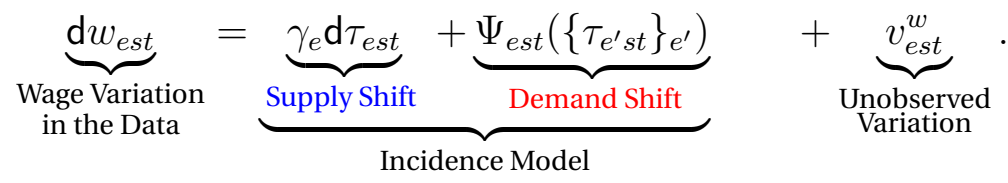

As discussed in Watson (2020), supply elasticities are identified using spillover based demand variation and conditioning on the own tax rate that controls for supply shifts; whereas, demand elasticities are identified using the tax reform supply shock and conditioning on the demand spillovers. 
A sufficient set of identifying assumptions for both labor supply and substitution elasticities is that:

$$
\begin{aligned}
& \mathrm{E}\left[\tau_{e s t} \cdot u_{e^{\prime} s t}^{D} \mid \Psi_{e s t}, X\right]=0, \forall e, e^{\prime} \in \mathcal{E} \\
& \mathrm{E}\left[\Psi_{e s t} \cdot u_{e^{\prime} c s t}^{S} \mid \tau_{e c s t}, X\right]=0, \forall e, e^{\prime} \in \mathcal{E},
\end{aligned}
$$

where $\tau_{e s t}=\theta_{e 0 s t} \tau_{e 0 s t}+\theta_{e 1 s t} \tau_{e 1 s t} .{ }^{35}$ In words, tax rate variation is uncorrelated to both unobserved non-spillover demand shocks - e.g., skill biased technical change or changes in hiring costs - and to unobserved supply shocks - e.g., employment opportunity costs. See Appendix C.1 for more details and derivation.

\subsection{Estimating Equations}

To estimate the labor supply and substitution elasticities, $\left(\left\{\varepsilon_{e^{\prime}}\right\}, \rho\right)$, I use two-step efficient GMM with standard errors clustered at the labor market level (Hansen, 1982). ${ }^{36}$ While theoretically possible to estimate the supply and substitution elasticities jointly, I estimate the parameters in two separate steps (Zoutman et al., 2018; Watson, 2020). ${ }^{37}$

I identify the labor supply elasticities, $\varepsilon_{d}^{L}$, using variation within demographic cells across state-years. That is, identification comes from the differences in EITC induced wage spillovers - i.e., demand shocks - within a demographic group due to differential exposure to EITC reforms in a given state-year. For example, suppose in state A relative to $\mathrm{B}$ there are more unmarried mothers, then state A has greater exposure to EITC reforms, so the resulting supply shock will create larger demand spillovers. Additionally, if A and B have similar shares of unmarried mothers but A implements a state EITC, then A will have a larger EITC policy shock. ${ }^{38}$ By conditioning on the demographic group's own

\footnotetext{
${ }^{35}$ These assumptions are slightly stronger than necessary, particularly for the substitution elasticity, but would imply the necessary assumption I show in Appendix C.1.

${ }^{36}$ Appendix D additional empirical specifications.

${ }^{37}$ The linearized deviations from equilibrium, used to arrive at equation 18 , form a linear system of equations that could be estimated using GMM, similar to Suárez Serrato and Zidar (2016). At the expense of efficiency, separating the estimation tasks allows for the parameters to be transparently identified and more robust to misspecification.

${ }^{38}$ Fourteen states (and DC) had an state EITC program between 1990 and 2000: CO, IA, IL, KS, MA, MD, ME, MN, NJ, NY, OR, RI, VT, WI.
} 
EITC change, the remaining skill-level variation in the EITC is due to demand shocks. I describe this argument in greater detail in Appendix C.1.

To estimate the heterogeneous labor supply elasticities, I specify the coefficient on log market wage as function of marriage, parental, and education status. This leads to the following estimation equations:

$$
\begin{aligned}
\ln [W]_{d s t}=\pi_{0} & +Z_{d s t} \Pi_{1}+\left[Z_{d s t} \cdot \mathrm{g}_{d}\right] \Pi_{d}+\pi_{2} \tau_{d s t}+\pi_{3} \ln \left[P_{d s t}\right] \\
& +\mathrm{d}_{d}+\mathrm{d}_{s t}+\mathrm{d}_{w_{0}^{\%}, t}+\mathrm{d}_{k s t}^{\text {waiver }}+e_{d s t}^{w} \\
\ln [L]_{d s t}=\beta_{0} & +\varepsilon_{1}^{L} \ln [W]_{d s t}+\varepsilon_{g}^{L}\left[\ln [W]_{d s t} \cdot \mathrm{g}_{d}\right]+\beta_{2} \tau_{d s t}+\beta_{3} \ln \left[P_{d s t}\right] \\
& +\mathrm{d}_{d}+\mathrm{d}_{s t}+\mathrm{d}_{w_{0}^{\%}, t}+\mathrm{d}_{k s t}^{\text {waiver }}+e_{d s t}^{L}
\end{aligned}
$$

where $Z$ are market level simulated EITC instruments from the 1990 Census, $\tau_{d s t}$ is the own EITC ATR simulated from the 1990 Census, $\ln \left[P_{d s t}\right]$ is log cell population, $\mathrm{g}_{d}$ are indicator variables for marriage, parental, and education status, $\mathrm{d}_{d}$ are demographic group fixed effects (FEs), $\mathrm{d}_{s t}$ are state-year FEs, $\mathrm{d}_{w_{0}^{\%}, t}$ are FEs for initial (1989) wage percentiles interacted with year indicators, and $d_{d s t}^{\text {waiver }}$ are FEs for state welfare waivers interacted with parental status indicators. The implied elasticity for a given labor market is $\varepsilon_{d}^{L}=\varepsilon_{1}^{L}+\varepsilon_{g(d)}^{L}$.

The controls are meant to absorb any demand or supply shocks other than the EITC policy changes that may affect labor supply. The demographic group FEs, $\mathrm{d}_{d}$, control for any time invariant correlation between wages and labor supply that is specific to a demographic group; e.g., demographic level tastes for working. The state-year FEs, $\mathrm{d}_{s t}$, control for any state-year level correlations across demographic groups; e.g., a state policy change that affect the cost of working for all workers. The initial wage percentile FEs, $\mathrm{d}_{w_{0}^{\%}, t}$, control for any correlations at specific to a market's wage segment before the EITC expansions; e.g., mean-reversion in wages or skill biased technological change. Finally, the waiver FEs, $d_{d s t}^{\text {waiver }}$, control for correlations that are due to state welfare changes prior to the Personal Responsibility and Work Opportunity Reconciliation Act of 1996 (PRWORA), provided by Kleven (2019). 
I identify the substitution elasticity by using using variation between skill levels across state-years. I use relative EITC supply shocks across skills as the identifying variation, and condition on market spillovers. I estimate a single substitution elasticity for all skill groups using the following equation:

$$
\begin{aligned}
\widetilde{\ln [W]_{e s t}=\gamma_{0}} & +\gamma_{1} \tilde{\tau}_{e s t}+\gamma_{2} \tilde{Z}_{e s t}+\gamma_{3} \widetilde{\ln [P]_{e s t}} \\
& +\mathrm{d}_{e}+\mathrm{d}_{s t}+\mathrm{d}_{w_{0}^{\%}, t}+u_{e s t}^{w} \\
\widetilde{\ln [L]_{e s t}}=\alpha_{0} & +\widetilde{\ln [W]_{e s t}}+\alpha_{2} \tilde{Z}_{e s t}+\alpha_{3} \widetilde{\ln [P]_{e s t}} \\
& +\mathrm{d}_{e}+\mathrm{d}_{s t}+\mathrm{d}_{w_{0}^{\%}, t}+u_{e s t}^{L},
\end{aligned}
$$

where $\tilde{x}_{e s t}=x_{e s t}-x_{0 s t}$, the log difference. I use controls analogous to the supply model but with interpretation based on relative quantities and wages. ${ }^{39}$

\subsection{Elasticity Estimates}

Table 2 displays the estimated elasticities. ${ }^{40}$ The results show that labor supply responsiveness decreases with education, that having children makes one less responsive to wages, and that married women are more responsive than unmarried women.

My estimate for the labor supply elasticity for unmarried mothers with low education attainment is quite similar to other estimates. I estimate the value 0.73 while Rothstein (2008) estimates a value of 0.75 and Meyer and Rosenbaum (2001) estimate 0.83 for participation for work in an average week. ${ }^{41}$ I find that unmarried women without children and less than a high school degree have an elasticity of 1.16 , and I can reject that the labor supply elasticities for unmarried women with and without children are equal. This can imply a violation of "parallel trends" when using difference-in-difference methods because workers will respond differently to labor market effects on gross wages.

\footnotetext{
${ }^{39}$ I do not use state Welfare Waivers in this specification because at the market level they are perfectly colinear with the state-year FEs. Additionally, the market level $\mathrm{FE}_{e}$ pools married and unmarried markets.

${ }^{40}$ In Appendix D, I present additional specification results, including alternative dependent variables.

${ }^{41}$ Additionally, Dickert et al. (1995) calibrate a labor supply estimate of 0.85 and the difference-indifferences result from Eissa and Liebman (1996) implies an elasticity of 1.16, which coincidentally is my estimate for unmarried women with low education but no children.
} 
My estimates for married women with low education are higher than previous estimates. I estimate the value 0.97 while Eissa and Hoynes (2004) estimate 0.27 for similarly educated married women. ${ }^{42}$ Bargain and Peichl (2016) survey labor supply elasticities across countries and show estimates for married women range from almost perfectly inelastic to 1.5 for the United States.

Table 2 - Labor Supply Elasticity Estimates by Labor Groups: $\varepsilon_{d}^{L}$

\begin{tabular}{|c|c|c|c|c|}
\hline & \multicolumn{4}{|c|}{ Hours per Worker } \\
\hline & \multicolumn{2}{|c|}{ w/o Children } & \multicolumn{2}{|c|}{ w/ Children } \\
\hline & Unmarried & Married & Unmarried & Married \\
\hline \multirow[t]{2}{*}{ Less HS } & 1.16 & 1.30 & 0.73 & 0.97 \\
\hline & $(0.10)$ & $(0.10)$ & $(0.12)$ & $(0.09)$ \\
\hline \multirow[t]{2}{*}{ HS } & 0.90 & 1.04 & 0.47 & 0.71 \\
\hline & $(0.08)$ & $(0.07)$ & $(0.10)$ & $(0.07)$ \\
\hline \multirow[t]{2}{*}{ Some College } & 0.92 & 1.09 & 0.49 & 0.72 \\
\hline & $(0.08)$ & $(0.07)$ & $(0.10)$ & $(0.06)$ \\
\hline \multirow[t]{4}{*}{ BA Plus } & 0.73 & 0.86 & 0.30 & 0.53 \\
\hline & $(0.06)$ & $(0.06)$ & $(0.08)$ & $(0.05)$ \\
\hline & Obs & AR F & KP rk Wald F & MOP Effective-F \\
\hline & 60,814 & 28.81 & 24.40 & 20.01 \\
\hline
\end{tabular}

All data from MORG 86-00, 1990 Census; EITC ATRs calculated using TAXSIM. Standard Errors clustered by (144) demographic groupings. Weighted by number of observations in each labor market. Model controls: log cell population, FEs for demographics, State-Year, Initial-Wage-PctYear, and Welfare Reforms. KP rk Wald F is cluster robust Cragg-Donald stat; AR is cluster robust $\mathrm{F}$ stat of IVs on structural equation residuals. MOP Effective-F is an alternative weak-IV F-statistic, calculated using a linear function of wages (Olea and Pflueger, 2013; Pflueger, 2015)

Table 3 presents estimates of the labor substitution elasticity between labor markets for the two relative labor supply measures. Column (1) is just identified using the 'relative' EITC ATR and column (2) is overidentified using the 'relative' EITC ATR, change in EITC amount, and share in the phase-in region. For each estimate I report the cluster robust standard error in parentheses. Additionally, I report the Weak IV Robust confidence interval based on Andrews (2018). For both specifications, I can reject that the substi-

\footnotetext{
${ }^{42}$ One reason for the difference could be that Eissa and Hoynes (2004) estimate a joint labor supply decision at the individual level while I hold constant the married partner's labor supply and treat this an non-labor income for the wife. Another reason could be that Eissa and Hoynes (2004) use a longer time series of policy variation, while my variation linked to the 1993 OBRA expansion only.
} 
tution elasticity is inelastic, which is in line with the immigration literature estimates around -1.4 (Katz and Murphy, 1992; Goldin and Katz, 2009; Borjas et al., 2012). A more inelastic estimate of $\rho$ will tend to imply larger magnitude incidence effects since $\rho$ is in the denominator of equations 15 and 18.

Table 3 - Labor Substitution Elasticity Estimates Across Labor Markets

\begin{tabular}{ccc}
\hline & \multicolumn{2}{c}{ Hours per Worker } \\
\hline & $(1)$ & $(2)$ \\
\hline Wald SE & -2.01 & -1.68 \\
WIVR CI & {$[0.27)$} & $(0.27)$ \\
\hline KP rk Wald F & 72.14 & 32.73 \\
Anderson-Rubin F & 91.13 & 11.92 \\
MOP Effective-F & 166.88 & 59.36 \\
\hline \# IVs & 1 & 3 \\
\hline Obs & 25,773 & 25,773
\end{tabular}

All data from MORG 86-00, 1990 Census; EITC ATRs calculated using TAXSIM. Column (1) is just identified using relative EITC ATRs; columns (2) uses additional IVs. Weighted by geometric mean of labor market observation pairs. Standard Errors clustered by (63) labor market groupings. Weak IV Robust CIs based using AR (1) or LC test $(2,3)$ (Andrews, 2018; Sun, 2018). Model controls: log relative cell population, FEs for Edu-Age-Year, State-Year, and InitialWage-Quintile-Year. KP rk Wald F is cluster robust Cragg-Donald stat; AR is cluster robust F stat of IVs on structural equation residuals. MOP Effective-F is an alternative weak-IV F-statistic (Olea and Pflueger, 2013; Pflueger, 2015).

While columns 1 and 2 seem to disagree with each other, each estimate is within the other's Weak IV Robust confidence sets, so statistically they are indistinguishable. The WIVR CI in column two covers the three possible pairs of overidentified specifications using the three IVS: $\{-2.24,-1.92,-1.83\}$ and has a midpoint of $-1.96 .^{43}$

\section{Empirical Policy Evaluation Methodology}

In this section, I outline how I combine the incidence model, estimated elasticities, and data to derive the policy evaluation results. I present three types of results: model implied

\footnotetext{
${ }^{43}$ Interestingly, the KP F stat is greater for each 2-IV pair - 36.2, 42.4, and 46.8, respectively - than the 3 -IV specification in column 2.
} 
gross wage changes, labor changes, and per dollar effects (multipliers). The wage and labor changes are based on estimates elasticities and tax/subsidy changes. The per dollar effects closely follow Rothstein (2010) but incorporate spillovers and update formulas to allow for changes in welfare program usage and tax payments given earnings changes.

\subsection{Data}

I use the Annual Social and Economic sample from the March CPS as this sample contains employment and income information in the previous calendar year that is necessary to calculate Federal average tax rates and EITC specific ATRs (Flood et al., 2018). Specifically, I use the 1994 ASEC for the 1993 OBRA expansion and the 2009 ASEC for the 2009 ARRA expansion. This sample delivers baseline labor and wage levels, unearned income levels, cost shares (labor share by demographic group), and average tax rates (Federal and EITC). I use the same definition of skills and demographics as in the empirical section. However, for the policy evaluations, I no longer distinguish between states and only use Federal EITC variation due to the ASEC being about 1/10 the sample size as the ORG samples in the empirical section. While the ASEC sample asks about welfare program usage, I combine this sample with the output of the Urban Institute's Transfer Income Model 3 (Urban Institute, 2020) to complement the reported amount. ${ }^{44}$ The TRIM3 simulates household and family level transfer program amounts that is analogous to the NBER's TAXSIM model for tax rates and credits. For more details about the sample, see Appendix B.2.

\subsection{Model Wage and Labor Changes}

To calculate model implied wage and labor changes, I combine the data described above and the elasticities from the Section 5 results. I calculate and report the model

\footnotetext{
${ }^{44}$ At every point in the earnings distribution, I find self reported amounts are less than from the TRIM model (Meyer et al., 2015; Meyer and Mittag, 2019). For the Empirical 1993 Incidence results, I take the simple average of the two measures for welfare usage; using the self reported amount is more conservative while the TRIM implies larger effects. For the EITC vs Welfare Reform counterfactuals I use the TRIM3 model exclusively since I am altering the program's parameters directly.
} 
implied wages percent changes, $\hat{w}_{e}$, using the general incidence formula in equation $18 . \mathrm{I}$ calculate the model implied labor percent changes as: $\hat{L}_{e, c}=\varepsilon_{e, c}\left(\hat{w}_{e}-\hat{\tau}_{e, c}\right)$. I then report the percentage point changes in labor force participation as $\mathrm{d} L_{e, c}=\hat{L}_{e, c} \cdot L_{e, c}$.

\subsection{Per Dollar Effects}

I calculate per dollar effects by summing the changes in total income for the economy divided by the change in EITC expenditure. By defining gross earnings as $Z^{G}=w \cdot L$ and net earnings as $Z^{N}=(1-\tau) \cdot Z^{G}$, I can look at sources of change in total income from the EITC reforms by totally differentiating the income measures. The total change in gross earnings is $\mathrm{d} Z^{G}=w \mathrm{~d} L+\mathrm{d} w L+\mathrm{d} w \mathrm{~d} L$ and the total change in net earnings is $\mathrm{d} Z^{N}=(1-\tau) \mathrm{d} Z^{G}-\mathrm{d} \tau\left(Z^{G}+\mathrm{d} Z^{G}\right)$.

I report the change in gross earnings due to labor changes $(w \mathrm{~d} L)$, the change due to wage changes $(\mathrm{d} w L)$, the total gross earnings change $\left(\mathrm{d} Z^{G}\right)$, and the total net earnings change $\left(\mathrm{d} Z^{N}\right)$. I additionally include what Rothstein (2010) refers to as the change in net-transfers $\left(\mathrm{d} Z^{G}+\mathrm{d} \tau Z^{G}\right)$ and the net-earnings $\left(\mathrm{d} Z^{G}+\mathrm{d} \tau Z^{G}\right)$, which hold all other taxes and transfers constant rather than allowing them to adjust given the gross earnings changes. Finally, the table reports the ex post 'fiscal externality' that measures the policy reform's effect on the government budget constraint incorporating extensive labor supply effects, dFE $=\tau w \mathrm{~d} L$ (Hendren, 2016; Kleven, 2018). ${ }^{45,46}$ To put these in per dollar terms, I divide the measures by the total new EITC expenditure.

\section{Incidence of 1993 EITC Expansion}

In this section, I use the estimated elasticities and the empirical average tax changes to calculate the general equilibrium incidence of the 1993 EITC expansion. I use data

\footnotetext{
${ }^{45}$ I calculate the extensive margin change in welfare usage, $B$, as $\mathrm{d} B=\left(\left.B\right|_{L=0}\right) \cdot \frac{\mathrm{d} \operatorname{Pr}(L=1)}{1-\operatorname{Pr}(L=1)}+$ $\left(\left.B\right|_{L=1, \text { Phase-In }}\right) \cdot \frac{\mathrm{d} \operatorname{Pr}(L=1)}{\operatorname{Pr}(L=1)}$, which assumes that labor force entrants, originally receiving maximal demographic average welfare benefit, enter into the EITC Phase-In earnings region and use Welfare programs at the pre-reform demographic average level for the Phase-In region earnings.

${ }^{46}$ Assuming a utilitarian social welfare function with a unit marginal value of cost of government revenue, one can interpret this as Consumer Welfare measure. See Section A.2.2 for a derivation of this result
} 
from the 1994 Annual Social and Economic Supplement (ASEC) of the CPS that includes labor market information for tax year 1993 (Flood et al., 2018). The ASEC includes labor and non-labor income information that allows me to calculate tax parameters necessary for estimating the effect of the 1993 expansion. In Appendix B, I describe the variable construction and present summary statistics for the empirical incidence sample. Here, I focus on aggregate effects, but in Appendix E I display individual level effects along with alternative elasticity specifications.

\section{$7.1 \quad 1993$ Incidence Results}

In Table 4, I present my estimates of the gross wage incidence effects of the 1993 OBRA EITC expansion. The table displays own EITC ATR change, PE Incidence (direct effect), GE Incidence (direct + spillover), and the relative magnitude ('Size') of the spillover and direct effects. Note, the incidence effects are not normalized by a $1 \%$ tax change since the incidence effects depend on multiple tax changes across skill groups. Unmarried women without a high school degree, which had the largest tax decrease, see the largest gross wage changes. In aggregate, spillovers represent between $10-16 \%$ of the total gross wage effects for unmarried women and between $50 \%$ for married women.

Table 4 - Empirical Incidence of the 1993 EITC Expansion on 1993 Gross Wages

\begin{tabular}{|c|c|c|c|c|c|c|c|c|c|c|c|c|c|c|c|c|}
\hline \multirow[b]{2}{*}{$(\%)$} & \multicolumn{4}{|c|}{$\begin{array}{l}\text { Unmarried } \\
\text { No Children }\end{array}$} & \multicolumn{4}{|c|}{$\begin{array}{c}\text { Unmarried } \\
\text { w/ Children }\end{array}$} & \multicolumn{4}{|c|}{$\begin{array}{c}\text { Married } \\
\text { No Children }\end{array}$} & \multicolumn{4}{|c|}{$\begin{array}{c}\text { Married } \\
\text { w/ Children }\end{array}$} \\
\hline & $\mathrm{d} \tau$ & $\mathrm{PE}$ & GE & Size & $\mathrm{d} \tau$ & $\mathrm{PE}$ & GE & Size & $\mathrm{d} \tau$ & $\mathrm{PE}$ & GE & Size & $\mathrm{d} \tau$ & PE & GE & Size \\
\hline LessHS & -1.47 & -0.36 & -0.34 & 7.0 & -2.98 & -0.82 & -0.80 & 4.1 & -0.42 & -0.15 & -0.13 & 17.2 & -0.04 & -0.02 & 0.00 & 28.6 \\
\hline HS & -1.16 & -0.25 & -0.23 & 9.0 & -1.73 & -0.37 & -0.35 & 6.4 & -0.05 & -0.02 & 0.00 & 48.7 & 0.05 & 0.01 & 0.03 & 59.3 \\
\hline Some Col. & -0.71 & -0.12 & -0.10 & 18.5 & -1.11 & -0.20 & -0.18 & 11.7 & 0.05 & 0.01 & 0.03 & 58.4 & 0.12 & 0.03 & 0.05 & 41.7 \\
\hline $\mathrm{BA}+$ & -0.25 & -0.05 & -0.02 & 35.4 & -0.29 & -0.05 & -0.03 & 32.0 & 0.06 & 0.01 & 0.03 & 68.2 & 0.08 & 0.02 & 0.04 & 58.4 \\
\hline Total & -0.94 & -0.21 & -0.19 & 16.0 & -1.70 & -0.40 & -0.38 & 10.0 & -0.06 & -0.02 & -0.00 & 50.7 & 0.06 & 0.02 & 0.04 & 50.3 \\
\hline
\end{tabular}

Table 5 translates the net wage changes into labor supply effects using the estimated labor supply elasticities. As expected, unmarried women with children and low levels of education increase their labor supply, but other groups have marginal labor supply changes. Figure 6 visually shows the model implied GE change in labor force participation 
Figure 6 - Model Implied Change in LFP by Demographic Group

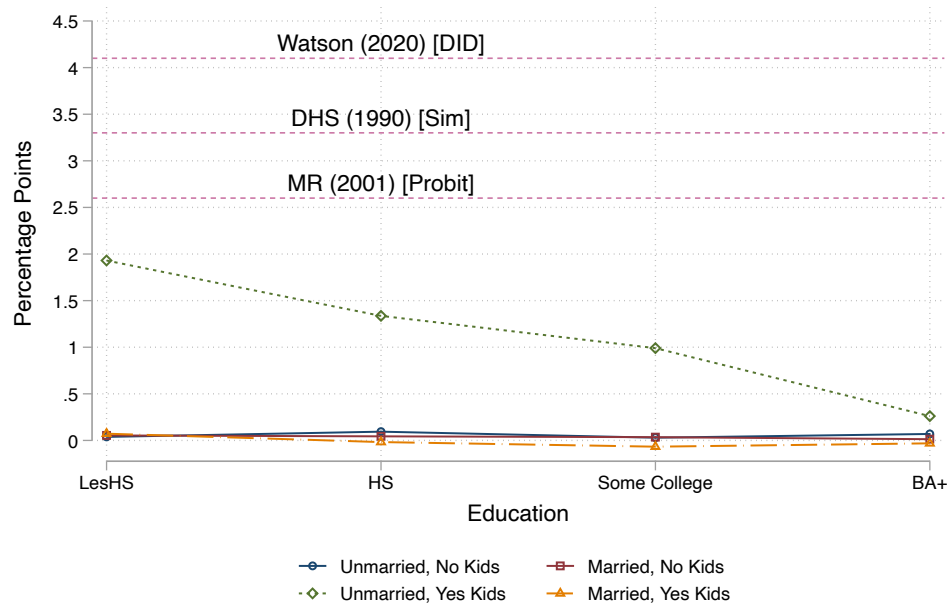

This plots the GE change in LFP by marriage, parental, and education group from the incidence model as well as the change from alternative empirical strategies, Dickert et al. (1995); Meyer and Rosenbaum (2001), and a simple difference in difference model, described in Appendix D.1.

by demographic group and compares it to three alternative empirical strategies, Dickert et al. (1995); Meyer and Rosenbaum (2001), and a simple difference in difference model, described in Appendix D.1. ${ }^{47}$ This figure supports the claim by Kleven (2018) that prior EITC elasticity estimates may have been contaminated by concurrent factors and biased up. Using my simulated IV and model based estimate, I find attenuated (but clearly positive, non-zero) labor supply effects that are below all other estimates.

Table 5 - Empirical Incidence of the 1994 EITC Expansion on Labor Supply

\begin{tabular}{c|cc|cc|cc|cc|cc}
\hline & \multicolumn{2}{|c|}{ Total } & \multicolumn{2}{c|}{$\begin{array}{c}\text { Nnmarried } \\
\text { No Children }\end{array}$} & $\begin{array}{c}\text { Unmarried } \\
\text { w/ Children }\end{array}$ & $\begin{array}{c}\text { Married } \\
\text { No Children }\end{array}$ & \multicolumn{2}{c}{$\begin{array}{c}\text { Married } \\
\text { w Children }\end{array}$} \\
\hline $\mathrm{d} L$ & $\mathrm{PE}$ & $\mathrm{GE}$ & $\mathrm{PE}$ & $\mathrm{GE}$ & $\mathrm{PE}$ & $\mathrm{GE}$ & $\mathrm{PE}$ & $\mathrm{GE}$ & PE & GE \\
\hline Less HS & 0.30 & 0.31 & 0.03 & 0.04 & 1.92 & 1.93 & 0.04 & 0.05 & 0.06 & 0.07 \\
HS & 0.17 & 0.18 & 0.08 & 0.09 & 1.33 & 1.34 & 0.03 & 0.04 & -0.03 & -0.02 \\
Some College & 0.09 & 0.10 & 0.01 & 0.03 & 0.98 & 0.99 & 0.02 & 0.03 & -0.08 & -0.07 \\
BA+ & 0.01 & 0.02 & 0.05 & 0.07 & 0.25 & 0.26 & -0.00 & 0.01 & -0.04 & -0.03 \\
\hline Total & 0.14 & 0.15 & 0.04 & 0.06 & 1.26 & 1.27 & 0.02 & 0.04 & -0.03 & -0.02 \\
\hline
\end{tabular}

Note: $\% \Delta L_{e, k}=\varepsilon_{e}^{L}\left(\% \Delta w_{e}-\mathrm{d} \tau_{e, k}\right)$. All data from 1994 March CPS, Women from Tax Units, and TRIM3 model. Values are average percentage point changes. Labor supply elasticities from Table 2 and column 1 in Table 3.

\footnotetext{
${ }^{47}$ These estimates are selected from Hotz and Scholz (2003) who document several empirical estimates of EITC expansions from 1986 to 2002.
} 
Table 6 - Empirical Incidence Results: Change Per Dollar of New Expenditure

\begin{tabular}{|c|c|c|c|c|c|c|c|c|c|c|}
\hline \multirow[b]{2}{*}{ Dollars } & \multicolumn{2}{|c|}{ Total } & \multicolumn{2}{|c|}{$\begin{array}{l}\text { Unmarried } \\
\text { No Children }\end{array}$} & \multicolumn{2}{|c|}{$\begin{array}{l}\text { Unmarried } \\
\text { w/ Children }\end{array}$} & \multicolumn{2}{|c|}{$\begin{array}{c}\text { Married } \\
\text { No Children }\end{array}$} & \multicolumn{2}{|c|}{$\begin{array}{c}\text { Married } \\
\text { w/ Children }\end{array}$} \\
\hline & $\mathrm{PE}$ & GE & $\mathrm{PE}$ & GE & $\mathrm{PE}$ & GE & $\mathrm{PE}$ & GE & $\mathrm{PE}$ & GE \\
\hline Labor & 0.31 & 0.35 & 0.06 & 0.08 & 0.28 & 0.28 & 0.01 & 0.02 & -0.04 & -0.03 \\
\hline Wages & -0.16 & -0.11 & -0.11 & -0.10 & -0.06 & -0.06 & -0.00 & 0.01 & 0.01 & 0.03 \\
\hline Gross Earnings & 0.15 & 0.24 & -0.05 & -0.02 & 0.21 & 0.22 & 0.01 & 0.04 & -0.02 & 0.00 \\
\hline Net Transfer, Fixed Taxes & 0.84 & 0.89 & -0.05 & -0.04 & 0.33 & 0.33 & 0.02 & 0.03 & 0.54 & 0.56 \\
\hline Net Earn, Fixed Taxes & 1.15 & 1.24 & 0.01 & 0.04 & 0.60 & 0.61 & 0.03 & 0.06 & 0.50 & 0.53 \\
\hline Net Earnings & 0.47 & 0.54 & 0.01 & 0.04 & 0.57 & 0.58 & 0.00 & 0.03 & -0.13 & -0.10 \\
\hline Fiscal Externality & 0.09 & 0.09 & 0.01 & 0.01 & 0.08 & 0.08 & 0.00 & 0.00 & -0.00 & -0.00 \\
\hline
\end{tabular}

Table 6 displays the incidence effects in terms of aggregate earnings changes per dollar of new EITC expenditure to make the effects. ${ }^{48}$ The 1993 EITC expansion effect on earnings is dominated by the labor supply effect. The aggregate change in gross earnings increases by $\$ 0.15$ in partial equilibrium and $\$ 0.24$ accounting for spillover effects, which is a $60 \%$ increase. The aggregate GE effect on net earning holding taxes constant is $\$ 1.24$ but is $\$ 0.54$ after accounting for changes in taxes and transfers due to earnings changes. Note, this difference is almost entirely due to lower net earnings for married mothers, who are more likely to be higher income workers with positive tax rates, rather than unmarried women who are lower income workers.

The fiscal externality is a $\$ 0.09$ increase per dollar of new EITC spending, implying a small net increase in government spending despite the large EITC expansion! This result complements the empirical finding by Bastian and Michelmore (2018) that the EITC 'pays for itself' as unmarried mothers who do not work tend to receive the maximal welfare benefits which is larger than the maximal EITC credit amount. Thus, moving an unmarried mother from non-work to the phase-in region of the EITC schedule results in a net positive position for the government budget. $^{49}$

\footnotetext{
${ }^{48}$ In Appendix E.1, I present individual level effects of the 1993 expansion.

${ }^{49}$ Hendren (2016) uses labor supply elasticities from the EITC literature to calculate a fiscal externality of $-\$ 0.09$ potentially due to holding constant welfare expenditure changes. If I hold welfare program expenditure constant, then I find a fiscal externality of -0.03 that is now negative but still smaller, which likely due to the smaller labor supply elasticities that I estimate.
} 
Across demographic groups there is considerable heterogeneity. Gross earnings decline for unmarried women without children but rise for other groups of women because the former group faces gross wage losses with essentially no increase in transfers. Net earnings decrease only for married women with children for three reasons. First and foremost, the OBRA reform implemented an asset test that decreased EITC amounts for higher income tax units, which tend to be married workers. Additionally, a large portion of married workers with positive EITC also face positive tax rates due to spousal earnings, so the EITC is 'taxed back.' Finally, since many married tax filers are in the phase-out region, increased gross earnings due to spillovers decreases the EITC amounts even more.

Interestingly, although wages fall for unmarried women without children, I find that net earnings actually rise for this group. First, there is a small credit for workings earning less than $\$ 10,000$ which more than offsets the wage decrease. Second, with progressive taxation, workers with earnings above $\$ 10,000$ who see gross wages fall end up paying less in taxes which unintentionally insures them from incidence effects.

\section{Comparing EITC and Welfare Reforms}

In this section, I use my estimated labor market elasticities to compare three hypothetical policy reforms based on the OBRA and PRWORA reforms in the mid-1990's. The first is an exogenously funded $\$ 100$ million dollar expansions of the 1992 EITC. The second is equal sized expansion of the combined 1992 ADFC and Food Stamps programs (which I refer to as simply 'Welfare'). ${ }^{50}$ The third experiment, which I call the Net EITC reform, simultaneously expands the EITC and contracts Welfare benefits to create an ex ante revenue neutral EITC expansion with no distortions on higher wage markets. ${ }^{51}$ This allows me to ignore the distortionary effects of financing the expansion as well as mirroring the tax and transfer system policy reforms of the 1990s.

\footnotetext{
${ }^{50}$ This reform is roughly the same as the hypothetical Negative Income Tax reform Rothstein (2010) considers. In Appendix E, I replicate his experiments and find qualitatively similar results.

${ }^{51}$ Because the experiment is a 'marginal reform,' taking the negative of the values reported for the Net EITC reform would be the same as conducting a Net Welfare expansion.
} 


\subsection{Simulating the Tax Reforms}

To implement the simulation, I characterize the tax system with transfer inclusive average tax rates, calculated using the reported income data, NBER TAXSIM, and the Urban Institute's TRIM3 welfare simulator (Feenberg and Coutts, 1993; Urban Institute, 2020). ${ }^{52}$ For each reform, I suppose that the government wishes to increase the generosity of its tax and transfer system for low income tax units by $\$ 100$ million through either an EITC expansion or Welfare expansion, but does not consider behavioral changes in response to the reforms. To implement the EITC expansion, I solve for the new maximum credit amount holding fixed the existing 'kink points' such that the total expenditure equals the targeted amount. To implement the welfare expansion, I approximate the existing welfare system as a fixed benefit and a rate at the benefit is taxed away, and then solve for the change in the benefit such that total new expenditure equals the targeted amount while keeping the same rate. The Net EITC reform implements the EITC expansion above and the negative of the welfare expansion to make the reform ex-ante revenue neutral. ${ }^{53}$ Figure 7 visually shows the reform transfer programs.

Figure 7 - True and Counterfactual 1992 Transfer Programs
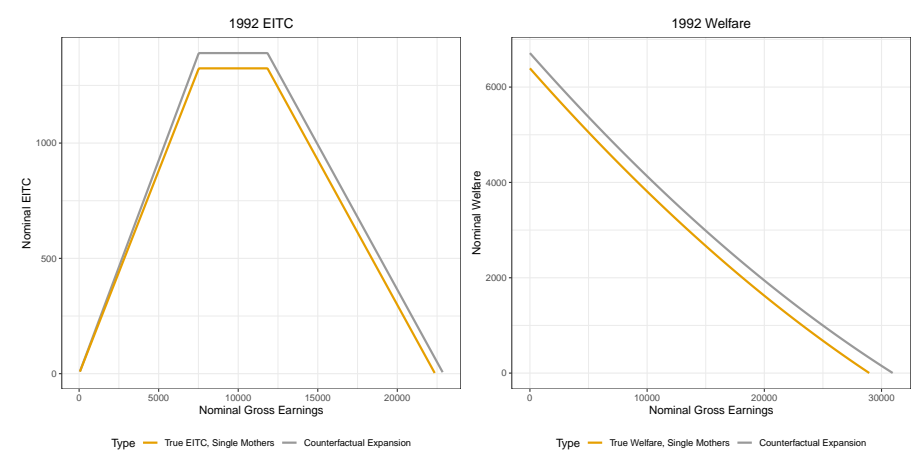

EITC and Composite Welfare for single women with one child in 1992.

\footnotetext{
${ }^{52}$ I do not consider an intensive hours margin, so I do not consider marginal tax rates. This accords with the preferred specification in Rothstein (2010), and most empirical literature on the EITC.

${ }^{53}$ These reforms roughly mirror the actual reforms in the 1990's but at a smaller scale.
} 


\subsection{Simulation Results}

Table 7 and 8 display the incidence results for the EITC, Welfare, and Net EITC simulated tax reforms at the aggregate and demographic level, respectively, and are interpreted the same as Table 6. For both tables, columns (1-3) show the partial equilibrium results and columns (4-6) incorporate spillovers. The main takeaway is that the 'bad' aspects of the EITC expansions (gross wage decreases) and the 'good' aspects of Welfare expansions (gross wage increases and positive welfare) are attenuated by the GE forces.

For the EITC, the dollar change due to wages is $-\$ 0.10$ in PE but only $-\$ 0.03$ in GE, but for the Welfare reform the $\$ 0.06$ wage growth in PE becomes $\$ 0.02$ in GE. For the Net EITC reform, the wage decline goes from $-\$ 0.15$ to $-\$ 0.05$, roughly a two-thirds decrease due to spillover effects. Aggregate gross earnings increase for the EITC and Net EITC programs but decrease for the Welfare expansion. This is because the Welfare expansion incentivizes workers to exit the labor force, and this source of earnings loss dominates the scarcity induced wage increases.

The difference between Net Earnings with Fixed Taxes, which Rothstein (2010) reports, and Net Earnings is that the latter measure accounts for the fact that the increase in gross wages will be taxed. If one holds taxes fixed, then the whole intended transfer is added to gross earnings, which overestimates the net earnings gain. The net earnings measure reported allows for additional earnings to be taxed (holding the ATR constant), so the some of the intended transfer goes to taxes as well as incidence effects. For the Welfare expansion, net earnings with fixed taxes is $\$ 0.88$ in GE but allowing for tax changes net earnings actually decrease by $-\$ 0.43$ ! For the EITC reforms, both measures of net earnings are positive.

As noted earlier, the welfare measure is the ex post fiscal externality of the reform. The EITC and net-EITC reforms have decrease of $\$ 0.08$ and $\$ 0.09$, respectively, but the Welfare expansion essentially has no externality. This means the EITC expansions impose an additional cost to the government to balance the budget but the Welfare reform does not. However, this should be considered along-side the gross and net earnings effects. The 
EITC expansion increases aggregate gross earnings (analogous to GDP) and net earnings by shifting some economic resources to lower income workers.

The implication of zero fiscal externality of the Welfare reform is worth delving into. Let there be three groups: high income (H) who always work, stable-labor low income (S) who always work, and marginal-labor low income (M) who would work less if able, where $\{\mathrm{M}, \mathrm{S}\}$ are in same labor market. Conceptually, the government is transferring income from $\mathrm{H}$ to $\mathrm{M}$, which allows $\mathrm{M}$ to exit market. Equilibrium forces increase the wages of $\mathrm{S}$ (due to induced scarcity) and lower wages of $\mathrm{H}$ (due to negative spillovers). This implies that $\mathrm{H}$ pay less taxes and $\mathrm{S}$ pay more taxes, and on balance these cancel out the payment to M. The payment of the Welfare reform comes from other low income workers rather than high income workers!

Table 7 - Incidence Results:

Aggregate Effects: All Women

\begin{tabular}{|c|c|c|c|c|c|c|}
\hline \multirow{3}{*}{ Dollars } & \multicolumn{3}{|c|}{ “PE" } & \multicolumn{3}{|c|}{ GE } \\
\hline & EITC & Welfare & Net EITC & EITC & Welfare & Net EITC \\
\hline & (1) & (2) & (3) & (4) & (5) & (6) \\
\hline Intended & 1.00 & 0.65 & 0.35 & 1.00 & 0.65 & 0.35 \\
\hline Labor & 0.19 & -0.12 & 0.31 & 0.24 & -0.14 & 0.38 \\
\hline Wages & -0.10 & 0.06 & -0.15 & -0.03 & 0.02 & -0.05 \\
\hline Gross Earnings & 0.10 & -0.06 & 0.15 & 0.21 & -0.12 & 0.33 \\
\hline Net Transfer, Fixed Taxes & 0.90 & 1.06 & -0.15 & 0.97 & 1.02 & -0.05 \\
\hline Net Earn, Fixed Taxes & 1.10 & 0.94 & 0.15 & 1.21 & 0.88 & 0.33 \\
\hline Net Earnings & 0.50 & -0.37 & 0.22 & 0.60 & -0.43 & 0.38 \\
\hline Welfare & -0.08 & 0.01 & -0.09 & -0.08 & 0.00 & -0.08 \\
\hline
\end{tabular}

Table 8 decomposes the aggregate effects by demographic groups. The net earnings for this unmarried women with children are positive at $\$ 0.78$, so the reason the aggregate net earnings are lower is due to the fact that net earnings fall for unmarried women without children by $-\$ 0.10$ (since this groups gets no subsidy yet faces the wage decreases) and 
married women with children by $-\$ 0.11$. For this latter group, the net earnings effect is negative because this group has the highest average tax rates on earned income due to spousal earnings.

The aggregate welfare effects are almost entirely due to changes from unmarried women with children, despite the fact that married mothers are also directly affected by the EITC and Welfare reforms. This is partially due to the fact that welfare changes do not depend on incidence (given zero profits and CRS assumptions) but on how behavior is affected. Because the EITC primarily affects unmarried mother's labor supply, this group drives the fiscal externality.

Table 8 - Incidence Results:

Aggregate Effects: Subgroups of Women

\begin{tabular}{|c|c|c|c|c|c|c|}
\hline \multirow{3}{*}{ Dollars } & \multicolumn{3}{|c|}{ “PE” } & \multicolumn{3}{|c|}{ GE } \\
\hline & EITC & Welfare & Net EITC & EITC & Welfare & Net EITC \\
\hline & (1) & $(2)$ & (3) & (4) & (5) & (6) \\
\hline & \multicolumn{6}{|c|}{ Unmarried Mothers } \\
\hline Net Earn, Fixed Taxes & 0.72 & 0.66 & 0.06 & 0.73 & 0.65 & 0.08 \\
\hline Net Earnings & 0.76 & -0.26 & 0.37 & 0.77 & -0.27 & 0.38 \\
\hline \multirow[t]{2}{*}{ Welfare } & -0.07 & 0.01 & -0.08 & -0.07 & 0.01 & -0.08 \\
\hline & \multicolumn{6}{|c|}{ Unmarried Women } \\
\hline Net Earn, Fixed Taxes & -0.14 & 0.03 & -0.17 & -0.10 & 0.01 & -0.12 \\
\hline Net Earnings & -0.12 & 0.03 & -0.15 & -0.09 & 0.01 & -0.11 \\
\hline \multirow[t]{2}{*}{ Welfare } & -0.01 & 0.00 & -0.01 & -0.01 & 0.00 & -0.01 \\
\hline & \multicolumn{6}{|c|}{ Married Mothers } \\
\hline Net Earn, Fixed Taxes & 0.50 & 0.24 & 0.27 & 0.54 & 0.21 & 0.33 \\
\hline Net Earnings & -0.15 & -0.15 & 0.01 & -0.12 & -0.17 & 0.06 \\
\hline \multirow[t]{2}{*}{ Welfare } & 0.00 & 0.00 & 0.00 & 0.00 & 0.00 & 0.00 \\
\hline & \multicolumn{6}{|c|}{ Married Women } \\
\hline Net Earn, Fixed Taxes & 0.01 & 0.02 & -0.01 & 0.04 & 0.00 & 0.04 \\
\hline Net Earnings & 0.01 & 0.02 & -0.01 & 0.04 & 0.00 & 0.04 \\
\hline Welfare & 0.00 & 0.00 & 0.00 & 0.00 & 0.00 & 0.00 \\
\hline
\end{tabular}

Units in table are changes in dollars of earnings summed across demographic groups. Note: $Z^{G}=w$. $L, Z^{N}=(1-\tau) \cdot w \cdot L$. All data from 1993 March CPS, Women from Tax Units. Labor supply elasticities from Model 1 in Table 2 and column 1 in Table 3. 


\section{Structural Model Parameterization}

The previous results were all derived using only the assumption of quasi-linearity of the utility function. In this section, I add a distributional assumption about the worker specific disutility of labor that allows me to parameterize demographic specific labor supply functions to calculate general equilibrium results for non-marginal and out-ofsample reforms. Specifically, I use labor participation probabilities and my elasticity estimates to parameterize a standard 'logit' binary choice model.

\subsection{Structural Model}

The utility problem for workers is the following discrete choice:

$$
\max _{L=\{0,1\}}\{\underbrace{u_{i}\left(T_{c}\left(0, m_{i}\right)\right)-\nu_{i}(0)}_{L=0}, \underbrace{u_{i}\left(T_{c}\left(w_{i}, m_{i}\right)\right)-\nu_{i}(1)}_{L=1}\}
$$

where $\nu_{i}$ is the idiosyncratic disutility of labor drawn from some distribution, $F_{e, c}(\nu)$. Initially, I assumed that $u_{i}(x)=x$, but now suppose that $u_{i}(x)=\beta_{e, c} \cdot x$, where $\beta_{e, c}$ can be interpreted as type-specifc marginal utility of consumption (or income). Additionally, suppose $\nu_{i}(0)-\nu_{i}(1)=\delta_{e, c}+\epsilon_{i}$, where $\epsilon_{i}$ distributed independent Type 1 Extreme Value $\left(F(\epsilon)=\mathrm{e}^{-\mathrm{e}^{-\epsilon}}\right)$ and $\delta_{e, c}$ is interpreted as an unobserved utility cost of labor (a supply 'shifter'). Then, demographic-specific (expected) labor supply function is:

$$
\operatorname{Pr}\left(L^{i}=1 \mid w_{e}, m_{e, c}, T_{c}\right)=\frac{\mathrm{e}^{\beta_{e, c} T_{c}\left(w_{e}, m_{e, c}\right)+\delta_{e, c}}}{\mathrm{e}^{\beta_{e, c} T_{c}\left(0, m_{e, c}\right)}+\mathrm{e}^{\beta_{e, c} T_{c}\left(w_{e}, m_{e, c}\right)+\delta_{e, c}}}:=\pi_{e, c} .
$$

\subsection{Recovering Structural Parameters}

Defining $\mathrm{v}_{e, c}:=T_{e, c}\left(w_{e}, m_{e, c}\right)-T_{e, c}\left(0, m_{e, c}\right)$ as the net wage, the model implies that:

$$
\begin{array}{cl}
\text { Gross Wage Elasticity: } & \varepsilon_{e, c}^{L}=\frac{\partial \pi_{e, c}}{\partial w_{e}} \frac{w_{e}}{\pi_{e, c}}=\beta_{e, c} \frac{\partial \mathrm{v}_{e, c}}{\partial w} w_{e}\left(1-\pi_{e, c}\right) \\
\text { Net Wage Elasticity: } \quad \eta_{e, c}^{L}=\frac{\partial \pi_{e, c}}{\partial \mathrm{v}_{e, c}} \frac{\mathrm{v}_{e, c}}{\pi_{e, c}}=\beta_{e, c} \mathrm{v}_{e, c}\left(1-\pi_{e, c}\right) .
\end{array}
$$

If the transfer function is $T_{e, c}\left(w_{e}, m_{e, c}\right)=\left(1-\tau_{e, c}\right)\left(w_{e} L\right)+b_{e, c}(1-L)+t(m)$, so that the net wage is $\left(1-\tau_{e, c}\right)\left(w_{e}\right)$, then $\frac{\partial \mathrm{v}_{e, c}}{\partial w} w_{e}=\mathrm{v}_{e, c}$ so that $\varepsilon_{e, c}^{L}=\eta_{e, c}^{L}$. Thus, I can recover the marginal 
utility of consumption parameters using the following:

$$
\frac{\varepsilon_{e, c}^{L}}{\left(\mathrm{v}_{e, c}\left(1-\pi_{e, c}\right)\right)}=\beta_{e, c} .
$$

With an estimate of $\beta_{e, c}$, I can then recover the unobservable net supply shifters using a Berry (1994) style inversion technique:

$$
\ln \left[\pi_{e, c}\right]-\ln \left[\left(1-\pi_{e, c}\right)\right]-\left(\beta_{e, c} \mathbf{v}_{e, c}\right)=\delta_{e, c}
$$

With the estimated structural utility parameters $\left\{\left(\widehat{\beta}_{e, c}, \widehat{\delta}_{e, c}\right)\right\}_{(e, c) \in \mathcal{D}}$, I can simulate nondifferential EITC reforms. Note, I estimate these parameters based on the elasticities estimates from the 1990's, so the underlying assumption of these parameters is that $\beta$ is a fixed utility parameter and any changes over time (conditional on the net wage) occur through the shifter, $\delta$.

\section{Childless Worker Reform}

Advocacy groups encourage policymakers to reform the EITC schedule such that workers without children are treated the same as workers with children. ${ }^{54}$ Advocates cite issues related to horizontal equity on the basis of skill as well as lifting more workers out of poverty. Another reason is, given that there are negative earnings effects for childless workers who are close substitutes, expanding the EITC for these workers can offset the incidence effects just like for unmarried women with children.

To quantify the effects of this reform, I equalize the 1994 EITC schedule for workers without children and workers with one qualifying dependent. ${ }^{55}$ That is, I create a counterfactual OBRA expansion where the credit for workers without children was equalized

\footnotetext{
${ }^{54}$ See discussions in Nichols and Rothstein (2016); Marr et al. (2016); Maag et al. (2019). Nichols and Rothstein (2016) note that both former President Obama and then former House Ways and Means committee chairman Ryan both advocated for increasing the generosity for childless workers.

${ }^{55} \mathrm{My}$ reform is larger than many existing proposals. Maag et al. (2019) use the 2016 American Community Survey to parameterize an equalization reform that triples the childless worker maximum credit and doubles the kink-point thresholds, but hold gross wages and labor supply constant, which ignores behavioral responses or incidence effects. President Obama's proposal doubled the maximum credit and extended the second kink-point by half Executive Office of the President and US Department of Treasury (2014).
} 
rather than set with a max of $\$ 306$. My model based approach can describe the labor supply and earnings effects of this and predict any additional take-up that may occur.

Note, the structural model results below and the incidence model results above do not yield the same quantitative values for two reasons. First, the incidence results use analytic results for changes in ATRs, while the structural results numerically solve for market clearing prices. Second, the incidence results, based on marginal changes in ATRs, hold constant other features of the tax and transfer system, while the structural results incorporate tax liability changes when calculating labor supply. Thus, the incidence model describes how the EITC expansions are shared between workers and the structural model shows the total effect of equalizing the EITC schedules on market equilibrium incorporating spillovers.

\subsection{Childless Worker Reform Results}

In Figure 8 and Tables 9 and 10, I display the results of the policy reform. To make comparisons as close as possible, I solve the model using the actual EITC schedule in tax year 1993 as a baseline, next solve the model using the actual 1994 schedule, and then solve the model using the counterfactual 1994 schedule. This holds all non-labor-market variables constant, such as labor supply shifters, aggregate productivity or demand shifts, and capital supply shifts. I then calculate the changes for each expansion from the baseline.

Figure 8 visually summarizes Table 9. There are two striking elements from the results. First, equalizing the credit schedules would substantially increase labor supply for unmarried workers without children - an $8.3 \%$ increase in aggregate but $22 \%$ for those without a high school degree. This is because these workers have a greater labor supply elasticity than workers with children and the expanded credit substantially increases their net income. Second, equalization creates a countervailing effect on unmarried mothers' the labor supply - from $2.1 \%$ to $1.3 \%$ in aggregate and $6.5 \%$ to $3.4 \%$ for those without a high school degree. This is due the same gross wage incidence effects from the 
much larger labor supply shock that advocates cite when promoting a childless worker expansion. Gross wages for unmarried workers initially decrease by about $0.5-0.4 \%$ under the actual expansion but decrease between $2.9-1.8 \%$ under the expansion regime. ${ }^{56}$

Figure 8 - Empirical Incidence Results: 1994 EITC Expansion + Equalization of Credit Schedule

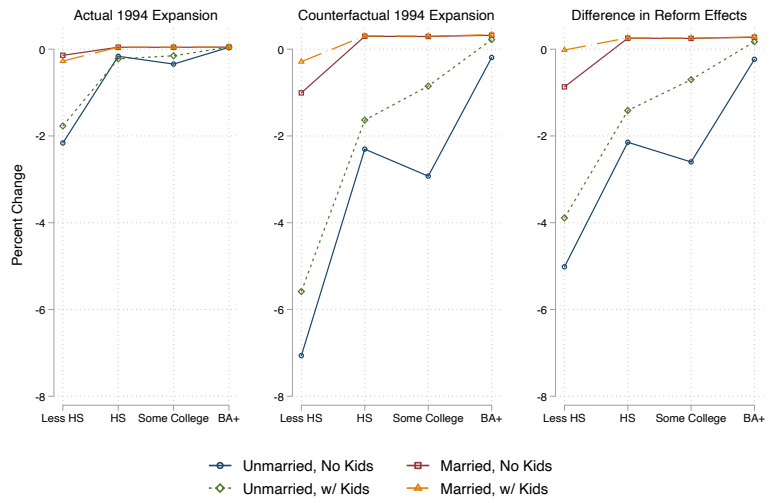

(a) Wages

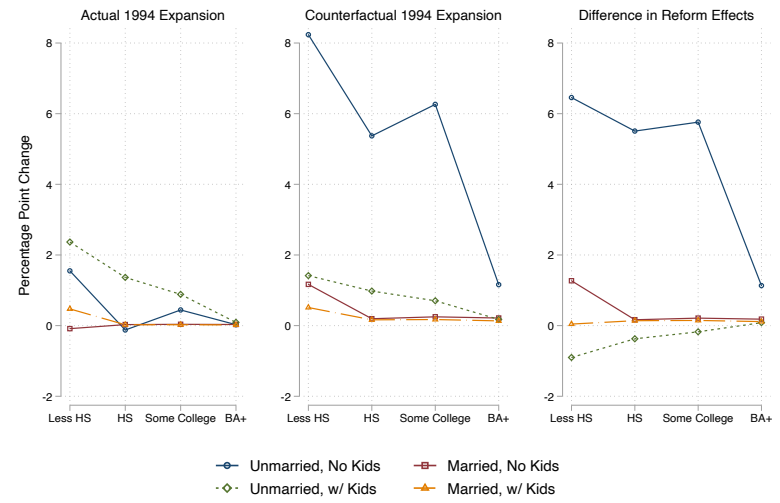

(b) Labor Supply

Labor market effects from actual 1993 expansion relative to the counterfactual equalized 1993 expansion calculated from structural model.

Table 10 puts the effects in terms of dollars of planned new expenditure and shows three important facts. First, neither the actual or counterfactual reform has much effect on married women mostly because these workers have household earnings that are too high to be affected by the policy. Second, the reforms have similar aggregate effects in terms of earnings and welfare measures. Third, the reforms have similar aggregate effects because the labor supply effects of the policy are almost exactly reversed for the unmarried women. Those without children supply more labor but those with children become much less likely to join the labor force.

While equalizing the EITC schedule may be more 'fair' and certainly will help many low income workers, these results imply that such a reform does not come without a cost. Policymakers wishing to reform the EITC face a dilemma: the current structure disadvantages workers without children but reforming the EITC may harm workers with

\footnotetext{
${ }^{56}$ These values are slightly different because of the workers do not perfectly overlap in demographic-skill based markets.
} 
Table 9 - Empirical Incidence Results:

1994 EITC Expansion + Equalization of Credit Schedule

\begin{tabular}{|c|c|c|c|c|c|c|c|c|c|c|c|c|}
\hline \multicolumn{13}{|c|}{ Percent Change in Wages } \\
\hline & \multicolumn{3}{|c|}{$\begin{array}{c}\text { Unmarried } \\
\text { No Children }\end{array}$} & \multicolumn{3}{|c|}{$\begin{array}{c}\text { Unmarried } \\
\text { w/ Children }\end{array}$} & \multicolumn{3}{|c|}{$\begin{array}{c}\text { Married } \\
\text { No Children }\end{array}$} & \multicolumn{3}{|c|}{$\begin{array}{c}\text { Married } \\
\text { w/ Children }\end{array}$} \\
\hline$\% \Delta w$ & Act & $\mathrm{Cft}$ & Diff & Act & $\mathrm{Cft}$ & Diff & Act & $\mathrm{Cft}$ & Diff & Act & $\mathrm{Cft}$ & Diff \\
\hline LessHS & -2.16 & -7.06 & -5.02 & -1.77 & -5.59 & -3.89 & -0.14 & -1.01 & -0.87 & -0.27 & -0.29 & -0.02 \\
\hline HS & -0.16 & -2.30 & -2.15 & -0.22 & -1.63 & -1.41 & 0.04 & 0.30 & 0.25 & 0.05 & 0.31 & 0.26 \\
\hline Some College & -0.34 & -2.93 & -2.60 & -0.15 & -0.85 & -0.70 & 0.04 & 0.29 & 0.25 & 0.04 & 0.30 & 0.26 \\
\hline $\mathrm{BA}+$ & 0.04 & -0.19 & -0.23 & 0.05 & 0.22 & 0.17 & 0.05 & 0.32 & 0.27 & 0.05 & 0.33 & 0.28 \\
\hline Total & -0.48 & -2.77 & -2.31 & -0.39 & -1.68 & -1.31 & 0.03 & 0.19 & 0.16 & 0.02 & 0.26 & 0.24 \\
\hline
\end{tabular}

Percentage Point Change in Labor Supply

\begin{tabular}{c|ccc|cccc|ccc|ccc}
\hline & \multicolumn{3}{|c}{$\begin{array}{c}\text { Nnmarried } \\
\end{array}$} & \multicolumn{2}{c}{ No Children } & \multicolumn{2}{c}{$\begin{array}{c}\text { Unmarried } \\
\text { w/ Children }\end{array}$} & \multicolumn{3}{c}{$\begin{array}{c}\text { Married } \\
\text { No Children }\end{array}$} & \multicolumn{3}{c}{$\begin{array}{c}\text { Married } \\
\text { w/ Children }\end{array}$} \\
\hline $\mathrm{d} L$ & Act & Cft & Diff & Act & Cft & Diff & Act & Cft & Diff & Act & Cft & Diff \\
\hline \multirow{2}{*}{ LessHS } & 1.55 & 8.24 & 6.46 & 2.37 & 1.41 & -0.90 & -0.09 & 1.17 & 1.27 & 0.47 & 0.51 & 0.04 \\
HS & -0.12 & 5.37 & 5.51 & 1.36 & 0.98 & -0.37 & 0.03 & 0.20 & 0.17 & 0.02 & 0.16 & 0.14 \\
Some College & 0.44 & 6.26 & 5.76 & 0.88 & 0.70 & -0.17 & 0.04 & 0.25 & 0.21 & 0.03 & 0.17 & 0.15 \\
BA+ & 0.03 & 1.16 & 1.13 & 0.09 & 0.17 & 0.08 & 0.03 & 0.22 & 0.18 & 0.02 & 0.13 & 0.11 \\
\hline \multirow{2}{*}{ Total } & 0.36 & 5.18 & 4.76 & 1.17 & 0.84 & -0.32 & 0.02 & 0.30 & 0.28 & 0.06 & 0.19 & 0.13 \\
\hline
\end{tabular}

'Act' : Actual EITC schedules; 'Cft' : Counterfactual EITC schedule where workers with no children get same credit as workers with one child; 'Diff' : Equalization specific effects All data from 1994 March CPS, Women from Tax Units. Values are average percent changes.

children (and through secondary effects their children). Just as policymakers should consider the spillover effects from the current EITC structure, they should be sure to understand the trade-offs in terms of families from a structural reform of the EITC.

\section{Incidence of the 2009 EITC Expansion}

In this section, I consider the labor market effects of the 2009 EITC expansion that was part of the American Recovery and Reinvestment Act of 2009. The reform made the credit schedule more generous for workers with three or more qualifying children as well as for married workers by extending the 'max credit' portion of the EITC to reduce 'marriage penalties' (Nichols and Rothstein, 2016). ${ }^{57}$ The reform was intended to provide counter-cyclical income support for low wage workers rather than strengthening labor

\footnotetext{
${ }^{57}$ The expansions were set to expire in 2017 but have since been made permanent.
} 
Table 10 - Empirical Incidence Results:

1994 EITC Expansion + Equalization of Credit Schedule

Change Per Dollar of New Planned Expenditure

\begin{tabular}{c|cc|ccc|cc|cc|cc}
\hline & \multicolumn{2}{|c|}{ Total } & \multicolumn{2}{c}{$\begin{array}{c}\text { Nnmarried } \\
\text { No Children }\end{array}$} & $\begin{array}{c}\text { Unmarried } \\
\text { w/ Children }\end{array}$ & $\begin{array}{c}\text { Married } \\
\text { No Children }\end{array}$ & $\begin{array}{c}\text { Married } \\
\text { w Children }\end{array}$ \\
\hline Dollars & Act & Cft & Act & Cft & Act & Cft & Act & Cft & Act & Cft \\
\hline Labor & 0.62 & 0.69 & 0.13 & 0.55 & 0.39 & 0.05 & 0.03 & 0.05 & 0.06 & 0.04 \\
Wages & -0.12 & -0.12 & -0.13 & -0.16 & -0.06 & -0.04 & 0.03 & 0.03 & 0.04 & 0.05 \\
Gross Earnings & 0.49 & 0.54 & -0.00 & 0.36 & 0.33 & 0.01 & 0.06 & 0.08 & 0.10 & 0.09 \\
\hline Net Transfer, Fixed Taxes & 0.88 & 0.88 & 0.13 & 0.70 & 0.65 & 0.07 & 0.03 & 0.05 & 0.07 & 0.06 \\
Net Earn, Fixed Taxes & 1.49 & 1.54 & 0.26 & 1.23 & 1.04 & 0.12 & 0.06 & 0.10 & 0.13 & 0.10 \\
\hline \multirow{2}{*}{ Net Earnings } & 1.37 & 1.44 & 0.26 & 1.17 & 0.96 & 0.12 & 0.04 & 0.08 & 0.11 & 0.07 \\
\hline Welfare & -0.10 & -0.09 & -0.01 & -0.06 & -0.06 & -0.01 & -0.01 & -0.01 & -0.02 & -0.01 \\
\hline
\end{tabular}

'Act' : Actual EITC schedules; 'Cft' : Counterfactual EITC schedule where workers with no children get same credit as workers with one child. Units in table are changes in dollars of earnings summed across demographic groups. Note: $Z^{G}=w \cdot L, Z^{N}=(1-\tau) \cdot w \cdot L$. All data from 1994 March CPS, Women from Tax Units.

force attachment. ${ }^{58}$ Nevertheless, because the expansion is the second largest EITC reform after the 1993 expansion, the reform gave economists an opportunity to revisit the EITC's labor market effects. In short, Iribarren (2016) and Kleven (2019) find no statistically significant effect from this reform.

There are three potential explanations for this. First, there was no effect, which is a conjecture recently advanced by Kleven (2019). Second, there were prevailing forces that dominated any EITC effect and a clean experiment is not possible. The existing papers rely on treatment and control group based estimates that should purge the overall economic forces during the recession period, so the results depend on appropriateness of these grouping decisions. Third, the reform was too small to see a large labor supply effect, even holding economic conditions constant. The expansion increased the maximum credit by $\$ 600$, which may not be enough to create large labor supply changes, and the targeted groups - workers with 3+ children, married workers - are a small proportion of the EITC claimers.

\footnotetext{
${ }^{58}$ It is theoretically ambiguous how the EITC fares in a recession since the laid-off worker will likely lose eligibility whereas workers with reduced hours may become eligible. Jones (2017) uses linked CPS-IRS data to show that unmarried mothers with low education had a higher likelihood of losing eligibility and lower likelihood of gaining eligibility through lost earnings.
} 
My incidence analysis allows me to provide a benchmark estimate of the 2009 expansion effects. If the labor market effects are small even when I am able to hold all other economic conditions constant, then this implies that standard difference-in-difference evidence may simply be under-powered to detect an effect. However, if the effects of the expansion are comparable to the larger 1993 expansion, then the a change in labor market fundamentals is necessary to explain the empirical null findings. Additionally, the results provide insight into why EITC expansion may have different effects over time. If labor supply elasticities are falling or costs increasing, then larger and larger EITC expansions are necessary to achieve the same labor supply effects.

\subsection{Incidence Results}

Compared to Table 4, Table 11 shows that the tax rate change for unmarried women is less than a third of the 1993 EITC expansion but the expansions are very similar for married women. As such, the direct and spillover effects are much smaller than the 1993 case. Table 12, show that unmarried mothers' aggregate labor supply should have increased by $0.7 \%$ while other groups show essentially no change, compared with $2.1 \%$ for the 1993 expansion. Despite the fact that the 2009 expansion reduced the two earners 'marriage penalty,' there is essentially no effect for married workers. The aggregate general equilibrium labor supply change effect is only $0.06 \%$.

Finally, in Table 13, I show the per dollar effect of the 2009 expansion. Again, the total effects as well as the spillover effects are much smaller than the 1993 expansion. The aggregate gross and net earnings changes are both less than half of the 1993 per dollar effects. This implies near zero aggregate welfare effects because there was little behavioral change. 
Table 11 - Empirical Incidence of the 1993 EITC Expansion on 1993 Gross Wages

\begin{tabular}{|c|c|c|c|c|c|c|c|c|c|c|c|c|c|c|c|c|}
\hline \multirow[b]{2}{*}{$\%$} & \multicolumn{4}{|c|}{$\begin{array}{l}\text { Unmarried } \\
\text { No Children }\end{array}$} & \multicolumn{4}{|c|}{$\begin{array}{c}\text { Unmarried } \\
\text { w/ Children }\end{array}$} & \multicolumn{4}{|c|}{$\begin{array}{c}\text { Married } \\
\text { No Children }\end{array}$} & \multicolumn{4}{|c|}{$\begin{array}{c}\text { Married } \\
\text { w/ Children }\end{array}$} \\
\hline & $\mathrm{d} \tau$ & $\mathrm{PE}$ & GE & Size & $\mathrm{d} \tau$ & $\mathrm{PE}$ & GE & Size & $\mathrm{d} \tau$ & $\mathrm{PE}$ & GE & Size & $\mathrm{d} \tau$ & $\mathrm{PE}$ & GE & Size \\
\hline LessHS & -0.40 & -0.11 & -0.10 & 4.1 & -0.85 & -0.27 & -0.27 & 2.4 & -0.19 & -0.07 & -0.07 & 13.4 & -0.21 & -0.08 & -0.08 & 20.2 \\
\hline HS & -0.38 & -0.08 & -0.08 & 6.7 & -0.66 & -0.14 & -0.13 & 3.7 & -0.02 & -0.01 & -0.00 & 28.0 & 0.04 & 0.01 & 0.02 & 25.2 \\
\hline Some Col. & -0.23 & -0.05 & -0.04 & 11.6 & -0.45 & -0.09 & -0.09 & 5.9 & 0.04 & 0.01 & 0.02 & 42.2 & 0.13 & 0.04 & 0.04 & 14.9 \\
\hline $\mathrm{BA}+$ & -0.08 & -0.02 & -0.02 & 21.4 & -0.12 & -0.03 & -0.03 & 14.0 & 0.05 & 0.01 & 0.02 & 35.0 & 0.10 & 0.02 & 0.03 & 16.3 \\
\hline Total & -0.27 & -0.06 & -0.06 & 11.0 & -0.53 & -0.13 & -0.12 & 5.9 & 0.01 & -0.00 & 0.00 & 32.9 & 0.06 & 0.02 & 0.02 & 18.3 \\
\hline
\end{tabular}

Table 12 - Empirical Incidence of the 2009 EITC Expansion on Labor Supply

\begin{tabular}{c|cc|cc|cc|cc|cc}
\hline & \multirow{2}{*}{ Total } & \multicolumn{2}{c|}{$\begin{array}{c}\text { No Charried } \\
\text { No Children }\end{array}$} & $\begin{array}{c}\text { Unmarried } \\
\text { w/ Children }\end{array}$ & $\begin{array}{c}\text { Married } \\
\text { No Children }\end{array}$ & \multicolumn{2}{c|}{$\begin{array}{c}\text { Married } \\
\text { w/ Children }\end{array}$} \\
\hline $\mathrm{d} L$ & PE & GE & PE & GE & PE & GE & PE & GE & PE & GE \\
\hline Less HS & 0.25 & 0.25 & -0.07 & -0.07 & 1.39 & 1.39 & 0.03 & 0.04 & 0.14 & 0.14 \\
HS & -0.02 & -0.02 & -0.24 & -0.24 & 0.56 & 0.56 & 0.02 & 0.02 & -0.09 & -0.09 \\
Some College & 0.03 & 0.03 & -0.02 & -0.02 & 0.67 & 0.67 & -0.00 & -0.00 & -0.12 & -0.12 \\
BA+ & 0.00 & 0.00 & 0.00 & 0.01 & 0.41 & 0.41 & 0.00 & 0.00 & -0.05 & -0.05 \\
\hline Total & 0.03 & 0.03 & -0.03 & -0.03 & 0.76 & 0.76 & 0.01 & 0.01 & -0.06 & -0.06 \\
\hline
\end{tabular}

Note: $\% \Delta L_{e, k}=\varepsilon_{e}^{L}\left(\% \Delta w_{e}-\mathrm{d} \tau_{e, k}\right)$. All data from 2009 March CPS, Women from Tax Units. Values are average percent changes. Labor supply elasticities from structural model implied by equation 33 .

Table 13 - Empirical Incidence of the 2009 EITC Expansion: Change Per Dollar of New Expenditure

\begin{tabular}{|c|c|c|c|c|c|c|c|c|c|c|}
\hline \multirow[b]{2}{*}{ Dollars } & \multicolumn{2}{|c|}{ Total } & \multicolumn{2}{|c|}{$\begin{array}{c}\text { Unmarried } \\
\text { No Children }\end{array}$} & \multicolumn{2}{|c|}{$\begin{array}{c}\text { Unmarried } \\
\text { w/ Children }\end{array}$} & \multicolumn{2}{|c|}{$\begin{array}{c}\text { Married } \\
\text { No Children }\end{array}$} & \multicolumn{2}{|c|}{$\begin{array}{c}\text { Married } \\
\text { w/ Children }\end{array}$} \\
\hline & $\mathrm{PE}$ & GE & $\mathrm{PE}$ & GE & $\mathrm{PE}$ & GE & $\mathrm{PE}$ & GE & $\mathrm{PE}$ & GE \\
\hline Labor & 0.10 & 0.11 & -0.04 & -0.04 & 0.21 & 0.21 & 0.02 & 0.02 & -0.08 & -0.08 \\
\hline Wages & -0.05 & -0.04 & -0.05 & -0.05 & -0.03 & -0.03 & 0.01 & 0.01 & 0.03 & 0.03 \\
\hline Gross Earnings & 0.05 & 0.07 & -0.09 & -0.08 & 0.17 & 0.17 & 0.03 & 0.04 & -0.06 & -0.05 \\
\hline Net Transfer, Fixed Taxes & 0.95 & 0.96 & -0.04 & -0.04 & 0.21 & 0.22 & 0.02 & 0.03 & 0.75 & 0.76 \\
\hline Net Earn, Fixed Taxes & 1.05 & 1.07 & -0.08 & -0.08 & 0.42 & 0.42 & 0.04 & 0.05 & 0.67 & 0.68 \\
\hline Net Earnings & 0.16 & 0.18 & -0.07 & -0.07 & 0.43 & 0.43 & 0.02 & 0.03 & -0.220 & -0.21 \\
\hline Welfare & -0.00 & 0.00 & -0.00 & -0.00 & 0.01 & 0.01 & 0.00 & 0.00 & -0.01 & -0.01 \\
\hline
\end{tabular}

March CPS, Women from Tax Units. Labor supply elasticities from structural model implied by equation 33. 


\section{Conclusion}

I evaluate the Earned Income Tax Credit allowing for general equilibrium interactions in the labor market and heterogeneous wage responsiveness. My approach allows one to evaluate any large scale program that affects average tax rates by mapping those changes to gross wages and labor supply as long as one has information on initial wages, quantities, and elasticities. When labor markets are imperfect substitutes, a tax induced supply change in one market will affect the marginal product of workers in other markets, creating cascading marginal product and wage spillovers across labor markets. Because the general equilibrium wage changes are theoretically ambiguous, I quantified the importance of general equilibrium effects in three ways.

First, I calculated the empirical incidence of the 1993 OBRA and 2009 ARRA EITC expansion. I find that spillovers represent about $15-30 \%$ of aggregate wage and net earnings effects in the direction of increasing dollars to workers. Second, to compare how different labor market policies affect spillovers, I simulated a \$100 million expansion of the EITC, of the AFDC and Food Stamps programs, and a reform that pays for the EITC expansion by reducing Welfare benefits. For all three policy reforms experiments, the GE incidence is less than one-third the PE incidence - for the EITC reforms this implies more dollars go to workers while for the Welfare reform workers receive fewer dollars. Third, I used my elasticities to parameterize a structural labor supply model to consider the effect of equalizing the the EITC schedule for workers with and without children. I find that equalizing the EITC would have the opposite issue of current EITC expansions: gross wage decreases would causes marginal workers with children not to enter the labor market.

Overall, these results show that the EITC is a cost effective program in transferring income to low wage workers. In all cases, the fiscal externality of the EITC expansions is always quite small relative to the increases in net earnings. The 1993 expansion created large labor market direct and indirect effects; however, the 2009 expansion appears not to have caused labor market disruptions. The best explanation for this seems to be simply 
that the 2009 expansion was smaller, focused on a smaller group, and in an environment where many people were already working. When labor market disruptions are small, the program is primarily functioning as an immediate anti-poverty tool in that dollars go to low income workers without distorting untreated workers' behaviors. When they are large, the program is acting as a immediate and long-run anti-poverty tool by increasing the earnings potential of workers and the economy as a whole.

The above assessment of the EITC's cost effectiveness is not without some caveats. First, the EITC has a positive fiscal externality only because net transfers from nonemployment to employment are positive rather than due to spillovers. Thus, while positive marginal product spillovers expand the economic capacity of the economy and tax base, ignoring this interaction with other transfers, the EITC would not 'pay for itself.' Second, the EITC has heterogeneous effects that may not yield horizontal equity. Similar skilled workers without children will be subject to gross earnings effects but will not receive the subsidy. I find that the welfare effects are ultimately small for these workers; nevertheless, proponents of expanding the EITC must accept that some workers will be financially hurt. As indicated, this also holds for those who want to expand the EITC for worker without children. Third, choosing an EITC expansion over a Welfare expansion - or any other policy that links benefit levels with non-employment - implies a judgement about the marginal value of leisure for workers on the margin of the labor supply threshold.

Finally, my approach still makes a number of simplifications worth pointing out. First, the production technology assumes a constant elasticity of substitution, so all factors are (imperfectly) substitutable in the same way. Second, the incidence is derived assuming frictionless labor market assumptions; e.g., perfect competition, price taking. Third, the model has abstracted from fully modeling the tax system or incorporating different industries or trade patterns. Incorporating and resolving these issues would be an interesting, informative, and potentially important contribution to understanding the incidence effects of government programs. 


\section{References}

Adao, Rodrigo, Michal Kolesár, and Eduardo Morales. 2018. "Shift-share designs: Theory and inference.” National Bureau of Economic Research Working Paper Series.

Agrawal, David R, and William H Hoyt. 2018. "Tax Incidence in a Multi-Product World: Theoretical Foundations and Empirical Implications.” Working Paper.

Andrews, Isaiah. 2018. "Valid two-step identification-robust confidence sets for GMM." Review of Economics and Statistics, 100(2): 337-348.

Azmat, Ghazala. 2019. "Incidence, salience, and spillovers: The direct and indirect effects of tax credits on wages.” Quantitative Economics, 10(1): 239-273.

Bargain, Olivier, and Andreas Peichl. 2016. "Own-wage labor supply elasticities: variation across time and estimation methods.” IZA Journal of Labor Economics, 5 1-31.

Bastian, Jacob. forthcoming. "The Rise of Working Mothers and the 1975 Earned Income Tax Credit.” American Economic Journal: Economic Policy.

Bastian, Jacob, and Maggie R. Jones. 2018. "Do eitc expansions pay for themselves? effects on tax revenue and public assistance spending." In 111th Annual Conference on Taxation. NTA.

Bastian, Jacob, and Katherine Michelmore. 2018. "The Long-Term Impact of the Earned Income Tax Credit on Children's Education and Employment Outcomes.” Journal of Labor Economics, 36 1127-1163.

Baughman, Reagan, and Stacy Dickert-Conlin. 2003. "Did expanding the eitc promote motherhood?” American Economic Review, 93 247-251.

Berry, Steven T. 1994. "Estimating discrete-choice models of product differentiation." The RAND Journal of Economics 242-262.

Borjas, George J, Jeffrey Grogger, and Gordon H Hanson. 2012. “Comment: On estimating elasticities of substition." Journal of the European Economic Association, 10(1): $198-210$.

Borusyak, Kirill, Peter Hull, and Xavier Jaravel. 2018. "Quasi-experimental shift-share research designs.” National Bureau of Economic Research Working Paper Series.

Buhlmann, Florian, Benjamin Elsner, and Andreas Peichl. 2018. "Tax refunds and income manipulation: evidence from the EITC.” International Tax and Public Finance, 25 1490-1518.

Bureau of Labor Statistics. 2019. "CPI Research Series Using Current Methods (CPI-URS) [Dataset].” URL: https://www.bls.gov/cpi/research-series/home.htm.

Chetty, Raj. 2009. "Sufficient statistics for welfare analysis: A bridge between structural and reduced-form methods." Annual Revue of Economics, 1(1): 451-488.

Chetty, Raj, Emmanuel Saez, and John N. Friedman. 2013. "Using Differences in Knowledge Across Neighborhoods to Uncover the Impacts of the EITC on Earnings." American Economic Review, 203 2683-2721. 
Dahl, Gordon B, and Lance Lochner. 2012. "The impact of family income on child achievement: Evidence from the earned income tax credit." American Economic Review, 102 1927-56.

Dickert-Conlin, Stacy, and Scott Houser. 2002. “EITC and Marriage.” National Tax Journal 25-40.

Dickert, Stacy, Scott Houser, and John Karl Scholz. 1995. "The Earned Income Tax Credit and Transfer Programs: a Study of Labor Market and Program Participation.” Tax policy and the economy, 9 1-50.

Eissa, Nada, and Hilary Hoynes. 2004. "Taxes And The Labor Market Participation Of Married Couples: The Earned Income Tax Credit.” Journal of Public Economics, 88 1931-1958.

Eissa, Nada, and Jeffery B. Liebman. 1996. "Labor Supply Response to the Earned Income Tax Credit.” Quarterly Journal of Economics, 11 605-37.

Evans, William N, and Craig L Garthwaite. 2014. "Giving mom a break: The impact of higher EITC payments on maternal health.” American Economic Journal: Economic Policy, 6 258-90.

Executive Office of the President and US Department of Treasury. 2014. "The President's Proposal to Expand the Earned Income Tax Credit.”Technical report, Washington, DC: Executive Office of the President.

Feenberg, Daniel, and Elizabeth Coutts. 1993. "An Introduction to the TAXSIM Model." Journal of Policy Analysis and Management, 12 189-194.

Fitzpatrick, Katie, and Jeffrey $\mathbf{P}$ Thompson. 2010. “The interaction of metropolitan cost-of-living and the federal earned income tax credit: one size fits all?" National Tax Journal, 63 419-445.

Flood, Sarah, Miriam King, Steven Ruggles, and J Robert Warren. 2018. "Integrated Public Use Microdata Series, Current Population Survey: Version 6.0 [dataset].” Minneapolis, MN: IPUMS.

Froemel, Maren, and Charles Gottlieb. 2019. “The Earned Income Tax Credit: Targeting the Poor but Crowding Out Wealth.” Canadian Journal of Economics.

Goldin, Claudia Dale, and Lawrence F Katz. 2009. The race between education and technology.: Harvard University Rress.

Goldsmith-Pinkham, Paul, Isaac Sorkin, and Henry Swift. 2018. "Bartik instruments: What, when, why, and how.” National Bureau of Economic Research Working Paper Series.

Goolsbee, Austan. 1998. "Investment tax incentives, prices, and the supply of capital goods.” The Quarterly Journal of Economics, 113 121-148.

Gruber, Jon, and Emmanuel Saez. 2002. “The elasticity of taxable income: evidence and implications.” Journal of public Economics, 84 1-32.

Hansen, Lars Peter. 1982. "Large sample properties of generalized method of moments estimators.” Econometrica: Journal of the Econometric Society 1029-1054. 
Hendren, Nathaniel. 2016. “The policy elasticity.” Tax Policy and the Economy, 30(1): 51-89.

Hotz, V Joseph, Charles H Mullin, and John Karl Scholz. 2002. "Welfare, Employment, and Income: Evidence on the Effects of Benefit Reductions from California." American Economic Review, 92 380-384.

Hotz, V. Joseph, and John Karl Scholz. 2003. “The Earned Income Tax Credit.” In Economics of Means-Tested Transfer Programs in the United States. ed. by Robert Moffitt, Chap. 3 141-197.

Hoynes, Hilary, Doug Miller, and David Simon. 2015. "Income, the earned income tax credit, and infant health.” American Economic Journal: Economic Policy, 7 172-211.

Hoynes, Hilary W, and Ankur J Patel. 2018. "Effective policy for reducing poverty and inequality? The Earned Income Tax Credit and the distribution of income." Journal of Human Resources, 53(4): 859-890.

Iribarren, Maria Luisa. 2016. “The effects of the 2009 Earned Income Tax Credit expansion on the labor supply of single women." Masters Thesis, Georgetown University.

Jones, Maggie R. 2017. “The Eitc Over the Great Recession: Who Benefited?” National Tax Journal, 70(4): 709-736.

Kasy, Maximilian. 2017. "Who wins, who loses? Identification of the welfare impact of changing wages.."

Katz, Lawrence F, and Kevin M Murphy. 1992. "Changes in relative wages, 1963-1987: supply and demand factors." The quarterly journal of economics, 107 35-78.

Kleven, Henrik. 2019. “The EITC and the Extensive Margin: A Reappraisal.”Technical report, National Bureau of Economic Research.

Kleven, Henrik J. 2018. “Sufficient Statistics Revisited.” Working Paper.

Lee, David, and Emmanuel Saez. 2012. "Optimal minimum wage policy in competitive labor markets.” Journal of Public Economics, 96 739-749.

Leigh, Andrew. 2010. "Who Benefits from the Earned Income Tax Credit? Incidence among recipients, coworkers and firms.” The B.E. Journal of Economic Analysis \& Policy, 10 1-43.

Maag, Elaine, Kevin Werner, and Laura Wheaton. 2019. "Expanding the EITC for Workers without Resident Children." Urban Institute.

Marr, Chuck, Chye-Ching Huang, and Nathaniel Frentz. 2016. "Strengthening the EITC for childless workers would promote work and reduce poverty." Washington: Center on Budget and Policy Priorities.

Maxfield, Michelle. 2015. "The effects of the earned income tax credit on child achievement and long-term educational attainment." Institute for Child Success.

Meyer, Bruce D, and Nikolas Mittag. 2019. "Using linked survey and administrative data to better measure income: Implications for poverty, program effectiveness, and holes in the safety net." American Economic Journal: Applied Economics, 11(2): 176-204. 
Meyer, Bruce D, Wallace KC Mok, and James X Sullivan. 2015. "Household surveys in crisis." Journal of Economic Perspectives, 29(4): 199-226.

Meyer, Bruce D, and Dan T Rosenbaum. 2001. "Welfare, the Earned Income Tax Credit, and the Labor Supply of Single Mothers.” The Quarterly Journal of Economics, 116 1063-1114.

Nichols, Austin, and Jesse Rothstein. 2016. “The Earned Income Tax Credit.” In Economics of Means-Tested Transfer Programs in the United States. ed. by Robert Moffitt, Chap. 2 137-218.

Olea, José Luis Montiel, and Carolin Pflueger. 2013. "A robust test for weak instruments." Journal of Business \& Economic Statistics, 31(3): 358-369.

Pflueger, C. E. 2015. “A robust test for weak instruments in Stata.” Stata Journal, 15(1): 216-225.

Rothstein, Jesse. 2008. “The Unintended Consequences of Encouraging Work: Tax Incidence and the EITC.” Working Paper.

Rothstein, Jesse. 2010. "Is the EITC as Good as an NIT? Conditional Cash Transfers and Tax Incidence.” American Economic Journal: Economic Policy, 2 177-208.

Ruggles, Steven, Sarah Flood, Ronald Goeken, Josiah Grover, Erin Meyer, Jose Pacas, and Matthew Sobek. 2018. "Integrated Public Use Microdata Series USA: Version 9.0 [dataset].” Minneapolis, MN: IPUMS.

Saez, Emmanuel. 2002. "Optimal Income Transfer Programs: Intensive versus Extensive Labor Supply.” Quarterly Journal of Economics, 107 1039-1073.

Suárez Serrato, Juan Carlos, and Owen Zidar. 2016. "Who benefits from state corporate tax cuts? A local labor markets approach with heterogeneous firms." American Economic Review, 106(9): 2582-2624.

Sun, Liyang. 2018. "Implementing Valid Two-Step Identification-Robust Confidence Sets for Linear Instrumental-Variables Models.” The Stata Journal, 18(4): 803-825.

Tax Policy Center. 2019. “EITC Parameters.” URL: https://www.taxpolicycenter.org/ statistics/eitc-parameters.

Urban Institute. 2020. “TRIM3 project website.” URL: trim3.urban.org.

Watson, C. Luke. 2020. "Comment: Estimating both supply and demand elasticities using variation in a single tax rate.." Working Paper.

Zoutman, Floris T, Evelina Gavrilova, and Arnt $\mathrm{O}$ Hopland. 2018. "Estimating both supply and demand elasticities using variation in a single tax rate." Econometrica, 86 763-771. 


\section{A Theory Appendix}

In this appendix, I describe additional theoretical details of the model in the main text as well as consider two theoretical extensions. First, I present the parameters for the numerical comparative statics from Figure 3 and describe how welfare is calculated within the model. Second, I present the equilibrium conditions that lead to the the many type model that is used in the empirical exercises. Adding additional types of labor in this context is relatively simple due to the symmetry of the modeling assumptions. Next, I return to the two skill model but now the high skill worker is able to switch between sectors. This extension is essentially a simplified version of Saez (2002) with endogenous wages. Finally, in the two skill model, I allow for two consumption goods producing industries that employ both high and low skill workers. This extension essentially 'stacks' the equilibrium conditions used in the single industry model in the main text.

\section{A. 1 Incidence Value Comparison}

Here, I compare the gross wage incidence from a one percent tax change ${ }^{59}$ between PE and GE and across labor market elasticities. I use equation 15 for the PE incidence and I use equation 17 for the GE incidence. The main takeaway is that the incidence effect magnitude depends primarily on the labor substitution elasticity, $\rho$, and the cost share of the subsidized market, $s_{L 0}$.

In Table 14, I present incidence values for various parameter pairings. I use the following baseline parameters: $\varepsilon_{0,0}^{L}=\varepsilon_{0,1}^{L}=0.75, \varepsilon_{1,0}^{L}=\varepsilon_{1,1}^{L}=0.6$, and $\varepsilon_{K}=1$, based on Rothstein (2010), Eissa and Hoynes (2004), and Goolsbee (1998), respectively. For the elasticity of substitution I use $\rho \in\{-0.3,-1,-2\}$, based on Rothstein (2010), my empirical analysis presented later $(\rho=-2)$, and an intermediate value. I set $s_{L}=0.66$ based on the approximate 1990s labor share of input costs. I set $s_{L 0}=0.125$ and $s_{L 1}=0.66-s_{L 0}$, based on the 1992 March CPS and my own calculations. For the first two panels I assume

\footnotetext{
${ }^{59}$ That is I plot $\hat{w}_{0} /\left(\theta_{0,1} \hat{\tau}\right)$, so that these results are not affected by the share of eligible workers within a skill level.
} 
that only the low wage market is subsidized $\left(\hat{\tau}_{1,1} / \hat{\tau}_{0,1}=0\right)$, but in the third panel I allow for a smaller subsidy on the high wage workers, $\left(\hat{\tau}_{1,1} / \hat{\tau}_{0,1}\right)>0$.

Table 14 - Summary:

Percent Change in Gross Wage for Low Wage Market from $1 \%$ Subsidy Increase

\begin{tabular}{l|cc}
\hline & Partial Equilibrium & General Equilibrium \\
\hline$\rho=-0.3$ & Using Baseline Supply Elasticities \\
$\rho=-1$ & -0.714 & -0.645 \\
$\rho=-2$ & -0.429 & -0.390 \\
\hline & -0.273 & -0.252 \\
$\varepsilon_{0}^{L}=1.0$ & Other Elasticities with $\rho=-2$ \\
$\varepsilon_{1}^{L}=0.3$ & -0.333 & -0.269 \\
$\varepsilon_{1}^{L}=0.9$ & -0.273 & -0.254 \\
$\varepsilon^{K}=2$ & -0.273 & -0.251 \\
\hline & -0.273 & -0.249 \\
\hline$\hat{\tau}_{1,1}=0.1$ & Allowing $\hat{\tau}_{1,1}>0$ with $\rho=-2$ \\
$\hat{\tau}_{0,1}=0.273$ & -0.240 \\
$\frac{\hat{\tau}_{1,1}}{\hat{\tau}_{0,1}=0.2}$ & -0.273 & -0.228 \\
\hline Baseline: $\varepsilon_{0}^{L}=0.75, \varepsilon_{1}^{L}=0.6, \varepsilon_{K}=1, \hat{\tau}_{1,1}=0$ & \\
Incidence results computed at $s_{L 0}=0.125, s_{L}=0.66$ &
\end{tabular}

Table 14 shows that the general equilibrium incidence always attenuates the PE incidence, especially as market size grows. The results highlight that the labor substitution elasticity appears to dictate the magnitude of the incidence effect. Using the value $\rho=-0.3$ from Rothstein (2010) implies a PE incidence of $-0.71 \%$ while a $\rho=-2$ implies only a $-0.25 \%$ change in gross wages.

Figure 3 is a graphical representation of Table 14. I plot the partial and general equilibrium incidence of the gross wage at different labor cost shares $\left(s_{L 0} \in[0,1]\right)$ and different substitution elasticities. The flat lines are the PE incidence and the upward sloping lines are the GE incidence. The graphical representation shows that as more workers are subsidized the GE incidence effects can quickly diverge from the PE effects. 


\section{A.2 Welfare}

Here, I describe the measure of welfare in the model and changes due to tax policy.

For this section, I adjust the notation. Let $i \in \mathcal{N}$ index each specific worker: $i=$ $\left(e_{i}, c_{i}, \nu_{i}\right)$. Let each worker have some non-labor income, $m_{i}$. Let each worker own some share of the firms in the economy, $\varsigma_{i} \in[0,1]$, such that $\sum_{i \in \mathcal{N}} \varsigma_{i}=1$.

\section{A.2.1 Welfare}

Total welfare in the economy is the sum of utility given the optimal decisions by workers and firms. In terms of Chetty (2009), with an added capital revenue equation, ${ }^{60}$ the model is the following:

$$
\begin{aligned}
\text { Utility : } & U(X, L ; \nu)=X+\nu \cdot L \\
\text { Tax Function : } & T_{i}(w L, m)=\left(w+\tau_{i}\right) L-b_{i}(1-L)-n_{i} \\
\text { Capital Revenue : } & R=\int_{j}\left(\left(r-\xi_{j}\right) \cdot k_{j}\right) \mathrm{d}_{j} \\
\text { Budget Set : } & X+T_{i}(w L, m)-w L-m \leq 0
\end{aligned}
$$

Thus, aggregate welfare with a Utilitarian SWF is aggregate consumption plus the utility cost of labor for those that work:

$$
\begin{aligned}
W & =\int_{i} \nu_{i} \mathrm{~d}_{i}+\int_{i}\left(T_{i}\right) \mathrm{d}_{i} \\
& =\int_{i}\left(\left(w_{i} L_{i}-T_{i}\right)+\nu_{i}\left(L_{i}\right)+\varsigma_{i} R\right) \mathrm{d}_{i}+\int_{i}\left(T_{i}\right) \mathrm{d}_{i} \\
& =\int_{i}\left(\left(w_{i} L_{i}\right)+\left(\nu_{i} \cdot L_{i}\right)+\varsigma_{i} R\right) \mathrm{d}_{i} .
\end{aligned}
$$

\section{A.2.2 Welfare Changes}

The change in welfare for the economy is determined by totally differentiating the aggregate welfare measure. I follow the methods specified in Chetty (2009) and Kleven (2018). That is, I totally differentiate equation 40 holding unemployment benefits constant but

\footnotetext{
${ }^{60}$ Recall that each worker has some $\varsigma_{\nu} \in(0,1)$ share of capital revenue as part of unearned income that is taken as given in the labor supply choice.
} 
adjusting the lump sum tax to finance the subsidy increase (and recall that $\tau_{i}=\mathrm{d} \tau_{i}=0$ if $\left.\left(e_{i}, c_{i}\right) \neq(0,1)\right)$ :

$$
\begin{aligned}
\mathrm{d} W^{\mathrm{GE}}= & \int_{i}\left(\left(\mathrm{~d} w_{i}+\mathrm{d} \tau_{i}\right) L_{i}+\left(w_{i}+\tau_{i}-b_{i}\right) \mathrm{d} L_{i}+\frac{\partial \nu_{i}}{\partial L_{i}} \mathrm{~d} L_{i}+\varsigma_{i} \mathrm{~d} R-\mathrm{d} n_{i}\right) \mathrm{d}_{i} \\
& \quad+\int_{i}\left(-\mathrm{d} \tau_{i} L_{i}-\left(\tau_{i}-b_{i}\right) \mathrm{d} L_{i}+\mathrm{d} n_{i}\right) \mathrm{d}_{i} \\
= & \int_{i}\left(\left(\mathrm{~d} w_{i}\right) L_{i}+\varsigma_{i} \mathrm{~d} R\right) \mathrm{d}_{i}+\int_{i}\left(-\left(\tau_{i}-b_{i}\right) \mathrm{d} L_{i}\right) \mathrm{d}_{i} \\
= & \int_{i}\left(-\left(\tau_{i}-b_{i}\right) \mathrm{d} L_{i}\right) \mathrm{d}_{i}=-\int_{i}\left(\left(\tau_{i}-b_{i}\right) \varepsilon_{i}^{L}\left(\mathrm{~d} w_{i}+\mathrm{d} \tau_{i}\right)\right) \mathrm{d}_{i} \\
= & -\int_{i}\left(\left(\tau_{i}-b_{i}\right) \varepsilon_{i}^{L}\left(\left(1+\gamma_{i}\right) \mathrm{d} \tau_{i}+\Gamma_{i}\right)\right) \mathrm{d}_{i} .
\end{aligned}
$$

From equation 42 to 43 , I use the envelope condition to remove $\frac{\partial \nu_{i}}{\partial L_{i}}$; from 43 to 44 , I use the zero profit condition to show that $\mathrm{d} R=\int_{i}\left(\left(\mathrm{~d} w_{i}\right) L_{i}\right) \mathrm{d}_{i}$; and from 44 to 45 , I use the incidence result to characterize the "fiscal externality" in terms of elasticities (Hendren, 2016; Kleven, 2018). The welfare measure's negative sign because the behavioral fiscal externality implies that the government is paying more subsidies due to the extensive margin response. However, if $\mathrm{d} L_{i}>0$, then the government is also paying less in unemployment benefits, as empirically shown in Bastian and Michelmore (2018).

The above supposes that lump sum taxation is used, so the fact that wages rise for other workers is not part of the fiscal externality; i.e., the fact that greater earnings lessen the need to change the lump sum tax. If instead an income tax was used (with individual rate $t_{i}$ ), then the change in welfare is the following:

$$
\mathrm{d} W^{\mathrm{GE}}=\int_{i}\left(t_{i} w_{i} \mathrm{~d} L_{i}\right) \mathrm{d}_{i}=\int_{i}\left(t_{i} w_{i} \varepsilon_{i}^{L}\left(\left(1+\gamma_{i}\right) \mathrm{d} \tau_{i}+\Gamma_{i}\right)\right) \mathrm{d}_{i} .
$$

See that high wage workers now contribute the following term to the welfare change: $t^{H} w^{H} \Gamma^{H}>0$. Because tax revenues increase for the high wage group, the government's budget constraint is further loosened which lessens the negative fiscal externality. The welfare change in this case cannot be theoretically signed, so the welfare impact becomes an empirical to question. 


\section{A.3 Model with Many Worker Types}

Here, I allow for each labor type to have a heterogeneous tax change, and then I solve the equations in the same manner as before using substitution after totally differentiating. Let worker types be indexed by $e \in\{0,1,2, \ldots, E\}=\mathcal{E} .^{61}$

I use the following equilibrium system (suppressing labor supply arguments):

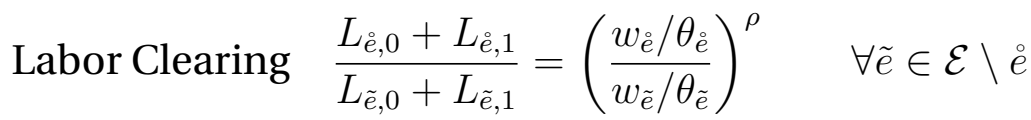

$$
\begin{aligned}
& \text { Factor Clearing } \frac{\sum_{e} L_{e}}{K^{S}(r)}=\left(\frac{\bar{w} / \alpha}{r / 1-\alpha}\right)^{-1} \\
& \text { Zero Profits } P=c\left(\left\{w_{e}\right\}_{e \in \mathcal{E}}, r\right):=1
\end{aligned}
$$

The incidence is solved using by taking the total derivative to linearize the system and then either iterative substitution or Cramer's rule to solve for the factor price changes as a function of the tax change. By adjusting the labor clearing condition (equation 47), I can solve for any specific market's incidence.

The general equilibrium incidence for type 0 labor is:

$$
\begin{aligned}
& \hat{w}_{0}^{\mathrm{GE}}=\frac{-\varepsilon_{(0,1)}^{L} \theta_{0,1} \hat{\tau}_{0}}{\varepsilon_{0}^{L}-\rho}+\frac{\Lambda\left(\sum_{e} \frac{s_{e} \varepsilon_{(e, 1,1}^{L} \theta_{e, 1} \hat{\tau}_{e}}{\varepsilon_{e}^{L}-\rho}\right)}{\left(\varepsilon_{0}^{L}-\rho\right)\left(1+\Lambda\left(\sum_{e} \frac{s_{e}}{\varepsilon_{e}^{L}-\rho}\right)\right)} \\
& =\left(\gamma_{0}+\Gamma_{0}\right) \hat{\tau}_{0}+\Psi_{0}\left(\left\{\tau_{e}\right\}_{e \in \mathcal{E} \backslash e=0}\right) \\
& \text { where } \Lambda=\left(\frac{\varepsilon_{K}+1}{s_{K}}+\frac{1+\rho}{s_{L}}\right) \text {. }
\end{aligned}
$$

Generally, one cannot sign the expression without knowing the direction of each $\left\{\tau_{d}\right\}_{d}$. This is similar to Agrawal and Hoyt (2018) in the context of taxing multiple consumer goods. For example, if the own tax change is large but all other tax changes are small, then very likely the partial equilibrium term will dominate, so the expression is negative. However, if the own tax change is small but all other are large and positive, then the general equilibrium spillovers will dominate, so the expression is positive.

Again, this shows that generally there will be two first order terms with respect to the tax change. Only if the general equilibrium spillover term is small will $w^{\mathrm{GE}} \approx w^{\mathrm{PE}}$. Note,

\footnotetext{
${ }^{61}$ In the calibrated model, $|\mathcal{E}|=72$ based on age, education, and marital status of women.
} 
with multiple tax changes, it is no longer sufficient to suppose that $s_{0} \approx 0$ for the GE terms to disappear. Rather, one needs to assume that the average cost share weighted tax change is equal to zero: $\mathrm{E}\left[s_{e} \theta_{e, 1} \hat{\tau}_{e}\right] \approx 0$.

\section{A.4 Model with Market Switching}

Here, I return three factor model but I allow the high wage workers, $e=1$, to switch between markets. Additionally, I allow for a differential tax change in both labor markets.

This set up is similar to the model used in Saez (2002), only simplified to fewer employment groups. This allows $e=1$ workers to substitute between unemployment, low wage work, and high wage work. Workers with $e=0$ are only able to adjust between unemployment and low wage work.

For example, in the EITC context, suppose that high wage mothers see the net lowwage sector wage increase relative to high-wage work, and if this worker is marginally attached to high wage work, then there she will switch to low wage work. Alternatively, if a $e=1$ worker without children originally chose low-wage work, then the potential real wage decrease relative to the high-wage sector will cause this worker to choose high wage work.

In this framework notation can get messy because workers of the same $(e, c)$ can earn different wages, so I need to track both worker type and worker labor choice for four different types of workers and three sectors. This is not conceptually difficult, but messy. I assume that $e=1$ workers are paid equal to $e=0$ if they participate in the low-wage sector. One foundation for this is that low-wage work involves some set tasks that cannot benefit from high-wage worker's skills, so workers of both $e$ types will have the same marginal product. ${ }^{62}$

Let the labor supply of a type $(e, c)$ worker be denoted as $L_{g, c}^{e}$, where $g \in\{0,1\}$ designates low or high wage labor group. Let $\varepsilon_{e, g, c}^{L}$ be the extensive labor supply elasticity, and for type $e=1$ workers let $\chi_{c}^{g \rightarrow g^{\prime}}$ be the cross wage elasticity with respect to sector

\footnotetext{
${ }^{62}$ Note, this rules out pricing power by firms to create a separating equilibrium among worker types.
} 
choice for workers. The latter elasticity is only concerned with incumbent workers who potentially switch sectors. I suppress the group conditional demographic shares, $\theta_{g, c}^{e}$, to ease notation.

This implies the following equilibrium system (suppressing labor supply arguments):

$$
\begin{array}{cl}
\text { Labor Clearing } & \frac{L_{0,0}^{0}+L_{0,0}^{1}+L_{0,1}^{0}+L_{0,1}^{1}}{L_{1,0}^{1}+L_{1,1}^{1}}=\left(\frac{w_{0} / \theta_{0,1}}{w_{1} / \theta_{1,1}}\right)^{\rho} \\
\text { Factor Clearing } & \frac{L_{0,0}^{0}+L_{0,0}^{1}+L_{0,1}^{0}+L_{0,1}^{1}}{K^{S}(r)}=\left(\frac{\bar{w} / \alpha}{r / 1-\alpha}\right)^{-1} \\
\text { Zero Profits } & P=c\left(w_{0}, w_{1}, r\right):=1
\end{array}
$$

The general equilibrium incidence for this model is:

$$
\begin{aligned}
\hat{w}_{0}^{\mathrm{GE}} & =\frac{-\left(\varepsilon_{0,1}^{L}-\tilde{\chi}_{1}^{1,0}\right) \hat{\tau}_{0}}{\left(\varepsilon_{0}^{L}-\tilde{\chi}^{1,0}-\rho\right)}+\frac{\Lambda\left(\sum_{d}\left(\frac{s_{d} \hat{\tau}_{d}\left(\varepsilon_{d, 1}^{L}-\tilde{\chi}_{1}^{d, d}\right)}{\left(\varepsilon_{d}^{L}-\tilde{\chi}^{-d, d}-\rho\right)}\right)\right)}{1+\sum_{d}\left(\frac{s_{d} \Lambda+\tilde{\chi}_{1}^{d, d}}{\left(\varepsilon_{d}^{L}-\tilde{\chi}^{d, d}-\rho\right)}\right)} \\
& =\left(\mathrm{p}_{0}+\Gamma_{0}+\mathcal{X}_{0}\right) \hat{\tau}_{0}+\Psi_{0}\left(\hat{\tau}_{2}\right)+\mathfrak{X}_{0}\left(\hat{\tau}_{2}\right)
\end{aligned}
$$

where $\varepsilon_{d, 1}^{L}$ and $\tilde{\chi}_{c}^{g, g^{\prime}}$ incorporate the relevant share of workers based on $\theta_{g, c}^{e}$. As before, $\Lambda=\left(\frac{\varepsilon_{K}+1}{s_{K}}+\frac{1+\rho}{s_{L}}\right)$.

The main difference is that the supply elasticities are more complicated, intuitively, because workers can make more choices and supply is not inelastic between markets. There are now five first order terms in the incidence analysis, each capturing a different supply responses to wages.

This shows an additional consequence of partial equilibrium analysis. If worker have the ability to switch between sectors, then a partial equilibrium analysis will hold the supply of the other markets fixed. This omits important equilibrium responses to subsidies even for the market being studied.

\section{A.5 Two Sector Model}




\section{A.5.1 Model}

Let there be two final goods, $\{X, Y\}$, for sale at market prices, $\left\{p_{x}, p_{y}\right\}$, produced using three factors, $\{L, H, K\}$, that are each elastically supplied given factor prices, $\left\{w_{x}, w_{y}, v_{x}, v_{y}, r_{x}, r_{y}\right\}$.

I refer to $L$ as low-skill labor, $H$ as high-skill labor, and $K$ as capital (or any other factor which is elastically supplied), $w$ as low-skill wages, $v$ as high-skill wages, and $r$ as capital rents. Let all agents that can supply $L$ or $H$ service (labor) be called 'workers' regardless of their labor force participation; e.g., a low-skill worker either participates in the labor force or does not participate.

\section{Production + Capital}

Let $X=F^{(X)}\left(g_{x}\left(L_{x}, H_{x}\right), K_{x}\right)$ and $Y=F^{(Y)}\left(g_{y}\left(L_{y}, H_{y}\right), K_{y}\right)$, where $F^{\cdot}(\cdot)$ are both CRS production functions with a CES subfunction that aggregates the two labor types. For production I use

$$
F=\left(\left(L^{\frac{1+\rho}{\rho}}+H^{\frac{1+\rho}{\rho}}\right)^{\alpha \frac{\rho}{1+\rho}} \cdot K^{(1-\alpha)}\right)
$$

which is a nested CES production function that satisfies the assumption. Profit for an industry $j$ is defined as $\pi_{j}=p_{j} X_{j}-w_{j} L_{j}-v_{j} H_{j}-r_{j} K_{j}$, and in equilibrium $\pi_{j}=0$.

Let $K$ be supplied according to the function $K^{S}\left(r_{x}, r_{y}\right)$, where the suppliers of capital consider the two sectors perfect substitutes. For example, if $r_{x}>r_{y}$, then $K_{x}=K^{S}(r)$ and $K_{y}=0$. Thus, in any equilibrium where both goods are produced, $r_{x}=r_{y}$, and we may only refer to $r$.

\section{Utility}

Let type $s$ worker utility be $u^{s}=U^{s}\left(X, Y, L_{x}, L_{y}, L_{o}\right)$, where $L_{o}=\mathcal{L}-L_{x}-L_{y}$ is leisure time. Let utility be separable so that $u^{s}=C^{s}(X, Y)+n\left(L_{x}, L_{y}, L_{o}\right)$. Further, let $C^{s}(X, Y)=$ $c(X / Y) \cdot Y$, so that utility is homothetic for goods. Since utility is quasi-linear with respect to aggregate consumption, the labor supply will not depend on relative output prices this can be relaxed. 
Importantly, the disutility of labor depends on the type of labor. Depending on the function form (and stochastic assumptions), this implies that two types of workers may make heterogeneous labor supply decisions given the same market prices. This can be micro-founded by assuming that workers draw a triple $\left(\left\{\epsilon_{x}, \epsilon_{y}, \epsilon_{o}\right\}\right)$ from some distribution, then solve the following problem:

$$
\max _{x, y, o}\left\{V^{\star}(x)+\epsilon_{x}, V^{\star}(y)+\epsilon_{y}, V^{\star}(o)+\epsilon_{o}\right\},
$$

where $V^{\star}(\cdot)$ is the optimal consumption choice given a labor supply decision and prices. This yields the probability that a worker will work in the respective sectors: $\mathrm{p}_{j}^{s}$. This approach is very common in the labor supply literature as well as in Saez (2002).

For an individual, this can be interpreted as the amount of labor supply devoted to each sector, where $\sum_{j} \mathbf{p}_{j}^{s}=1$. Or, one can assume that each worker truly chooses only one sector but that the aggregate employment is matched exactly: $L=N \cdot \mathrm{p}$.

\section{Budget Constraint + Subsidy}

The worker budget constraint is $p_{x} X+p_{y} Y \leq \mathcal{T}^{s}\left(w_{x} L_{x}, w_{y} L_{y}, L_{o}\right)$. Let $\mathcal{T}^{s}(\cdot)=\left(w_{x}+\tau_{s}\right) L_{x}^{s}+$ $w_{y}^{s} L_{y}^{s}+b_{s} L_{o}^{s}-T^{s}$, where $\tau_{s}$ is a labor subsidy for sector $X, b_{s}$ in an unemployment benefit, and $T^{s}$ is a lump sum tax on all workers regardless of labor supply. Given that utility only depends on leisure, the net return to supplying labor in the two sectors implies that in any equilibrium with both goods being produced, $\left(w_{x}^{s}+\tau_{s}\right)=w_{y}^{s}$.

To pay for the subsidy to sector $X$ and unemployment, the government must set the lump-sum taxes to cover this cost in equilibrium. Let the government budget constraint be $T^{L}+T^{H}=\tau_{L} L_{x}+b_{L} L_{o}+\tau_{H} H_{x} b_{H} H_{o}$. 


\section{A.5.2 Equilibrium}

The following are the equilibrium conditions:

$$
\begin{aligned}
\text { X Labor Market Clearing: } & \frac{L_{x}^{S}\left(w_{x}+\tau_{L}, w_{y}, b_{L}\right)}{H_{x}^{S}\left(v_{x}+\tau_{H}, v_{y}, b_{H}\right)}-\psi_{x}\left(w_{x} / v_{x}\right)=0 \\
\text { X Factor Market Clearing: } & \frac{L_{x}^{S}\left(w_{x}+\tau_{L}, w_{y}, b_{L}\right)}{K_{x}^{S}(r)}-\psi_{x}\left(w_{x} / v_{x}\right) \Psi_{x}\left(w_{x} / r\right)=0 \\
\text { X Zero Profits: } & p_{x}-c_{x}\left(w_{x}, v_{x}, r\right)=0 \\
\text { Y Labor Market Clearing: } & \frac{L_{y}^{S}\left(w_{y}, w_{x}+\tau_{L}, b_{L}\right)}{H_{y}^{S}\left(v_{y}, v_{x}+\tau_{H}, b_{H}\right)}-\psi_{y}\left(w_{y} / v_{y}\right)=0 \\
\text { Y Factor Market Clearing: } & \frac{L_{y}^{S}\left(w_{y}, w_{x}+\tau_{L}, b_{L}\right)}{K_{y}^{S}(r)}-\psi_{y}\left(w_{y} / v_{y}\right) \Psi_{y}\left(w_{y} / r\right)=0 \\
\text { Y Zero Profits: } & p_{y}-c_{y}\left(w_{x}, v_{x}, r\right)=0
\end{aligned}
$$

The model has seven endogenous prices $\left\{w_{x}, w_{y}, v_{x}, v_{y}, p_{x}, p_{y}, r\right\}$ and there are six equations, so I normalize $p_{y}=1 .^{63}$ This system is essentially the same as in the main text, but with an extra output sector and additional prices.

\section{A.5.3 Solving for Wage Incidence}

In this section, I will solve the model for incidence terms by linearizing the system in terms of differential changes in the subsidy.

Let $\tau_{H}=0$ and $\mathrm{d} b_{s}=0$.

In matrix form, the equilibrium system is:

$$
A \hat{z}=\nu \cdot \hat{\tau}
$$

\footnotetext{
${ }^{63}$ The endogenous quantities, $\left\{L_{j}, H_{j}, K_{j}, X, Y\right\}$, all depend on the endogenous prices.
} 


$$
\left[\begin{array}{cccccc}
\varepsilon_{x}^{L}-\rho_{x} & -\left(\varepsilon_{x}^{H}-\rho_{x}\right) & \chi_{x}^{L} & -\chi_{x}^{H} & 0 & 0 \\
\varepsilon_{x}^{L}+1-\left(1+\rho_{x}\right) \frac{s_{x}^{H}}{1-s_{x}^{K}} & -\left(1+\rho_{x}\right) \frac{s_{x}^{H}}{1-s_{x}^{K}} & \chi_{x}^{L} & 0 & 0 & -\left(\varepsilon_{x}^{K}+1\right) \\
\chi_{y}^{L} & -\chi_{y}^{H} & \varepsilon_{y}^{L}-\rho_{y} & -\left(\varepsilon_{y}^{H}-\rho_{y}\right) & 0 & 0 \\
\chi_{y}^{L} & \varepsilon_{y}^{L}+1-\left(1+\rho_{y}\right) \frac{s_{y}^{H}}{1-s_{y}^{K}} & -\left(1+\rho_{y}\right) \frac{s_{y}^{H}}{1-s_{y}^{K}} & & 0 & -\left(\varepsilon_{y}^{K}+1\right) \\
s_{x}^{L} & s_{x}^{H} & 0 & 0 & 1 & s_{x}^{K} \\
0 & 0 & s_{y}^{L} & s_{y}^{H} & 0 & s_{y}^{K}
\end{array}\right]\left[\begin{array}{c}
\hat{w}_{x} \\
\hat{v}_{x} \\
\hat{w}_{y} \\
\hat{v}_{y} \\
\hat{p} \\
\hat{r}
\end{array}\right]=\left[\begin{array}{c}
-\varepsilon_{x}^{L} \hat{\tau} \\
-\varepsilon_{x}^{L} \hat{\tau} \\
-\chi_{x}^{L} \hat{\tau} \\
-\chi_{x}^{L} \hat{\tau} \\
0 \\
0
\end{array}\right]
$$

\section{A.5.4 Two 'Tricks' for Solving}

If $A z=b$, then by Cramer's Rule:

$$
\begin{aligned}
\text { Cramer's Rule: } \quad z_{i} & =\frac{\operatorname{det}(A \mid b)}{\operatorname{det}(A)} \\
\text { Laplace Expansion: } & =\frac{\sum_{j} b_{i, j} \operatorname{det}\left(A^{(j)}\right)}{\operatorname{det}(A)} \\
& =\frac{\sum_{j} \frac{b_{i, j}}{a_{i, j}} a_{i, j} \operatorname{det}\left(A^{(j)}\right)}{\operatorname{det}(A)} \\
\text { Matrix Derivative: } & =\frac{\sum_{j} \frac{b_{i, j}}{a_{i, j}} a_{i, j}\left(\frac{\partial \operatorname{det}(A)}{\partial a_{i, j}}\right)}{\operatorname{det}(A)} \\
& :=\sum_{j}\left(\left(\frac{b_{i, j}}{a_{i, j}}\right)\left(\gamma_{a_{i, j}}\right)\right),
\end{aligned}
$$

where $\gamma_{a_{i, j}}=\left(\frac{\partial \operatorname{det}(A)}{\partial a_{i, j}} \frac{a_{i, j}}{\operatorname{det}(A)}\right)$ is the elasticity of the determinant with respect to the matrix element.

This parameter is geometrically interpretable as the percent change in the area of the $\mathrm{n}$-dimensional parallelogram formed by the system of equations from a $1 \%$ elemental change. Economically, the closest interpretation is that $\gamma$ summarizes the effect of the exogenous variation $(b)$ through the system of equations $(A)$ from each equilibrium channel (the other elements of $z$ ). 
Additionally, using some algebra:

$$
\begin{aligned}
z_{i} & =\frac{\sum_{j} \frac{b_{i, j}}{a_{i, j}} a_{i, j} \operatorname{det}\left(A^{(j)}\right)}{\operatorname{det}(A)} \\
& =\frac{\sum_{j} \frac{b_{i, j}}{a_{i, j}} a_{i, j} \operatorname{det}\left(A^{(j)}\right)}{\sum_{j} a_{i, j} \operatorname{det}\left(A^{(j)}\right)} \\
& =\sum_{j} \frac{b_{i, j}}{a_{i, j}} \frac{a_{i, j} \operatorname{det}\left(A^{(j)}\right)}{\sum_{j} a_{i, j} \operatorname{det}\left(A^{(j)}\right)} \\
& =\frac{b_{i, i}}{a_{i, i}}+\left[\sum_{j \backslash i}\left(\frac{b_{i, j}}{a_{i, j}}-\frac{b_{i, i}}{a_{i, i}}\right) \frac{a_{i, j} \operatorname{det}\left(A^{(j)}\right)}{\sum_{j} a_{i, j} \operatorname{det}\left(A^{(j)}\right)}\right] \\
& =\frac{b_{i, i}}{a_{i, i}}+\left[\sum_{j \backslash i}\left(\frac{b_{i, j}}{a_{i, j}}-\frac{b_{i, i}}{a_{i, i}}\right) \gamma_{a_{i, j}}\right]
\end{aligned}
$$

\section{A.5.5 Low Wage X Sector Incidence}

It can be show using Cramer's Rule, Laplace Cofactor Expansion, and some algebra that

$$
\frac{\hat{w}_{x}^{L}}{\hat{\tau}}=\underbrace{\frac{-\varepsilon_{x}^{L}}{\varepsilon_{x}^{L}-\rho_{x}}}_{\text {Partial Equilibrium }}+\underbrace{\gamma_{a_{2,1}}\left(\frac{\left(1+\rho_{x}\right)\left(1-\frac{s_{x}^{H}}{1-s_{x}^{K}}\right)}{\varepsilon_{x}^{L}+1-\left(1+\rho_{x}\right) \frac{s_{x}^{H}}{1-s_{x}^{K}}}\right)+\left(\gamma_{a_{3,1}}+\gamma_{a_{4,1}}\right)\left(\frac{\rho_{x}}{\varepsilon_{x}^{L}-\rho_{x}}\right)}_{\text {Spillover Terms }}
$$




\section{B Data Description and Summary Statistics}

In this appendix, I provide additional descriptions and summary statistic information for the data used in the empirical sections. Broadly, I use the Current Population Survey from 1986 to 2010 (Flood et al., 2018) and the 1990 US Census 5\% sample, (Ruggles et al., 2018). I additionally use the Urban Institute's Transfer and Income Model, which requires the following disclosure:

Information presented here is derived in part from the Transfer Income Model, Version 3 (TRIM3) and associated databases. TRIM3 requires users to input assumptions and/or interpretations about economic behavior and the rules governing federal programs. Therefore, the conclusions presented here are attributable only to the authors of this report.

\section{B.1 Outgoing Rotation Group Samples}

The ORG samples come from the Current Population Survey. A CPS respondent household is surveyed in two waves for four months each with an eight month break. On months four and eight, the surveyors ask the respondent additional labor market questions, such as usual hours and weekly earnings. The month-in-sample is staggered across respondents, so about one-fourth of any monthly sample is in an ORG.

I use the ORG samples for labor market quantities: wages and labor supply. ${ }^{64}$ In table 15, I provide the underlying sample of women in the CPS ORG that are aggregated for the main analysis. As described in the main text, I calculate hourly wages by dividing usual weekly earnings by usual hours worked at main job. I discard calculated wages from workers with imputed earnings and/or hours. I discard observations where the respondent says their usual hours vary, workers reporting less than one hour per week, workers workers with implied real $\$ 1990$ wages less than $\$ 0.50$ or greater than $\$ 150.00$, and finally

\footnotetext{
${ }^{64}$ The major issue in using the ORG sample is that cannot it does not have enough information to predict EITC usage, which is based on previous year income and living arrangements.
} 
if the worker is out of the labor force and reports being in school full time over two-thirds of their CPS observations. ${ }^{65}$

Table 15 - Market State Year Observations for Estimation Sample

\begin{tabular}{ccccccc}
\hline & \multicolumn{2}{c}{$1989-1994$} & \multicolumn{2}{c}{$1995-2000$} & \multicolumn{2}{c}{ Difference } \\
& Mean & SD & Mean & SD & Dif & $t$ \\
\hline Age & 38.98 & 12.24 & 39.91 & 11.99 & $0.93^{* * *}$ & $(39.21)$ \\
Married & 0.63 & 0.48 & 0.62 & 0.49 & $-0.01^{* * *}$ & $(-14.19)$ \\
White & 0.83 & 0.37 & 0.82 & 0.38 & $-0.01^{* * *}$ & $(-19.13)$ \\
Black & 0.12 & 0.32 & 0.13 & 0.34 & $0.01^{* * *}$ & $(9.69)$ \\
Less HS & 0.15 & 0.36 & 0.13 & 0.33 & $-0.02^{* * *}$ & $(-35.49)$ \\
High School & 0.39 & 0.49 & 0.34 & 0.47 & $-0.06^{* * *}$ & $(-59.15)$ \\
Some College & 0.32 & 0.47 & 0.30 & 0.46 & $-0.02^{* * *}$ & $(-22.04)$ \\
BA+ & 0.14 & 0.35 & 0.24 & 0.43 & $0.10^{* * *}$ & $(130.04)$ \\
Qualifying Child & 0.48 & 0.50 & 0.47 & 0.50 & $-0.01^{* * *}$ & $(-14.21)$ \\
Age of Youngest & 7.74 & 6.07 & 7.93 & 5.95 & $0.19^{* * *}$ & $(11.18)$ \\
\hline LFP & 0.68 & 0.46 & 0.71 & 0.46 & $0.02^{* * *}$ & $(23.43)$ \\
EPOP & 0.64 & 0.48 & 0.68 & 7.00 & $0.03^{* * *}$ & $(32.98)$ \\
\hline $\begin{array}{c}\text { Real Weekly Earnings } \\
\text { All data from 1989-2000 CPS MORG samples, only women ages }\end{array}$ & 431.63 & 276.65, accessed from IPUMS. All demo- \\
graphic, employment variables weighted by CPS Basic Weight, real wage and earnings by Earnings Weight \\
× Hours. Real wages and earings inflated to 2018 dollars by BLS CPS Research Series. Real wage based on \\
weekly earnings divided by usual hours for main job. Qualifying child based on child age, school status, and \\
family structure.
\end{tabular}

In table 16, I display the number of demographic cells by marriage and education group that are used in the incidence calculations. I only include market-state-year cells that have a minimum of five workers with children and five workers without children. This causes me to have an unbalanced panel of cells, but ensures that the market averages

\footnotetext{
${ }^{65}$ Additionally, I drop workers who are in group housing, who have no identified head of house, who are in households with greater than ten members (as it is too hard to form tax units), who are in the armed forces, and who are married with absent or separated spouses.
} 
are calculated using a reasonable number of workers. The table itself also highlights demographic changes overtime. As can be seen, with population growth, the total number of cells goes from 14.2 thousand to 20.3 thousand. We can also see education attainment increasing, as there is a decrease in workers without a high school degree to those with a college degree. Interestingly, there is an increase in unmarried women with some college but a decrease for married women, as this latter group shifts towards attaining their college degree.

Table 16 - Market State Year Observations for Estimation Sample

\begin{tabular}{lcccccccc|cc}
\hline & \multicolumn{2}{c}{ Less HS } & \multicolumn{2}{c}{ HS } & \multicolumn{2}{c}{ Some College } & \multicolumn{2}{c}{ BA Plus } & \multicolumn{2}{c}{ Total } \\
\hline Year & Unmarried & Married & Unmarried & Married & Unmarried & Married & Unmarried & Married & Unmarried & Married \\
\hline 1990 & 246 & 282 & 572 & 714 & 386 & 660 & 46 & 172 & 1,250 & 1,828 \\
1991 & 258 & 252 & 536 & 738 & 428 & 658 & 46 & 176 & 1,268 & 1,824 \\
1992 & 268 & 240 & 496 & 680 & 378 & 572 & 166 & 500 & 1,308 & 1,992 \\
1993 & 210 & 216 & 512 & 684 & 418 & 584 & 158 & 510 & 1,298 & 1,994 \\
1994 & 186 & 182 & 506 & 634 & 430 & 572 & 142 & 494 & 1,264 & 1,882 \\
1995 & 182 & 180 & 494 & 602 & 444 & 590 & 176 & 522 & 1,296 & 1,894 \\
1996 & 158 & 162 & 496 & 580 & 454 & 542 & 152 & 514 & 1,260 & 1,798 \\
1997 & 156 & 140 & 494 & 550 & 454 & 536 & 160 & 532 & 1,264 & 1,758 \\
1998 & 144 & 138 & 490 & 544 & 458 & 556 & 190 & 530 & 1,282 & 1,768 \\
1999 & 154 & 116 & 506 & 546 & 484 & 562 & 218 & 556 & 1,362 & 1,780 \\
2000 & 156 & 126 & 520 & 532 & 470 & 566 & 204 & 550 & 1,350 & 1,774 \\
\hline Total & 2,118 & 2,034 & 5,622 & 6,804 & 4,804 & 6,398 & 1,658 & 5,056 & 14,202 & 20,292 \\
\hline All data from 1993 March CPS, Women from Tax Units, Wage in $\$ 1993$ & & & & & &
\end{tabular}

All variam 1993 March CPS, Women from Tax Units, Wage in $\$ 1993$

All variables weighted by CPS March Supplement Wt $\times$ Hours

\section{B.1.1 Assignment of Children in ORG}

We do not observe who claims EITC qualifying children is the CPS, so children must be assigned by the researcher according to some (ad hoc) rules. I assign children based on who seems the most likely primary care-giver in the social role of a parent. While not perfect, I heavily use the fact that children typically follow their primary care-giver in the record layout, in addition to family unit and relationship pointer variables. For most cases, this is simple and there is no ambiguity; however, household living arrangements 
can be complex. The main consequence of my allocation rules can be stated in two examples.

First, consider a household with a 40 year old head of house $(\mathrm{HoH})$, a 16 year old child of $\mathrm{HoH}$, and a 1 year old grandchild of $\mathrm{HoH}$ who is directly related to the child. I assign the grandchild to the child rather than to the $\mathrm{HoH}$. Another researcher may assign both to the HoH. Second, consider a household with a 40 year old $\mathrm{HoH}$ and a 20 year old non-relative "roommate" (so not a foster or adoptive child) who is unmarried and in school. I do not assign the non-relative to the $\mathrm{HoH}$; although, another researcher may.

IPUMS constructs family relationship information, such as number of own children (nchild), based on an their definition of a family. Their goal is a combination of accuracy and scalability for many millions of observations. However, I find that this definition is does not suit my purpose of matching children to their most likely care-giver. When Census family identifying variables are available (primarily in the ASEC samples, discussed below), I am able to find many examples of child assignment that are not intuitive. Nevertheless, using the IPUMS family definitions result is the same qualitative results with minimal quantitative differences.

\section{B.2 Annual Social and Economic Samples}

I use the ASEC samples from the Current Population Survey to perform the simulation exercises: 1993-1995 for the OBRA expansion, 2008-2010 for the ARRA expansion. The ASEC samples is based on the March CPS and an oversampling from other months to increase data quality. March is chosen to coincide with tax-filing season, the surveyors ask additional questions about income, insurance, and other issues from the previous year. To reduce sampling errors, the surveyors include additional households for the ASEC from February and April (starting in 2002) and oversample Hispanic households (starting in 1976) (Flood et al., 2018).

I use the ASEC samples for incidence calculations because the possibility of calculating EITC usage given the income and family variables. However, the wage information is not 
as good as the ORG sample, since wages must be imputed using previous year annual earnings and work information rather than weekly earnings.

I present summary statistics on the incidence samples of women for tax year 1992 in Table 19 and for 2008 in Table $18 .{ }^{66}$ As described in the main text, I calculate hourly wages by dividing annual earnings last year (all types) by the product usual hours worked at main job last year times weeks worked last year. The incidence sample is restricted to women ages 16 to 65. I drop women who are full or part time students and have not participated in the labor force for over one year and women who have negative tax unit self-employment earnings. ${ }^{67}$

Because the labor market variables are based on annual information, I classify an individual as a 'worker' if she satisfies the following: at least 40hrs of work last year, an average of at least 8hrs per week, must earn at least \$100 per year (in \$1990 dollars), and must have an implied wage of at least \$0.50 (in \$1990 dollars). This essentially relabels extreme part-time workers as 'non-workers.'

The most notable feature of the data is that the EITC is heavily concentrated in the unmarried women with children segment, but this segment is also the smallest in labor cost terms and labor supply term. This implies that since their market share is reasonably small, that the GE effects are likely to be closer to the PE incidence, all else equal.

\section{B.2.1 Assignment of Children in ASEC}

As discussed above, the assignment of EITC qualifying children is up to the researcher. I use Census coded family unit ID, household record numbers, and relationship pointers to link EITC eligible children to (most likely) parents. Again, for creating tax units, the Census definition is closer in spirit to what researchers are aiming to capture rather than IPUMS definitions.

\footnotetext{
${ }^{66}$ Note, for the empirical exercise in Section 8, I also use the 1993 ASEC, but the sample is marginally different due to simulating the Welfare program measures. There is effectively no impact on the summary statistics in Table 19.

${ }^{67}$ Additionally, I drop workers who are in group housing, who have no identified head of house, who are in households with greater than ten members (as it is too hard to form tax units), who are in the armed forces, and who are married with absent but non-separated spouses.
} 
Table 17 - Summary Statistics for Simulation Incidence Sample Tax Year 1992

\begin{tabular}{lcccc}
\hline & Age & Anykids & Married & Get Eic \\
\hline Unmarried Women & 33.00 & 0.00 & 0.00 & 0.00 \\
Married Women & 47.62 & 0.00 & 1.00 & 0.00 \\
Unmarried Mothers & 34.29 & 1.00 & 0.00 & 0.50 \\
Married Mothers & 36.90 & 1.00 & 1.00 & 0.18 \\
\hline & Less HS & HS Only & Less BA & BA+ \\
Unmarried Women & 0.26 & 0.26 & 0.30 & 0.18 \\
Married Women & 0.15 & 0.41 & 0.23 & 0.21 \\
Unmarried Mothers & 0.23 & 0.39 & 0.27 & 0.10 \\
Married Mothers & 0.12 & 0.38 & 0.28 & 0.22 \\
\hline & Worker & Wage & Share of Workers & Cost Share \\
Unmarried Women & 0.72 & 10.14 & 0.32 & 0.20 \\
Married Women & 0.67 & 11.18 & 0.24 & 0.18 \\
Unmarried Mothers & 0.68 & 9.79 & 0.10 & 0.07 \\
Married Mothers & 0.70 & 10.86 & 0.35 & 0.23 \\
\hline All data from 1993 March CPS, Women from Tax Units, Wage in \$1992. Demographic variables \\
weighted by CPS March Supplement Wt, Wage by Supplement Wt $\times$ Usual Hours Last Year.
\end{tabular}

\section{B.2.2 Sample Differences between Rothstein (2010)}

There is primary difference between my ASEC sample and that of Rothstein (2010), who uses nearly the same criteria labor market criteria. Rothstein drops from the initial sample any person who is not labeled as the head of a family unit. This is roughly $36 \%$ of the initial sample, $13 \%$ of the initial 18 or older sample, and $6 \%$ of the initial 25 or older sample, who would not be dependents (sample proportions are unweighted). These individuals have roughly $\$ 4000$ less in wage and salary income (conditional on age, education, race, marital status, and gender) meaning they are more likely to qualify for the EITC based on income. ${ }^{68}$

\footnotetext{
${ }^{68}$ They are also younger, more likely to have a high school degree or less, less likely to be white, more likely to be men, and much less likely to be or have been married.
} 
Table 18 - Summary Statistics for Simulation Incidence Sample Tax Year 2009

\begin{tabular}{lcccc}
\hline & Age & Anykids & Married & Get Eic \\
\hline Unmarried Women & 34.16 & 0.00 & 0.00 & 0.05 \\
Married Women & 50.20 & 0.00 & 1.00 & 0.04 \\
Unmarried Mothers & 35.98 & 1.00 & 0.00 & 0.55 \\
Married Mothers & 39.54 & 1.00 & 1.00 & 0.20 \\
\hline & Less HS & HS Only & Less BA & BA+ \\
Unmarried Women & 0.23 & 0.23 & 0.31 & 0.23 \\
Married Women & 0.08 & 0.33 & 0.28 & 0.31 \\
Unmarried Mothers & 0.17 & 0.32 & 0.35 & 0.16 \\
Married Mothers & 0.10 & 0.25 & 0.28 & 0.37 \\
\hline & Worker & Wage & Share of Workers & Cost Share \\
Unmarried Women & 0.65 & 18.13 & 0.33 & 0.19 \\
Married Women & 0.69 & 20.19 & 0.25 & 0.17 \\
Unmarried Mothers & 0.76 & 16.75 & 0.12 & 0.07 \\
Married Mothers & 0.71 & 21.49 & 0.31 & 0.21 \\
\hline All data from 2009 March CPS, Women from Tax Units, Wage in \$2008. Demographic variables \\
weighted by CPS March Supplement Wt, Wage by Supplement Wt $\times$ Usual Hours Last Year.
\end{tabular}

The effect of this is that in Rothstein's analysis there are only three women under the age of 24 without children. Such a sample makes sense in the empirical literature in order to perform difference-in-difference estimation (this is because the need for parallel trends pushes one to remove these young workers). However, it is not obvious that it should be done in the incidence calculation, which is mostly theoretical simulation exercise. Because I believe many of these workers are within-market rivals of unmarried women with children, I include them in my simulations. This increases the women in the sample by roughly six thousand individuals and changes the average age of unmarried women without children from 41 to 33 .

Additionally,Rothstein essentially assigns all individuals who potentially qualify as EITC dependents (based on age and education enrollment) to the head of household. In the end, Rothstein assigns about two thousand more workers at least one EITC de- 
pendents than my procedure (that is his procedure yields more workers with a qualifying dependent than my sample procedure).

The two changes I make - more workers in the sample and fewer EITC claimants should mitigate the incidence effects.

\section{B.3 1990 US Census 5\% Sample}

I use the 1990 US Census 5\% Sample (Ruggles et al., 2018) to create the simulated tax instruments.

Table 19 - Summary Statistics for Simulation Incidence Sample 1990 Census

\begin{tabular}{lcccc}
\hline & Age & Anykids & Married & Get Eic \\
\hline Unmarried Women & 32.68 & 0.00 & 0.00 & 0.00 \\
Married Women & 47.29 & 0.00 & 1.00 & 0.00 \\
Unmarried Mothers & 35.15 & 1.00 & 0.00 & 0.49 \\
Married Mothers & 36.43 & 1.00 & 1.00 & 0.15 \\
\hline & Less HS & HS Only & Less BA & BA+ \\
Unmarried Women & 0.30 & 0.24 & 0.28 & 0.12 \\
Married Women & 0.20 & 0.36 & 0.25 & 0.13 \\
Unmarried Mothers & 0.26 & 0.34 & 0.31 & 0.07 \\
Married Mothers & 0.16 & 0.34 & 0.30 & 0.14 \\
\hline & Worker & Wage & Share of Workers & Cost Share \\
Unmarried Women & 0.75 & 9.29 & 0.33 & 0.21 \\
Married Women & 0.66 & 10.26 & 0.23 & 0.18 \\
Unmarried Mothers & 0.73 & 9.10 & 0.09 & 0.06 \\
Married Mothers & 0.70 & 9.70 & 0.34 & 0.22 \\
\hline
\end{tabular}

All data from 1990 US Census, 5\% Sample March CPS, Women from Tax Units, Wage in \$1989. Demographic variables weighted by Census sample weight, Wage by sample weight $\times$ Usual Hours Last Year. 


\section{Empirical Tax Instruments}

\section{1 Identification of Elasticities}

To identify the labor supply and labor substitution elasticities, there are two sets of exclusion restrictions. The first set are used for the supply elasticities and the second for the substitution elasticity. The incidence model results imply an identification strategy. Direct changes in the own EITC ATR, $\tau$, shift supply that allows me to identify the labor substitution elasticity that governs labor demand. GE spillover effects shift demand curves that allows me to identify the labor supply elasticities. Below, I formalize this using arguments from Watson (2020).

Consider the following simultaneous equations model [SEM]:

$$
l_{i t}^{D}=\alpha_{0}+\alpha_{1} w_{i t}+u_{i t}^{D} \quad l_{i t}^{S}=\beta_{0}+\beta_{1} w_{i t}+\beta_{1} \tau_{i t}+u_{i t}^{S} \quad l_{i t}^{S}=l_{i t}^{D} .
$$

This implies the following first stage and reduce form equations:

$$
\begin{aligned}
w_{i t} & =\frac{\alpha_{0}-\beta_{0}}{\beta_{1}-\alpha_{1}}+\frac{-\beta_{1}}{\beta_{1}-\alpha_{1}} \tau_{i t}+\frac{u_{i t}^{D}-u_{i t}^{S}}{\beta_{1}-\alpha_{1}}:=\pi_{0}+\pi_{1} \tau_{i t}+v_{i t}^{w}, \\
l_{i t} & =\frac{\alpha_{0} \beta_{1}-\alpha_{1} \beta_{0}}{\beta_{1}-\alpha_{1}}+\frac{-\alpha_{1} \beta_{1}}{\beta_{1}-\alpha_{1}} \tau_{i t}+\frac{\beta_{1} u_{i t}^{D}-\alpha_{1} u_{i t}^{S}}{\beta_{1}-\alpha_{1}}:=\mu_{0}+\mu_{1} \tau_{i t}+v_{i t}^{L},
\end{aligned}
$$

where all variables are in logs and $\ln [(1+\tau)] \approx \tau$. I assume that labor demand depends on the gross-wage while labor supply depends on the net-wage, and I suppress any dependence on covariates, $X$.

Now, I use the theoretical results from the main text imply the following wage incidence equation:

$$
\underbrace{\mathrm{d} w_{i t}}_{\text {Wage Change in Data }}=\underbrace{\gamma_{1} \mathbf{d} \tau_{i t}+\Psi_{i t}}_{\text {Incidence Induced Change }}+\underbrace{\gamma_{0}+v_{i t}}_{\text {Unobs Wage Change }},
$$

where $\Psi_{e s t}$ is a theoretical measurement of the GE spillover effect.

Combining the SEM with the incidence equation, the following equivalence must hold in the post period:

$$
\underbrace{\gamma_{0}+v_{i t}+\gamma_{i} \mathrm{~d} \tau_{i t}+\Psi_{i t}}_{\text {Incidence }+ \text { Unobs }}=\underbrace{\mathrm{d} w}_{\text {Data }}=\underbrace{\frac{\alpha_{0}-\beta_{0}}{\beta_{1}-\alpha_{1}}+\frac{-\beta_{1}}{\beta_{1}-\alpha_{1}} \mathrm{~d} \tau_{i t}+\frac{\mathrm{d} u_{i t}^{D}-\mathrm{d} u_{i t}^{S}}{\beta_{1}-\alpha_{1}}}_{\text {SEM }} .
$$


One obvious way to reconcile the two equations is the following:

$$
v_{i t}=\frac{-1}{\beta_{1}-\alpha 1} \mathrm{~d} u_{i t}^{S} \quad \Psi_{i t}=\frac{1}{\beta_{1}-\alpha 1} \mathrm{~d} u_{i t}^{D} \quad \gamma_{0}=\frac{\alpha_{0}-\beta_{0}}{\beta_{1}-\alpha_{1}} \quad \gamma_{1}=\frac{-\beta_{1}}{\beta_{1}-\alpha_{1}} .
$$

The above implies that if $\operatorname{Cov}(\tau, Z) \neq 0$, then $\operatorname{Cov}\left(\tau, u^{D}\right) \neq 0$, so $\tau$ is technically an invalid instrument in the SEM above. However, using the RF equation, the own tax change and spillovers can be used in tandem to estimate the elasticities:

$$
\frac{\partial l}{\partial \Psi}=\frac{\beta_{1}}{\beta_{1}-\alpha_{1}} \frac{\partial u^{D}}{\partial Z} \quad \& \quad \frac{\partial w}{\partial \Psi}=\frac{1}{\beta_{1}-\alpha_{1}} \frac{\partial u^{D}}{\partial \Psi} \quad \Longrightarrow \frac{\partial l / \partial \Psi}{\partial w / \partial \Psi}=\beta_{1} .
$$

It is straight-forward to show: $\frac{\partial w}{\partial \Psi}=\frac{\partial[w+\tau]}{\partial \Psi}$ and $\frac{\partial l / \partial u^{S}}{\partial w / \partial u^{S}}=\alpha_{1}$. Additionally, I can allow for orthogonal demand unobservable changes: $v_{i t}=u_{i t}^{S}+u_{i t}^{D, 2}$, where $\operatorname{Cov}\left(\tau_{i t}, u_{i t}^{D, 2}\right)=0$ and $\operatorname{Cov}\left(\Psi_{i t}, u_{i t}^{D, 2}\right)=0$.

The main conclusion of Watson (2020) is that "in the context of the labor market SEM, we can use the tax reform treatment as a supply shifter and a measure of spillovers as a demand shifter." Let $\dot{y}_{x}$ be the residual from from a regression of $y$ on $x$.

\section{Proposition 1.}

If $\tau$ is exogenous with the above SEM, then $\frac{\widehat{\operatorname{Cov}}\left(\dot{i}_{\tau}, \dot{Z}_{\tau}\right)}{\widehat{\operatorname{Cov}}\left(\dot{w}_{\tau}, \dot{Z}_{\tau}\right)} \rightarrow_{p} \beta_{1}$ and $\frac{\widehat{\operatorname{Cov}}\left(i_{Z}, \dot{\tau}_{Z}\right)}{\widehat{\operatorname{Cov}}\left(\dot{w}_{Z}, \dot{\tau}_{Z}\right)} \rightarrow_{p} \alpha_{1}$, where 'exogenous' means that $\operatorname{Cov}\left(\tau, u^{S}\right)=0$.

Thus, to identify $\beta_{1}$, I need a measure of the demand spillovers, which proxy for demand shifters, and to condition on the own tax rate as a proxy for supply shifters. The exclusion restriction is that the EITC tax reform and its spillovers are uncorrelated to unobservable differences in labor supply (conditional on the model controls):

$$
\mathrm{E}\left[\tau_{\text {ecst }} \cdot u_{e^{\prime} c s t}^{S} \mid X\right]=0, \forall e, e^{\prime} \in \mathcal{E}
$$

This assumption would be violated if the EITC policy changes across demographic groups and state-years were chosen because the policymakers knew certain groups were more likely to systemically change their labor supply. Because the OBRA expansion was done at the national level (federal EITC rules are uniform across states), this would require that policymakers were able to precisely design the national change to take advantage of sub-state trends. More plausible is that state policy makers strategically implemented state-EITC reforms. ${ }^{69}$ However, prior studies find that state EITC introductions and

\footnotetext{
${ }^{69}$ Nine states had a state program by 1995 and eighteen by 2000 .
} 
policy changes appear plausibly exogenous to local economic conditions (Leigh, 2010; Buhlmann et al., 2018).

Alternatively, if there are social program reforms that are correlated with EITC reforms, then I will misattribute to the EITC wage effects that are actual to due other program changes. The most obvious example is PRWORA that replaced Aid to Families with Dependent Children (AFDC) with Temporary Assistance for Needy Families (TANF) in 1996. This reform "was the culmination of state-led welfare reform efforts starting in the late 1980s ... implemented under the heading of welfare waivers, permissions from the federal government allowing states to experiment with their welfare programs Kleven (2019).” To account for this possibility, I interact an indicator for having children with indicators for implementation of state 'welfare waivers'. ${ }^{70}$ Given that I include state-year FEs, these variables will control for any variation in EITC ATRs, wages, and supply that are due to differential effects of welfare reforms by parental status.

To identify the substitution elasticity, I rely on a similar argument as for $\alpha_{1}$ in the above SEM. I now need to condition on the spillovers and use the direct EITC change as a supply instrument:

$$
\mathrm{E}\left[\frac{\tau_{e s t}}{\tau_{0 s t}} \cdot u_{(e, 0), s t}^{D} \mid X, \Psi_{e s t}\right]=0 .
$$

That is, the relative tax change between skills is uncorrelated with the relative demand unobservables conditional on covariates and spillovers.

This assumption would be violated if the EITC was implemented in a way that was complementary to underlying skill biased technical change where firms were demanding more low skill labor just as the EITC was expanding labor supply. To the extent that this occurred, I interact 1990 wage deciles with year indicators to capture any wage trends across states and skills.

\footnotetext{
${ }^{70}$ These are provided by Kleven (2019) in online replication material accessed on the author's personal website.
} 


\section{C.2 Construction}

There are two ways of using EITC policy variation as an instrument for market variables. First, one can use the EITC policy parameters directly, such as maximum EITC benefit given number of children which varies at the state-year level (Leigh, 2010; Kasy, 2017; Bastian and Michelmore, 2018). This variable is very simple to implement but is constant across all labor markets in a state.

The second method is using a simulated tax instrument, similar to Gruber and Saez (2002); Rothstein (2008), for each demographic group across states. ${ }^{71}$ Using a fixed distribution of worker characteristics from the 1990 Census, I calculate average tax rates due to the EITC over multiple years of policy changes. By fixing the distribution of workers, endogenous changes in ATRs due to changes in labor market variables are purged. This construction allows the instrument to vary at the labor market-state-year level.

To calculate this, I need to estimate the true EITC benefits and the counterfactual EITC benefits if the worker did not work. I calculate the true EITC benefits, $E_{i}^{\text {act }}$, by using TAXSIM on the actual data, where $E$ is the federal and state EITC benefit. To calculate the counterfactual benefits, $E_{i}^{\mathrm{cf}}$, I set the worker's labor earnings equal to zero but leaving all else equal and rerun TAXSIM. ${ }^{72}$ Finally, I calculate the EITC Average Tax Rate as the difference in the actual minus the counterfactual benefits over earned income:

$$
\tau_{i}^{\mathrm{EITC}}=\frac{E_{i}\left(L=L_{i}\right)-E_{i}(L=0)}{w_{i} \cdot h_{i}} .
$$

I use the market level sample weighted mean to calculate $\tau_{\text {ecst }}$.

As stated above, I use the 1990 Census to calculate the tax instrument. I replicate the data for each tax year and send the data to Internet TAXSIM. To avoid issues of 'bracketcreep', I inflate monetary values by the BLS CPI All Items Research Series but do not change any other quantity.

\footnotetext{
${ }^{71}$ Leigh (2010) and Bastian and Michelmore (2018) both also use this type of approach secondary analysis.

${ }^{72}$ In married couple tax units, the counterfactual is with respect to the wife's labor supply decision. I assume the husband's earned income remains unchanged.
} 
The above only calculated the EITC ATR for a specific labor market, $\tau_{\text {ecst }}$. However, the total incidence also depends on a weighted sum of tax changes in other labor markets within a state-year, $\Psi_{e c}\left(\left\{\tau_{e, c^{\prime}}\right\}_{e, c^{\prime} \in \mathcal{D}}\right)$. Thus, I need an empirical counterpart for the $\Psi_{e c s t}$ terms, but this depends on the parameters that I wish to estimate - see equation 50 .

I approximate the function by creating two different averages of the tax change for across labor markets and then match this to a given market:

$$
\Psi_{e c s t}=H\left(\left\{\tau_{e^{\prime} c s t}\right\}_{e c^{\prime} \in \mathcal{D}}\right) \approx \mathrm{a}_{1} \bar{\tau}_{g_{1}(e), c s t}+\mathrm{a}_{2} \bar{\tau}_{g_{2}(e), c s t}+\nu_{e c s t} .
$$

The first match-group is based on age groups and the second match group is based on education groups. Each average the change in the EITC ATR for all women, married and unmarried, with qualifying children. For example, if $(\tilde{e}, c)$ is married women with some college between ages of 25 and 30, then $\bar{\tau}_{g_{1}(\tilde{e}), c s t}$ equals the average EITC ATR for women with some college pooled across age groups, $\bar{\tau}_{g_{2}(\tilde{e}), c s t}$ equals the average EITC ATR for women between ages of 25 and 30 pooled across education groups.

Additionally, I use two other simulated EITC statistics as instruments, such as the share of workers receiving EITC benefits and the mean change in expected EITC amounts.

\section{C.2.1 Labor Supply Instruments}

For every group $\tilde{d}=(e, c)$, I seven market level simulated instruments for wages:

1. the EITC ATR: $\left\{\tau_{\tilde{d} s t}^{\text {ATR }}\right.$

2. the portion of $\tilde{d}$ workers with positive EITC: $\left\{z_{\tilde{d} s t}^{\mathrm{Sh}}\right\}$

3. the mean change in ETIC amount for $\tilde{d}:\left\{z_{\tilde{d} s t}^{\mathrm{dE}}\right\}$

4,5. two EITC ATR approximation averages: $\left\{\bar{\tau}_{g_{(\cdot)}(\tilde{d}) s t}\right\}$

6,7. two additional approximation averages: $\left\{\bar{z}_{g_{1}(\tilde{d}) s t}^{\mathrm{Sh}}, \bar{z}_{g_{2}(\tilde{d}) s t}^{\mathrm{Sh}}\right\}$.

In Appendix D, I show that the elasticity estimates are robust to various combinations of the instruments. Based on the identification arguments above, I condition on the demographic specific simulated EITC ATR, share with EITC, and average change in EITC: $\left\{\tau_{\text {ecst }}, z_{\text {ecst }}^{\mathrm{sf}}, z_{\text {ecst }}^{\mathrm{dE}}\right\}$. 


\section{C.2.2 Labor Substitution Instruments}

The labor substitution elasticity depends on the relative wage, $\ln \left[w_{\text {est }} / w_{e_{0} s t}\right]$. My main specification uses a just identified model using the 'relative EITC ATRs' to instrument for relative wages:

$$
\tau_{\left(\tilde{e}, e_{0}\right) s t}=\frac{\tau_{\tilde{e} s t}}{\tau_{e_{0} s t}} .
$$

I also construct relative share of EITC claimants and the relative change in the EITC subsidy to estimate an overidentified model.

\section{C.3 Comparison with Traditional Approaches}

Here, I quickly describe the issues using more traditional approaches in the EITC literature to estimating relevant parameters when allowing worker heterogeneity and general equilibrium effects.

\section{C.3.1 Labor Supply Difference in Difference}

Previous authors have estimated labor supply responses using difference-in-difference style assumptions for unmarried women with and without children - see Eissa and Liebman (1996); Hotz et al. (2002) for an early example and a review of the empirical literature list of examples. This assumption supposes that these workers face similar market forces, such as being perfectly substitutable conditional on age and education (and experience), so that in a narrow window around EITC expansions the only change between these workers is the difference in EITC policy effects. Such assumptions lead to expecting "parallel trends" before the reform and using the post-reform dynamics of women without children to form a counterfactual baseline for women with children. 
To see the implications of these assumptions, consider the following model, where $\tau_{e, c, t}=0$ if $t=0$ and $\tau_{e, c, t}=0$ if $c=0$ :

$$
\begin{gathered}
\mathrm{E}\left[l_{e c t}^{S}\right]=\beta_{0}+\beta_{e, c}\left(w_{e, t}+\tau_{e, c, t}\right)+\lambda_{e} \\
\Longrightarrow \\
\mathrm{E}\left[l_{e c, 1}^{S}\right]-\mathrm{E}\left[l_{e c, 0}^{S}\right]=\beta_{e, c}\left(w_{e, 1}-w_{e, 0}+\tau_{e, c, 1}-\tau_{e, c, 0}\right) \\
\Longrightarrow\left(\mathrm{E}\left[l_{e, 1,1}^{S}\right]-\mathrm{E}\left[l_{e, 1,0}^{S}\right]\right)-\left(\mathrm{E}\left[l_{e, 0,1}^{S}\right]-\mathrm{E}\left[l_{e, 0,0}^{S}\right]\right)= \\
\underbrace{\left(w_{e, 1}-w_{e, 0}\right)}_{\text {Incidence Effects }} \cdot \underbrace{\left(\beta_{e, 1}-\beta_{e, 0}\right)}_{\text {Elasticity Differences }}+\underbrace{\beta_{e, 1} \tau_{e, c, 1}}_{\text {ATET }} .
\end{gathered}
$$

If one assumes that wages are fixed, $\left(w_{e, 1}-w_{e, 0}\right)=0$, then the DiD estimates the ATET with no additional assumptions about behavioral responses to wages. If one allows for wage changes (via exogenous changes or incidence effects), then one needs to assume that the wage responsiveness of workers with and without children is equivalent; i.e., $\left(\beta_{e, 1}-\beta_{e, 0}\right)=0$. This latter restriction is testable in the data with an appropriate empirical strategy.

Without either assumption, then the DiD estimate of the ATET is biases in an unknown direction unless one knows the parameters $\left\{\beta_{e, 1}, \beta_{e, 0}\right\}$, in which case estimation is not necessary. My approach allows for heterogeneous labor supply elasticities and uses wage and EITC variation across states and demographic groups to estimate the elasticities.

\section{C.3.2 Log Wage Difference in Difference}

The empirical literature on the EITC has not focused much on wage effects, due to typically assuming fixed wages. Leigh (2010) regresses log wages at the individual level on the maximum state EITC amount, but does not report incidence parameters directly.

To see how this fits with the incidence model, suppose we observe wages and tax rates for skill level $e$ across states $s$ and years $t$. The incidence results imply the following 
equation, where $\tau_{\text {est }}=\Psi_{\text {est }}=0$ if $t=0$ :

$$
\begin{gathered}
\mathrm{E}\left[w_{e s t}\right]=\gamma_{0}+\gamma_{e} \tau_{e s t}+\lambda_{s}+\Psi_{e s t} \\
\Longrightarrow \mathrm{E}\left[w_{e s 1}\right]-\mathrm{E}\left[w_{e s 0}\right]=\gamma_{e} \tau_{e s 1}+\Psi_{e s 1} \\
\Longrightarrow\left(\mathrm{E}\left[w_{e 11}\right]-\mathrm{E}\left[w_{e 10}\right]\right)-\left(\mathrm{E}\left[w_{e 01}\right]-\mathrm{E}\left[w_{e-0}\right]\right) \\
\gamma_{e}\left(\tau_{e 11}-\tau_{e 01}\right)+\underbrace{\Psi_{e 11}-\Psi_{e 01}}_{\text {GE Bias }} .
\end{gathered}
$$

Unless one can control for GE spillovers or knows when they are negligible, then, even within a skill group, spillovers create a GE bias. If we compare across skill groups, $e \in\{0,1\}$, in the same state where we know $\tau_{\text {est }}=0$ for $e=0$, then we still get GE bias unless skill group $e=0$ has no exposure to skill group $e=1: \gamma_{1} \tau_{1 s t}+\Psi_{1 s 1}-\Psi_{0 s 1}$. However, if skill group $e=0$ has no GE exposure, then we cannot trust that this is a valid control group. My approach deals with this GE bias by adding structural assumptions about labor demand and estimating labor market elasticities that compose the GE spillovers based on the incidence model. 


\section{Additional Estimation Results}

In Table 20, I provide additional elasticity estimates for labor supply. These specifications differ on five dimensions: method, weighting, sample, IVs, and dependent variable. The table displays the KP rk Wald F is a cluster robust Cragg-Donald statistic for first stage strength.

A larger elasticity for unmarried women with children ('treated' workers) implies that that the spillover effect will be large on the 'untreated' workers. A larger elasticity for untreated workers implies that spillovers will be larger on the treated workers.

The first line is the baseline estimates used in the main text: I use two-step efficient GMM, weighted by the number of wage observations in a cell, using cells with at least three observations, using the baseline set of simulated tax instruments. I additionally consider a two-stage least squares method for the baseline, which tends to make the estimates more elastic.

I next consider the effect of weighting. The unweighted results have lower first stage estimates than the weighted estimates, and as such tend to amplify the estimated elasticities. Weighting by the sample size or the wage variance gives lower weight to the observations with more noise which helps in precision. I additionally create a subsample (1) with a lower bound of at least three wage observations per cell. This subsample can be thought of as an additional discrete weighting.

I then look at the effect of different combinations of instruments - the set of IVs are described in more detail in Appendix C. ${ }^{73}$ The first stage statistics all decrease when I remove IVs implying that each IV provides some additional identification. As expected, a weaker first stage amplifies the elasticity estimates.

Finally, I consider using the (log) total number of workers in the labor force as the dependent variable. This measure is more coarse than the hours-per-worker variable that I use but is potentially subject to less measurement error. Because the hours based

\footnotetext{
${ }^{73}$ The last specification, IV Set 8, includes a simulated Federal Earnings ATR, which uses variation other than EITC changes. This provides a stronger first stage but muddies the identification.
} 
elasticities include the extensive and any potential intensive margin effects, the supply based elasticities are smaller. See that:

$$
\begin{aligned}
& \mathrm{d} h_{i} \ell_{i}=\mathrm{d} h_{i} \ell_{i}+h_{i} \mathrm{~d} \ell_{i}+\mathrm{d} h_{i} \mathrm{~d} \ell_{i} \\
& \Longrightarrow \varepsilon^{L}=\mu^{h}+v^{\ell}+\xi^{h \cdot \ell} .
\end{aligned}
$$

Panel (C) in the table shows estimates of $v^{\ell}$ while the parameter used in the main text and Panels (A) and (B) are $\varepsilon^{L}$.

Table 20 - Additional Elasticity Specifications

\begin{tabular}{|c|c|c|c|c|c|c|c|c|c|}
\hline Obs & Method & Weighting & Sample & IVs & $\begin{array}{l}\text { KP rk } \\
\text { F Stat }\end{array}$ & $\begin{array}{l}\text { Unmarried } \\
\text { No Children }\end{array}$ & $\begin{array}{c}\text { Unmarried } \\
\text { w/ Children }\end{array}$ & $\begin{array}{c}\text { Married } \\
\text { No Children }\end{array}$ & $\begin{array}{c}\text { Married } \\
\text { w/ Children }\end{array}$ \\
\hline (A) & \multicolumn{9}{|c|}{ Log Total Hours per Person: Baseline Elasticities used in Main Results } \\
\hline 60,814 & GMM & Wage Obs & Baseline & Baseline & 24.4 & 0.93 & 0.50 & 1.07 & 0.73 \\
\hline (B) & \multicolumn{9}{|c|}{ Log Total Hours per Person } \\
\hline 60,814 & 2sls & Wage Obs & Baseline & Baseline & 24.4 & 1.42 & 1.17 & 1.05 & 0.71 \\
\hline 67,749 & GMM & Wage Obs & All & Baseline & 23.5 & 0.97 & 0.58 & 1.11 & 0.74 \\
\hline 62,815 & GMM & Wage Obs & Subsample 1 & Baseline & 24.0 & 1.02 & 0.65 & 1.17 & 0.81 \\
\hline 61,076 & GMM & Cell Obs & Baseline & Baseline & 23.3 & 1.09 & 0.59 & 1.24 & 0.92 \\
\hline 61,076 & GMM & Unweighted & Baseline & Baseline & 10.7 & 1.37 & 1.03 & 1.45 & 1.22 \\
\hline 68,525 & GMM & Unweighted & All & Baseline & 13.4 & 1.23 & 0.83 & 1.40 & 0.85 \\
\hline 59,796 & GMM & Wage Var 1 & Baseline & Baseline & 12.6 & 0.74 & 0.55 & 1.10 & 0.26 \\
\hline 51,759 & GMM & Wage Var 1 & Subsample 1 & Baseline & 17.0 & 1.28 & 1.01 & 1.63 & 1.16 \\
\hline 59,599 & GMM & Wage Var 2 & Baseline & Baseline & 11.5 & 1.26 & 0.80 & 1.51 & 0.77 \\
\hline 51,759 & GMM & Wage Var 2 & Subsample 1 & Baseline & 15.1 & 1.39 & 1.14 & 1.56 & 1.23 \\
\hline 60,814 & GMM & Wage Obs & Baseline & IV Set 1 & 11.4 & 0.49 & -0.28 & 0.76 & 0.26 \\
\hline 60,744 & GMM & Wage Obs & Baseline & IV Set 2 & 21.8 & 0.84 & 0.51 & 1.05 & 0.67 \\
\hline 60,175 & GMM & Wage Obs & Baseline & IV Set 3 & 23.2 & 0.72 & 0.47 & 0.96 & 0.59 \\
\hline 60,738 & GMM & Wage Obs & Baseline & IV Set 4 & 22.2 & 0.90 & 0.55 & 1.06 & 0.70 \\
\hline 60,738 & GMM & Wage Obs & Baseline & IV Set 5 & 13.4 & 0.61 & 0.05 & 0.88 & 0.46 \\
\hline 60,814 & GMM & Wage Obs & Baseline & IV Set 6 & 23.4 & 1.11 & 0.91 & 1.32 & 1.12 \\
\hline 60,814 & GMM & Wage Obs & Baseline & IV Set 7 & 21.6 & 0.88 & 0.48 & 0.99 & 0.62 \\
\hline 60,814 & GMM & Wage Obs & Baseline & IV Set 8 & 33.2 & 0.87 & 0.63 & 1.05 & 0.65 \\
\hline (C) & \multicolumn{9}{|c|}{ Log Total Labor Supply } \\
\hline 60,812 & GMM & Wage Obs & Baseline & Baseline & 24.4 & 0.85 & 0.57 & 0.92 & 0.75 \\
\hline 60,812 & 2sls & Wage Obs & Baseline & Baseline & 24.4 & 0.93 & 0.46 & 1.01 & 0.66 \\
\hline 61,292 & GMM & Unweighted & Baseline & Baseline & 11.3 & 1.15 & 0.96 & 1.19 & 1.05 \\
\hline 59,960 & GMM & Wage Var 1 & Baseline & Baseline & 12.2 & 0.78 & 0.18 & 0.92 & 0.75 \\
\hline 59,598 & GMM & Wage Var 2 & Baseline & Baseline & 11.6 & 0.95 & 0.76 & 1.19 & 0.68 \\
\hline 60,812 & GMM & Wage Obs & Baseline & IV Set 8 & 33.2 & 0.70 & 0.50 & 0.75 & 0.60 \\
\hline
\end{tabular}
Average within Demographic Groups 
In Table 21, I display alternative estimations for the labor substitution parameter. These specifications differ on four dimensions: weighting, sample, IVs, and dependent variable. The table also displays the KP rk Wald F, a cluster robust Cragg-Donald statistic.

Broadly, the overidentified models have lower first stage statistics and the estimates tend to be smaller in magnitude. Additionally, the Labor Supply based $\rho$ tend to be larger than the Hours per Worker specification. This could be for two reasons. Given that $\rho=\mathrm{d} \ln \left[L_{1} / L_{0}\right] / \mathrm{d} \ln \left[w_{1} / w_{0}\right]$, either the numerator is larger or the denominator is smaller.

Approximately and using an equilibrium relationship with the supply functions, we can write this as $\rho \approx \frac{\mu_{1}^{h}+v_{1}^{\ell}+\xi_{1}^{h \cdot \ell}}{\mu_{0}^{h}+v_{0}^{\ell}+\xi_{0}^{h \cdot \ell}}$. If $\frac{\mu_{1}^{h}+v_{1}^{\ell}+\xi_{1}^{h \cdot \ell}}{\mu_{0}^{h}+v_{0}^{\ell}+\xi_{0}^{h \cdot \ell}}<\frac{v_{1}^{\ell}}{v_{0}^{\ell}}$, then this implies that the relative hours response is lower for the lower skill workers than the higher skill workers. Another possibility is that new entrant low skill workers work fewer hours than the incumbent workers, so $\xi_{0}<0$.

\section{1 Difference in Difference Regressions}

To complement the model implied labor supply effects, I estimate a simple difference in difference specification. I use the 1990-1996 ASEC samples for the OBRA expansion and the 2006-2012 samples for the ARRA expansion. I regress an indicator for labor force participation during the previous year on an post indicator (1994-1996 and 2010-2012) times a parental status indicator. I include state-year indicators and demographic group indicators that interact age, education, marriage, parental status. I use robust standard errors clustered at the demographic group level and weight the regressions using the ASEC supplement weights.

In typical EITC DiD studies, one compares unmarried women with no qualifying children to those with qualifying children (Eissa and Liebman, 1996; Eissa and Hoynes, 2004; Bastian, forthcoming). One rationale for this is that unmarried workers who do not work definitely do not receive EITC benefits and these workers are thought to work in similar labor markets. As long as there is no other parental specific time-varying labor market changes around EITC expansions, then this should estimate the average 
Table 21 - Additional Elasticity Specifications Average within Demographic Groups

\begin{tabular}{|c|c|c|c|c|c|c|}
\hline Obs & Weighting & Sample & IVs & $\begin{array}{l}\text { KP rk } \\
\text { F Stat }\end{array}$ & $\begin{array}{c}\rho \\
\text { Hours per Worker }\end{array}$ & $\begin{array}{c}\rho \\
\text { Labor Supply }\end{array}$ \\
\hline (A) & \multicolumn{6}{|c|}{ Baseline in Main Results } \\
\hline 25,773 & Wage Obs & Baseline & - & 72.14 & -2.01 & -2.44 \\
\hline (B) & \multicolumn{6}{|c|}{ Just Identified } \\
\hline 29,604 & Wage Obs & All & - & 70.30 & -2.11 & -2.52 \\
\hline 19,501 & Wage Obs & Subsample 1 & - & 82.48 & -1.67 & -2.26 \\
\hline 10,265 & Wage Obs & Subsample 2 & - & 89.55 & -1.74 & -2.36 \\
\hline 25,773 & Unweighted & Baseline & - & 48.50 & -2.29 & -2.35 \\
\hline 29,604 & Unweighted & All & - & 60.17 & -2.36 & -2.41 \\
\hline 19,501 & Unweighted & Subsample 1 & - & 64.38 & -1.17 & -1.65 \\
\hline 25,773 & Wage Variance & Baseline & - & 110.94 & -2.10 & -2.30 \\
\hline 29,405 & Wage Variance & All & - & 41.73 & -1.61 & -1.88 \\
\hline 19,501 & Wage Variance & Subsample 1 & - & 73.36 & -1.71 & -2.17 \\
\hline (C) & \multicolumn{6}{|c|}{ Overidentified (GMM) } \\
\hline 25,773 & Wage Obs & Baseline & Baseline & 32.74 & -1.60 & -2.10 \\
\hline 19,501 & Wage Obs & Subsample 1 & Baseline & 37.52 & -1.02 & -1.76 \\
\hline 25,773 & Wage Variance & Baseline & Baseline & 44.53 & -1.94 & -2.23 \\
\hline 19,501 & Wage Variance & Subsample 1 & Baseline & 34.11 & -1.66 & -2.14 \\
\hline 25,773 & Wage Obs & Baseline & IV Set 1 & 38.64 & -1.85 & -2.36 \\
\hline 25,773 & Wage Variance & Baseline & IV Set 1 & 58.71 & -2.02 & -2.28 \\
\hline 25,773 & Wage Obs & Baseline & IV Set 2 & 46.51 & -1.89 & -2.28 \\
\hline 25,773 & Wage Variance & Baseline & IV Set 2 & 64.63 & -2.03 & -2.24 \\
\hline 25,773 & Wage Obs & Baseline & IV Set 3 & 38.17 & -1.46 & -1.56 \\
\hline 25,773 & Wage Variance & Baseline & IV Set 3 & 34.29 & -1.73 & -1.75 \\
\hline
\end{tabular}

treatment effect on the treated which is a measure of the direct labor supply effects of the EITC. Because the ARRA expansion was most generous specifically for workers with three or more qualifying child, I include two additional specifications. In column (3), I compare workers with no qualifying children to workers with three qualifying children. 
In column (4), I compare workers with one or two qualifying children to workers with three qualifying children.

Table 22 - EITC Difference-in-Difference Results

\begin{tabular}{c|c|ccc}
\hline & $\begin{array}{c}\text { OBRA } \\
(1)\end{array}$ & $(2)$ & $(3)$ & $(4)$ \\
\hline Post $\times$ Parent Status & 0.039 & 0.010 & -0.006 & -0.011 \\
& $(0.010)$ & $(0.007)$ & $(0.014)$ & $(0.013)$ \\
\hline Sub-Sample & - & - & $C \in\{0,3\}$ & $C \in\{1,2,3\}$ \\
Obs & 78,549 & 119,082 & 82,826 & 43,379 \\
Clusters & 64 & 64 & 64 & 32 \\
\hline
\end{tabular}

Unmarried women not in school full time between the age of 20-55. All data from March CPS, ASEC samples, 1990-1996 \& 2006-2012. All regressions include state-year indicators and demographic group indicators, as in the main text. 


\section{E Additional Incidence Results}

\section{E.1 Individual Level Effects of 1993 Expansion}

In Table 23 I report individual level results rather than aggregate as in the main text. These results show how an individual's EITC amount is affected by incidence and behavioral responses. The change in the EITC is the naive change that holds all labor supply and wages constant. In Panel (A), unmarried mothers get roughly $\$ 417$ in expanded EITC but lose roughly a fourth of that amount due to wage incidence. For unmarried mothers, wage spillovers are less important, at roughly $15 \%$ of the wage effect, primarily because the direct effects dominate. However, for married mothers and women without children, spillovers are $38-92 \%$ of the wage effect. Figure 9 graphs selected variables from the table and adds the total net earning effect that incorporates labor supply effects.

\section{E.2 Additional 1993 Incidence Specifications}

In Table 24, I show the individual level effect of the 1993 OBRA expansion on workers using various combinations of elasticities. The baseline results are the same as in Table 23, but I consider using a constant labor supply elasticities $\left(\varepsilon_{e, c}^{L}=0.75\right)$ and an inelastic substitution elasticity ( $\rho=-0.3$ ), which match the parameters in the baseline specification of Rothstein (2010). ${ }^{74}$ Qualitatively, the results are similar, but quantitatively there are some important differences.

Comparing baseline (A) vs 'Rothstein' (B) results, the results in (B) are much larger than in (A). This is for two reasons. First, an inelastic substitution elasticity magnifies the direct effects (since $\rho$ is in the denominator) and then this magnifies the spillover effects; this can be seen in Panel (c). Second, because I estimate substitution elasticities that smaller for higher education groups, the direct (and thus spillover) effects are also magnified; this can be seen in Panel (D).

\footnotetext{
${ }^{74}$ Again, I note that Rothstein (2010) used several specifications to show how his results varied with different elasticity assumptions, but I focus on his preferred specification.
} 
Table 23 - Incidence Results: Individual Effects of 1993 Expansion

\begin{tabular}{|c|c|c|c|c|c|c|c|c|}
\hline EDU & $\begin{array}{l}w L \\
\text { (a) }\end{array}$ & $\begin{array}{c}\text { ChEITC } \\
\text { (b) }\end{array}$ & $\begin{array}{c}\mathrm{d} w^{\mathrm{PE}} L \\
\text { (c) }\end{array}$ & $\begin{array}{c}\mathrm{d} w^{\mathrm{GE}} L \\
\text { (d) }\end{array}$ & $\begin{array}{c}\left(\mathrm{d} w^{\mathrm{GE}}-\mathrm{d} w^{\mathrm{PE}}\right) L \\
\text { (e) }\end{array}$ & $\begin{array}{c}\frac{\mathrm{d} w^{\mathrm{GE}} L}{\mathrm{~d}^{\mathrm{PE}} L}-1 \\
\text { (f) }\end{array}$ & $\begin{array}{c}\frac{\mathrm{d} w^{\mathrm{PE}} L}{\mathrm{ChEITC}} \\
(\mathrm{g})\end{array}$ & $\begin{array}{c}\frac{\mathrm{d} w^{\mathrm{GE}} L}{\mathrm{ChEITC}} \\
\text { (h) }\end{array}$ \\
\hline (A) & \multicolumn{8}{|c|}{ Unmarried Mothers } \\
\hline LessHS & $10,059.1$ & 417.4 & -101.7 & -99.7 & 2.0 & -3.2 & -25.0 & -25.5 \\
\hline HS & $17,637.0$ & 313.6 & -67.6 & -63.8 & 3.8 & -6.7 & -12.1 & -12.9 \\
\hline SomeCol & $18,259.4$ & 260.2 & -38.8 & -34.9 & 3.9 & -12.7 & -8.2 & -9.1 \\
\hline $\mathrm{BA}+$ & $30,936.0$ & 98.9 & -15.6 & -8.7 & 6.9 & -48.1 & -0.7 & -1.2 \\
\hline Total & $19,055.9$ & 272.9 & -53.0 & -48.9 & 4.1 & -14.9 & -10.4 & -11.2 \\
\hline (B) & \multicolumn{8}{|c|}{ Married Mothers } \\
\hline LessHS & $10,796.2$ & 162.2 & -2.4 & -0.3 & 2.0 & 15.6 & -0.1 & -0.4 \\
\hline HS & $15,367.4$ & 55.5 & 1.6 & 4.7 & 3.2 & 66.5 & 0.2 & 0.1 \\
\hline SomeCol & $19,334.3$ & 34.5 & 6.0 & 10.0 & 4.0 & 85.5 & 0.3 & 0.2 \\
\hline $\mathrm{BA}+$ & $31,027.4$ & 10.2 & 5.2 & 12.1 & 6.8 & 153.3 & 0.1 & 0.0 \\
\hline Total & $20,513.8$ & 44.6 & 3.6 & 8.0 & 4.3 & 92.2 & 0.2 & 0.1 \\
\hline (C) & \multicolumn{8}{|c|}{ Women without Children } \\
\hline LessHS & $11,196.2$ & 19.5 & -39.6 & -37.5 & 2.1 & -9.3 & -7.4 & -7.6 \\
\hline HS & $16,967.1$ & 8.8 & -24.0 & -20.6 & 3.5 & 48.3 & -1.0 & -1.2 \\
\hline SomeCol & $18,859.6$ & 3.9 & -16.9 & -13.0 & 3.9 & 31.4 & -0.6 & -0.7 \\
\hline $\mathrm{BA}+$ & $30,888.3$ & 2.4 & -6.1 & 0.6 & 6.7 & 50.6 & 0.0 & 0.0 \\
\hline Total & $20,880.4$ & 6.5 & -18.3 & -13.9 & 4.4 & 38.7 & -1.2 & -1.3 \\
\hline
\end{tabular}

All items are average across workers, weighted by hours $\times$ sample weights. All data from 1994 March CPS, Women from Tax Units Baseline labor supply elasticities in table 2 and $\rho=-2.0$.

\section{E.3 EITC vs NIT}

In Table 25, I present an EITC vs Negative Income Tax simulation results using the labor supply elasticities from Table 2. This exercise compares the main specification of Rothstein (2010), as presented in Table 5, with the general equilibrium effects this paper describes. 
Figure 9 - Selected Individual Level Effects of 1993 Expansion

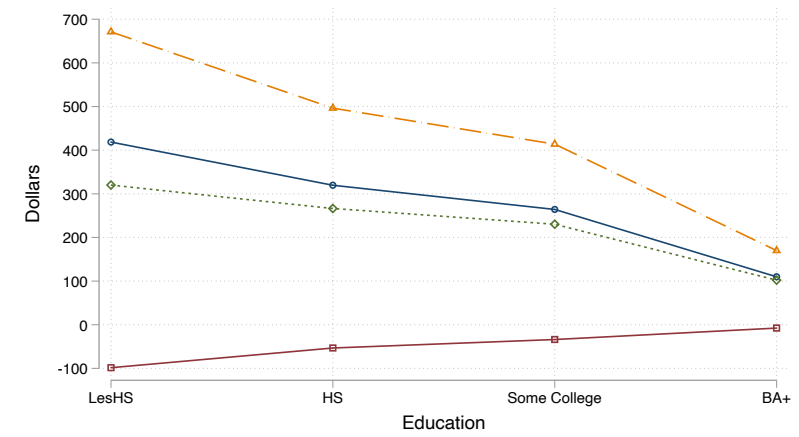

$\rightarrow$ Ch EITC Amount
$\rightarrow$ Ch GrossEarn, LS fixed
$\rightarrow$ Ch NetEarn, LS fixed

(a) Unmarried Mothers

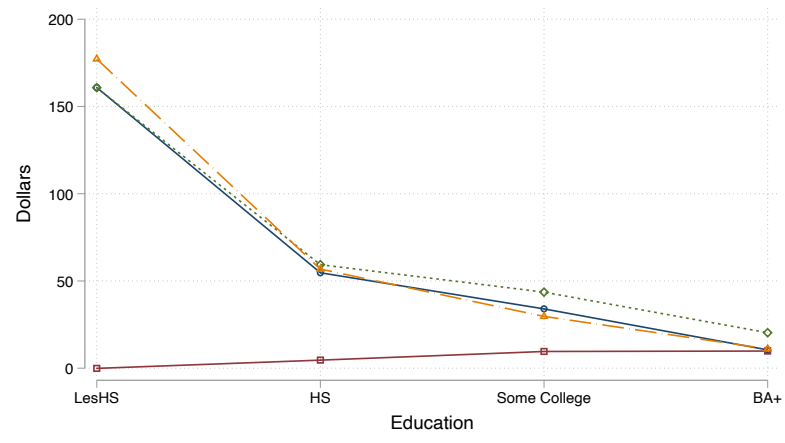

$\rightarrow$ Ch EITC Amount
$\rightarrow$ Ch NetEarn, LS fixed

(b) Married Mothers

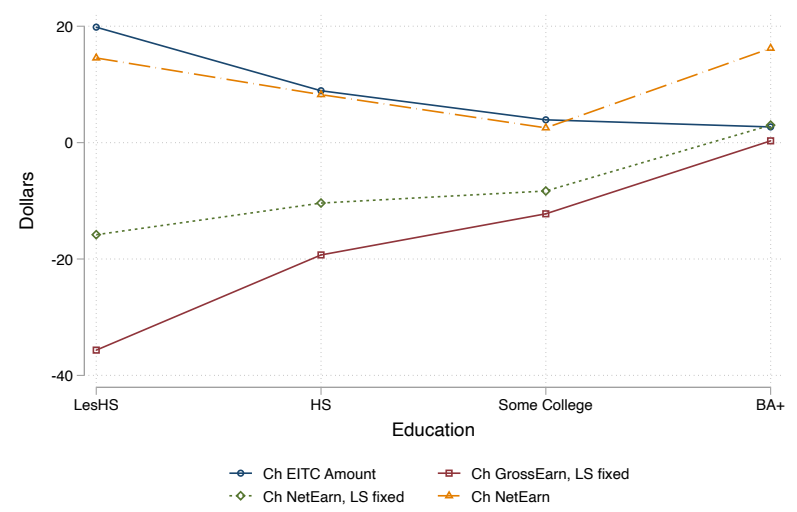

(c) Women without Children

Graphs of changes in Naive EITC and gross and net earnings; all data are women in tax units from 1994 CPS ASEC sample.

In the table below, the 'Rothstein' specification replicates the first column of Table 5 of Rothstein (2010) using my incidence sample (where differences are described in Appendix B). For these columns, I use a homogeneous labor supply elasticity of $\varepsilon^{L}=0.75$ and the labor substitution elasticity $\rho=-0.3$. The values closely correspond to the values in Rothstein. For example, I calculate a labor effect of $\$ 0.13$ for the EITC and $-\$ 0.18$ for the NIT while Rothstein calculates $\$ 0.09$ and $-\$ 0.16$, respectively.

The next set of columns (D-G) use the estimated labor supply elasticities from Table 2 but use the same $\rho=-0.3$. The heterogeneous labor supply elasticity changes the labor supply shocks, which amplifies and attenuates different labor market effects. For 
Table 24 - Incidence Results:

Unmarried Mothers' Individual Effects

Alternate Elasticity Specifications

\begin{tabular}{|c|c|c|c|c|c|c|c|c|}
\hline EDU & $\begin{array}{c}\mathrm{d} w^{\mathrm{PE}} L \\
\text { (a) }\end{array}$ & $\begin{array}{c}\mathrm{d} w^{\mathrm{GE}} L \\
\text { (b) }\end{array}$ & $\begin{array}{c}\left(\mathrm{d} w^{\mathrm{GE}}-\mathrm{d} w^{\mathrm{PE}}\right) L \\
\text { (c) }\end{array}$ & $\begin{array}{l}\frac{\mathrm{d} w^{\mathrm{GE}} L}{\mathrm{~d}^{\mathrm{PE}} L}-1 \\
\text { (d) }\end{array}$ & $\begin{array}{c}\frac{\mathrm{d} w^{\mathrm{PE}} L}{\mathrm{ChEITC}} \\
\text { (e) }\end{array}$ & $\begin{array}{l}\frac{\mathrm{d} w^{\mathrm{GE}} L}{\mathrm{ChEITC}} \\
\text { (f) }\end{array}$ & $\begin{array}{c}\mathrm{d} Z^{\text {Net,PE }} \\
\text { (g) }\end{array}$ & $\begin{array}{c}\mathrm{d} Z^{\text {Net,GE }} \\
\text { (h) }\end{array}$ \\
\hline (A) & \multicolumn{8}{|c|}{ Baseline } \\
\hline LessHS & -101.7 & -99.7 & 2.0 & -3.2 & -25.5 & -25.0 & 662.7 & 666.5 \\
\hline Total & -53.0 & -48.9 & 4.1 & -14.9 & -11.2 & -10.4 & 417.7 & 423.2 \\
\hline (B) & \multicolumn{8}{|c|}{ Constant $\varepsilon^{L}=0.75, \rho=-0.3$} \\
\hline LessHS & -261.6 & -246.3 & 15.3 & -9.5 & -65.4 & -61.4 & 368.7 & 397.8 \\
\hline Total & -183.2 & -154.2 & 28.9 & -26.4 & -38.1 & -32.7 & 313.8 & 361.9 \\
\hline (C) & \multicolumn{8}{|c|}{ Baseline $\varepsilon^{L}, \rho=-0.3$} \\
\hline LessHS & -243.7 & -233.6 & 10.2 & -7.0 & -61.0 & -58.3 & 395.5 & 414.6 \\
\hline Total & -139.4 & -115.5 & 23.9 & -32.3 & -28.8 & -24.5 & 289.9 & 322.2 \\
\hline (D) & \multicolumn{8}{|c|}{ Constant $\varepsilon^{L}=0.75, \rho=-2.0$} \\
\hline LessHS & -99.9 & -97.5 & 2.4 & -3.9 & -25.0 & -24.3 & 676.4 & 681.1 \\
\hline Total & -69.9 & -65.4 & 4.6 & -11.0 & -14.6 & -13.7 & 507.2 & 514.8 \\
\hline
\end{tabular}

Earnings Naive Ch EITC

LessHS $\quad 10,059.1 \quad 417.4$

Total $\quad 19,055.9 \quad 272.9$

All items are average across workers, weighted by hours $\times$ sample weights. All data from 1993 March CPS, Unmarried Mothers from Tax Units Baseline labor supply elasticities in table 2 and $\rho=-2.0$. Alternate elasticities based on Rothstein (2010) with $\varepsilon^{L}=0.75$ for all and $\rho=-0.3$.

example, the EITC wage effects are $-\$ 0.42$ in column (B) but are only $-\$ 0.25$ in column (D).

The last set of columns (H-K) use the estimated labor supply elasticities and substitution elasticity from Table 2, $\rho=-2$. This has a pronounced effect on the PE labor market effects but less on the GE effects. For example, the EITC wage effects are $-\$ 0.42$ in column (B) but are only $-\$ 0.10$ in column (H) but for columns (F) and (I) the effects much closer at $-\$ 0.04$ and $-\$ 0.03$. 
Table 25 - Incidence Results:

Aggregate Effects: All Women Rothstein (2010) Replication Extension

\begin{tabular}{|c|c|c|c|c|c|c|c|c|c|c|}
\hline \multirow{4}{*}{ Dollars } & \multirow{2}{*}{\multicolumn{2}{|c|}{$\begin{array}{l}\text { Rothstein } \\
\text { "PE" }\end{array}$}} & \multicolumn{4}{|c|}{$\rho=-0.3$} & \multicolumn{4}{|c|}{$\rho=-2.00$} \\
\hline & & & \multicolumn{2}{|c|}{ "PE" } & \multicolumn{2}{|c|}{ GE } & \multicolumn{2}{|c|}{ "PE" } & \multicolumn{2}{|c|}{ GE } \\
\hline & EITC & NIT & EITC & NIT & EITC & NIT & EITC & NIT & EITC & NIT \\
\hline & (B) & (C) & (D) & (E) & (F) & (G) & (H) & (I) & $(\mathrm{J})$ & $(\mathrm{K})$ \\
\hline Intended & 1.00 & 0.56 & 1.00 & 0.56 & 1.00 & 0.56 & 1.00 & 0.56 & 1.00 & 0.56 \\
\hline Labor & 0.13 & -0.18 & 0.08 & -0.13 & 0.23 & -0.40 & 0.19 & -0.33 & 0.24 & -0.42 \\
\hline Wage & -0.42 & 0.60 & -0.25 & 0.43 & -0.04 & 0.07 & -0.10 & 0.17 & -0.03 & 0.06 \\
\hline Gross Earnings & -0.30 & 0.42 & -0.18 & 0.30 & 0.19 & -0.33 & 0.10 & -0.17 & 0.21 & -0.36 \\
\hline Net Transfer, Fixed Taxes & 0.58 & 1.50 & 0.75 & 1.43 & 0.96 & 1.07 & 0.90 & 1.17 & 0.97 & 1.06 \\
\hline Net Earn, Fixed Taxes & 0.70 & 1.42 & 0.82 & 1.30 & 1.19 & 0.67 & 1.10 & 0.83 & 1.21 & 0.64 \\
\hline Net Earnings & 0.12 & -0.35 & 0.22 & -0.45 & 0.56 & -1.03 & 0.50 & -0.90 & 0.60 & -1.07 \\
\hline Fiscal Externality & -0.10 & 0.05 & -0.08 & 0.04 & -0.07 & 0.02 & -0.08 & 0.03 & -0.08 & 0.02 \\
\hline
\end{tabular}

Units in table are changes in dollars of earnings summed across demographic groups. Note: $Z^{G}=w \cdot L, Z^{N}=(1-\tau) \cdot w \cdot L$. All data from 1993 March CPS, Women from Tax Units Labor supply elasticities in table 2, except 'Rothstein' which uses $\varepsilon^{L}=0.75$ for all.

One noteworthy point is that if Rothstein had used a general equilibrium analysis, then, comparing the differences in columns (D,E) to (F,G), the EITC would have fared far better. First, note that Rothstein primarily used net earnings and transfers with fixed taxes to compare the programs. I have provided the additional columns of net earnings that allow taxes to change (given a fixed average tax rate) and the change in welfare assuming the expansions are revenue neutral.

Evaluating the programs based on Rothstein's criteria, in PE the EITC does worse on both measures, but in GE the measures give a mixed signal. Using the net earnings allowing for tax changes, fares better in both PE and GE. The net earnings for the EITC are always positive while are always negative for the NIT expansions. This is because the EITC expands production by bringing new workers into the labor force while the NIT decreases production by having workers leave. For some workers, the NIT drives wages up which causes this group to pay more in taxes, which can cause net earnings to decrease. 
Finally, the welfare changes are always negative for the EITC and either positive or negative for the NIT depending on the parameterization. A negative welfare change here implies that the government expenditure increases (the welfare measure is the 'fiscal externality' - see Section A.2.2). For the EITC, the government is spending more because it is paying entering workers more in EITC. For the NIT, the government is spending more because it is paying exiting workers not to work. Balancing these two different reasons for increased government expenditure is a normative question. 


\section{F Structural Model Implied Parameters}

Using the approach outlined in Section 9, I back-out the structural parameters and calculate the model implied elasticities for the out-of-sample period. In Figure 10 I plot the model implied average labor shifters and average supply elasticity by marriage and parental status over time.

The labor shifters appear to trend downward over time for unmarried women but constant for married women. This implies that the utility cost of labor supply is weakly increasing for unmarried women. For all groups, the elasticities are increasing since the late 1990's. Given equation 33, this is largely due to roughly stagnant real net wage growth and declining labor force participation in the 2000's. Together, for unmarried women this implies that the per dollar effectiveness of the EITC relative to the early 1990's is ambiguous, but should be more effective for married women.

Figure 10 - Model Implied Parameters
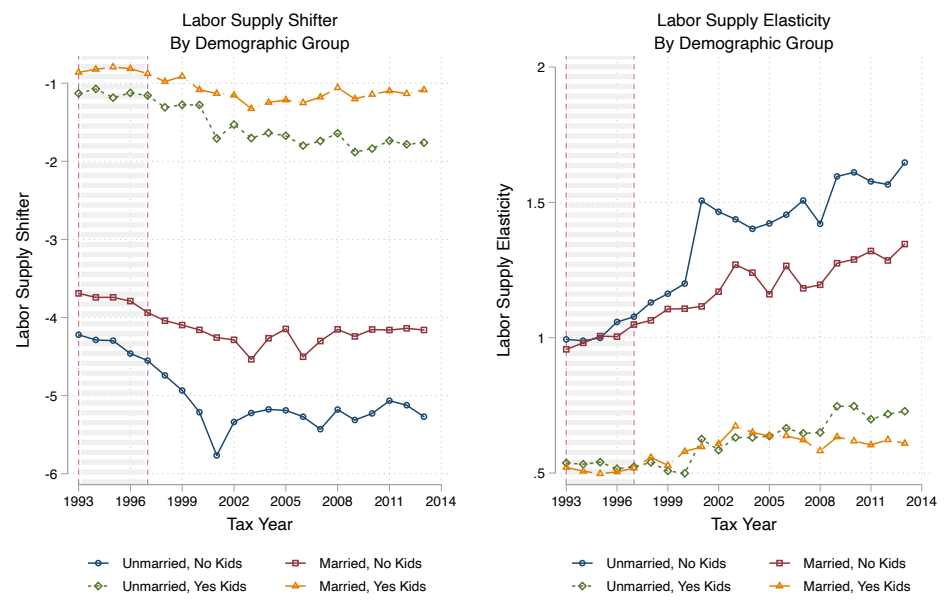

Supply shifter based on equation 34; elasticity based on equation 33; parameter $\beta^{d}$ recovered from tax years 1993-1997 and estimated elasticities from Table 2 and tax and transfer inclusive real net wage. 